\title{
Upgrade of recommended nuclear cross section data base for production of therapeutic radionuclides
}

\author{
F. Tárkányi ${ }^{1} \cdot$ A. Hermanne ${ }^{2} \cdot$ A. V. Ignatyuk ${ }^{3} \cdot$ S. Takács $^{1} \cdot$ R. Capote ${ }^{4}$
}

Received: 27 July 2021 / Accepted: 2 January 2022 / Published online: 20 February 2022

(C) The Author(s) 2022

\begin{abstract}
The IAEA Nuclear Data Section has coordinated several actions to setup and improve a database for recommended cross sections and nuclear decay data for various charged-particle reactions that can be used for medical radionuclide production. Some of the earlier evaluations did not provide uncertainties for the recommended cross sections. Updated evaluations with uncertainty quantification for 25 reactions relevant for production of ${ }^{67} \mathrm{Cu},{ }^{103} \mathrm{Pd},{ }^{102 \mathrm{mg}} \mathrm{Rh},{ }^{114 \mathrm{~m}} \mathrm{In},{ }^{125} \mathrm{I},{ }^{169} \mathrm{Yb},{ }^{177 g} \mathrm{Lu}$, ${ }^{186} \mathrm{Re},{ }^{192} \mathrm{Ir}$ and ${ }^{210,211}$ At therapeutic radioisotopes are presented. Recommended cross-section data and their uncertainties for production of therapeutic radionuclides are available on the Web page of the IAEA Nuclear Data Section at https://nds. iaea.org/radionuclides and also at the IAEA medical portal https://nds.iaea.org/medportal.
\end{abstract}

Keywords Nuclear data $\cdot$ Radionuclide production $\cdot$ Medical radioisotopes $\cdot$ Nuclear reaction modelling $\cdot$ Accelerator production

\section{Introduction}

Optimization of radionuclide production for those isotopes of interest in medical applications are of considerable interest to IAEA. The IAEA Nuclear Data Section has hence coordinated several actions to set up a database for recommended cross-sections and associated nuclear decay data for various charged-particle reactions used for medical radionuclides production over the last 25 years. The results of these evaluations were published in webpages of the IAEA-NDS and documented in [1-7] and at numerous conferences. For most of the reactions studied these evaluations resulted in recommended cross section data with uncertainties and production yield data. For few earlier evaluations the uncertainties of the recommended cross section data are missing. Over the last 2 years an upgrade of these evaluations to

R. Capote

r.capotenoy@iaea.org

Institute of Nuclear Research, Debrecen, Hungary

2 Vrije Universiteit Brussel, Brussels, Belgium

3 Institute of Physics and Power Engineering (IPPE), Obninsk, Russia

4 NAPC, Nuclear Data Section, International Atomic Energy Agency, 1400 Vienna, Austria include an uncertainty quantification was carried out. The results are presented in this work for 25 reactions relevant for production of ${ }^{67} \mathrm{Cu},{ }^{103} \mathrm{Pd},{ }^{102 \mathrm{~m}, \mathrm{~g}} \mathrm{Rh},{ }^{114 \mathrm{~m}} \mathrm{In},{ }^{125} \mathrm{I},{ }^{169} \mathrm{Yb}$, ${ }^{177 \mathrm{~m}, \mathrm{~g}} \mathrm{Lu},{ }^{186} \mathrm{Re},{ }^{192} \mathrm{Ir}$ and ${ }^{210,211}$ At therapeutic isotopes.

\section{Methods of compilation, correction, selection and data fitting}

The main steps of this upgrading evaluation process are:

- Survey of new or missing literature for experimental data of studied production routes.

- Correction of the published datasets for up-to-date monitor cross sections or nuclear decay characteristics.

- Selection of the data sets for fitting of all available corrected datasets considering the earlier evaluations and the results of model calculations.

- Fit of the selected experimental data using Padé approach (approximant by rational function) [8,9].

- Deducing recommended data with uncertainties.

- Calculation of integral production yields based on recommended cross-section data. 
Some additional, important comments should be repeated related to above mentioned steps:

- The experimental circumstances and the nuclear decay data used are often not documented properly in the original publications. In those cases, corrections for nuclear data are practically impossible, when the only information available is the year of publication to estimate the values of the used decay data.

- Without detailed experimental description decay data can only be corrected for the linearly contributing parameters (intensities) and correction for half-life is, in most cases, impossible.

- Systematic differences of cross sections often exist between the different publications. One of the main reasons is an improper estimation of the number of incident particles that can be determined by direct measurement of collected charge (or secondary particles) or indirectly by using monitor reactions. The proper technical base and equipment for direct charge measurement are available only at a limited number of experimental sites. To determine the beam intensity by using monitor reactions requires in principle exact knowledge of the incident energy on the monitor foils. In most cases the energy of the extracted beams is not well defined and by using only one monitor foil, especially in an energy region where the excitation function is rapidly changing, improper estimation of the beam intensity can be obtained.

- It is a well-known experimental fact that cross section data deduced from spectra measured at different times and different sample-detector distances may be systematically different (within usual 3-4\% uncertainties), due to uncertainties in the efficiency of the detector and different dead-time corrections during measurements. To reduce uncertainties hence in principle the monitor and target foils should be measured practically simultaneously, which in most cases is not possible.

- The estimation of the target thickness and hence number of target atoms present, is also improper in many cases, especially for targets made by sedimentation, pressing, electro-deposition etc. Improper target preparation can result in systematic errors of the measured data, but also can be the source of scattering of the obtained data.

- An important factor in data selection is the experience of the research group in data measurement and data evaluation. Some laboratories have a proper technical background and large expertise in data measurement and reporting, proved by several earlier publications. Usually, more weight is given to results measured in these laboratories when only limited number of discrepant data points are available.

- In the evaluations the weight of each experiment is determined by the reported uncertainties, which hence deserve special attention. In reported data uncertainties difference by a factor of two are seen for laboratories having the same level of technical background and expertise. Evaluations based only on original data, without critically considering uncertainties, will often result in erroneous recommended data.

- Theoretical data and systematics can be helpful for selection of experimental data especially for decisions on very outlying data points, on overall shape of the excitation function and for systematic energy shifts. This is especially true near the threshold of the reaction as the theoretical calculations are reliable and depend only on the well-measured masses. During the data selections, these outlying data points are mostly neglected, and systematic energy shift can be only partly corrected when the data set covers a large energy range.

- The fitting process requires often additional de-selection of outlying data points, or to introduce additional "guessed" points in energy ranges not covered or represented by the reported experimental results.

- Uncertainties in the fitted results were estimated via a least-squares method with an addition of a $4 \%$ systematic uncertainty which is an expert estimate of overall unrecognized uncertainties as discussed in Ref. [10].

Detailed information on the method of collection and selection of experimental data including extensive discussion of the Padé fitting methodology and obtaining uncertainties of the fit, can be found in the introductory chapters of the IAEA related publications: [1-7].

\section{Evaluated nuclear reactions}

The summary of the evaluated reactions in the present report is collected in the Table 1 that contains the list of reactions, the number of available experimental data sets, the maximal energy of the experimental data, the number of selected data series and the parameters of the final Padé fit. The main decay data used in the evaluation of the reported radionuclides and the parameters showing their applicability in nuclear medicine are collected in Table 2.

For each radionuclide of interest, we mention shortly the possible medical applications in separate subsections. They were discussed in detail in the IAEA TRS 473 [2] and specially dedicated paper [6]. After presentation of the decay data of the reaction product the evaluation and the results for each of the reactions studied (multiple reactions possible for one medical radioisotope) are illustrated in two figures: the first figure shows all available experimental data (corrected if necessary), the second figure contains only the selected experimental data with their uncertainties and the 
Table 1 List of evaluated nuclear reactions for radionuclide production

\begin{tabular}{|c|c|c|c|c|c|}
\hline Product & Reaction & Exp. serie & $\begin{array}{l}\text { Max. energy } \\
(\mathrm{MeV})\end{array}$ & $\begin{array}{l}\text { Selected- } \\
\text { exp. serie }\end{array}$ & Padé parameters \\
\hline \multirow[t]{4}{*}{${ }^{67} \mathrm{Cu}$} & ${ }^{68} \mathrm{Zn}(p, 2 p){ }^{67} \mathrm{Cu}$ & 10 & 430 & 8 & Padé $8, N=80, \chi^{2}=1.50$ \\
\hline & ${ }^{70} \mathrm{Zn}(p, \alpha){ }^{67} \mathrm{Cu}$ & 3 & 39.6 & 2 & Padé $7 \mathrm{cc}, \mathrm{N}=41, \chi^{2}=0.88$ \\
\hline & ${ }^{\text {nat }} \mathrm{Zn}(p, \mathrm{x}){ }^{67} \mathrm{Cu}$ & 4 & 140.5 & 3 & Padé $9, \mathrm{~N}=36, \chi^{2}=0.74$ \\
\hline & ${ }^{\text {nat }} \mathrm{Zn}(d, \mathrm{x}){ }^{67} \mathrm{Cu}$ & 2 & 48.3 & 2 & Padé $9, \mathrm{~N}=30, \chi^{2}=0.85$ \\
\hline \multirow[t]{2}{*}{${ }^{103} \mathrm{Pd}$} & ${ }^{103} \mathrm{Rh}(p, \mathrm{n}){ }^{103} \mathrm{Pd}$ & 9 & 39.65 & 8 & Padé $13, N=156, \chi^{2}=2.00$ \\
\hline & ${ }^{103} \mathrm{Rh}(d, 2 \mathrm{n}){ }^{103} \mathrm{Pd}$ & 2 & 39.9 & 2 & Padé $9, \mathrm{~N}=53, \chi^{2}=0.52$ \\
\hline \multirow[t]{2}{*}{${ }^{102 \mathrm{~m}} \mathrm{Rh}$} & ${ }^{103} \mathrm{Rh}(p, \mathrm{x}){ }^{102 \mathrm{~m}} \mathrm{Rh}$ & 2 & 63.86 & 2 & Padé $7, N=46, \chi^{2}=1.47$ \\
\hline & ${ }^{103} \mathrm{Rh}(d, \mathrm{x}){ }^{102 \mathrm{~m}} \mathrm{Rh}$ & 3 & 49.8 & 3 & Padé $14, N=122, \chi^{2}=2.14$ \\
\hline \multirow[t]{2}{*}{${ }^{102 g} \mathrm{Rh}$} & ${ }^{103} \mathrm{Rh}(p, \mathrm{x}){ }^{102 \mathrm{~g}} \mathrm{Rh}$ & 2 & 53.74 & 2 & Padé $7, \mathrm{~N}=36, \chi^{2}=1.15$ \\
\hline & ${ }^{103} \mathrm{Rh}(d, \mathrm{x}){ }^{102 \mathrm{~g}} \mathrm{Rh}$ & 3 & 39.6 & 3 & Padé $9, \mathrm{~N}=49, \chi^{2}=0.87$ \\
\hline \multirow[t]{3}{*}{${ }^{114 m}$ In } & ${ }^{114} \mathrm{Cd}(p, \mathrm{n}){ }^{114 \mathrm{~m}} \mathrm{In}$ & 17 & 400 & 12 & Padé $11, N=122, \chi^{2}=2.41$ \\
\hline & ${ }^{114} \mathrm{Cd}(d, 2 \mathrm{n}){ }^{114 \mathrm{~m}} \mathrm{In}$ & 5 & 20.7 & 4 & Padé $10, \mathrm{~N}=61, \chi^{2}=1.42$ \\
\hline & ${ }^{116} \mathrm{Cd}(p, 3 \mathrm{n}){ }^{114 \mathrm{~m}} \mathrm{In}$ & 3 & 400 & 3 & Padé $17, N=49, \chi^{2}=0.92$ \\
\hline \multirow[t]{2}{*}{${ }^{125} \mathrm{I}$} & ${ }^{125} \mathrm{Te}(p, \mathrm{n})^{125} \mathrm{I}$ & 5 & 105 & 4 & Padé $10, N=33, \chi^{2}=0.89$ \\
\hline & ${ }^{124} \mathrm{Te}(d, \mathrm{n}){ }^{125} \mathrm{I}$ & 1 & 14.1 & 1 & Padé $8, N=23, \chi^{2}=0.994$ \\
\hline \multirow[t]{2}{*}{${ }^{169 g} \mathrm{Yb}$} & ${ }^{169} \mathrm{Tm}(p, \mathrm{n}){ }^{169} \mathrm{Yb}$ & 4 & 44.9 & 4 & Padé $8, N=55, \chi^{2}=1.76$ \\
\hline & ${ }^{169} \operatorname{Tm}(d, 2 \mathrm{n}){ }^{169} \mathrm{Yb}$ & 4 & 49.8 & 4 & Padé $7, \mathrm{~N}=35, \chi^{2}=0.95$ \\
\hline \multirow[t]{2}{*}{${ }^{177 g} \mathrm{Lu}$} & ${ }^{176} \mathrm{Yb}(d, p){ }^{177} \mathrm{Yb}$ & 3 & 25.2 & 3 & Padé $11, N=54, \chi^{2}=0.87$ \\
\hline & ${ }^{176} \mathrm{Yb}(d, \mathrm{x}){ }^{177 \mathrm{~g}} \mathrm{Lu}$ & 5 & 39.2 & 5 & Padé $18, N=51, \chi^{2}=0.452$ \\
\hline \multirow[t]{2}{*}{${ }^{186 g} \mathrm{Re}$} & ${ }^{186} \mathrm{~W}(p, \mathrm{n}){ }^{1869} \mathrm{Re}$ & 11 & 68.9 & 9 & Padé $12, N=115, \chi^{2}=2.68$ \\
\hline & ${ }^{186} \mathrm{~W}(d, 2 \mathrm{n}){ }^{186 \mathrm{~g}} \mathrm{Re}$ & 11 & 49.2 & 8 & Padé $10, N=130, \chi^{2}=3.31$ \\
\hline \multirow[t]{2}{*}{${ }^{192 g} \mathrm{Ir}$} & ${ }^{192} \mathrm{Os}(p, \mathrm{n})^{192 \mathrm{~m} 1+\mathrm{g}} \mathrm{Ir}$ & 3 & 66.5 & 3 & Padé $10, N=66, \chi^{2}=1.12$ \\
\hline & ${ }^{192} \mathrm{Os}(d, 2 \mathrm{n}){ }^{192 \mathrm{~m} 1+\mathrm{g}} \mathrm{Ir}$ & 2 & 49.8 & 2 & Padé $17, N=32, \chi^{2}=0.99$ \\
\hline${ }^{211}$ At & ${ }^{209} \mathrm{Bi}(\alpha, 2 \mathrm{n}){ }^{211} \mathrm{At}$ & 6 & 89.14 & 6 & Padé $9, \mathrm{~N}=150, \chi^{2}=1.59$ \\
\hline${ }^{210} \mathrm{At}$ & ${ }^{209} \mathrm{Bi}(\alpha, 3 \mathrm{n}){ }^{210} \mathrm{At}$ & 10 & 90 & 10 & Padé $9, N=101, \chi^{2}=1.84$ \\
\hline
\end{tabular}

Padé fit that defines the recommended cross sections for the evaluated reaction. The uncertainties defined for the recommended cross sections are expressed as percentages on the secondary axis of the figure. The theoretical predictions taken from the TENDL 2017 [11] and TENDL 2019 libraries [12], based on TALYS-model code calculations, are also shown for comparison in the first figure. Integral yields for every reaction (integrated yield for a given incident energy down to the reaction threshold) are calculated from the recommended cross section data, as shown in a separate figure at the end of each subsection. The results represent the physical yields (obtained in an instantaneous irradiation time) $[13,14]$.

\section{${ }^{67}$ Cu production}

${ }^{67} \mathrm{Cu}$ is the longest-lived radioisotope of copper, is ideally suited for both radionuclide therapy and imaging. Along with $100 \% \beta^{-}$emission, ${ }^{67} \mathrm{Cu}$ emits gamma photons of 92 and $184 \mathrm{keV}$ that are suitable for gamma scintigraphy (Fig. 1).
The ${ }^{68} \mathrm{Zn}(p, 2 p){ }^{67} \mathrm{Cu},{ }^{70} \mathrm{Zn}(p, \alpha){ }^{67} \mathrm{Cu},{ }^{\text {nat }} \mathrm{Zn}(p, \mathrm{x}){ }^{67} \mathrm{Cu}$ and ${ }^{\text {nat }} \mathrm{Zn}(d, \mathrm{x}){ }^{67} \mathrm{Cu}$ production routes were evaluated.

\section{Cross sections for production of ${ }^{67} \mathrm{Cu}$}

\section{${ }^{68} \mathrm{Zn}(p, 2 p){ }^{67} \mathrm{Cu}$ reaction}

A total of 10 data sets were found in literature: [18-29] (Fig. 2). Out of them two [28, 29] are new and were not included in the previous evaluation [2].

Only one data point at $200 \mathrm{MeV}$ was reported in Mirzadeh et al [22] that was not considered in the evaluation process. The data of McGee [21] were adjusted in order to account for improved IAEA monitor data. Data of Levkovskij [23] were corrected by 0.8 to adjust to the new monitor data. No correction was done for the small contribution of the reactions on ${ }^{70} \mathrm{Zn}$ for data measured on ${ }^{\text {nat }} \mathrm{Zn}$.

Two data sets were deselected. Cohen [18] data were rejected because the authors state a very high uncertainty for their ${ }^{67} \mathrm{Cu}$ cross-sections; Schwarzbach [28] published relative data that showed a very large scatter. Twelve data points in the energy range 35-45 $\mathrm{MeV}$ of Stoll [24] were 
Table 2 Decay data of investigated reaction products taken from ENSDF [15]. ENSDF nuclear structure and decay data can be easily extracted, understood and studied in an attractive user-friendly manner by means of LiveChart of Nuclides [16] and NuDat [17]

\begin{tabular}{|c|c|c|c|c|c|}
\hline $\begin{array}{l}\text { Product or isomer, } \\
\text { excitation energy, isomer } \\
\text { spin } \mathrm{J}^{\pi}\end{array}$ & $\begin{array}{l}\text { Half life and decay mode } \\
(\%)\end{array}$ & $\mathrm{E}_{\alpha, \max }(\mathrm{keV})$ & $\begin{array}{l}<\mathrm{E}_{\beta-}>\text { or } \\
<\mathrm{E}_{\beta+}> \\
(\mathrm{keV})\end{array}$ & $\begin{array}{l}\text { Main electrons auger }(\mathrm{AE}) \text {, } \\
\text { conversion }(\mathrm{CE}) \mathrm{E}_{\mathrm{e}}(\mathrm{keV}) \\
\text { and } \mathrm{I}_{\mathrm{e}}(\%) \text { in parentheses }\end{array}$ & $\begin{array}{l}\text { Main gamma lines } \mathrm{E}_{\gamma}(\mathrm{keV}) \\
\text { and } \mathrm{I}_{\gamma}(\%) \text { in parentheses } \\
\text { X-ray are indicated }\end{array}$ \\
\hline${ }^{67} \mathrm{Cu}$ & $\begin{array}{l}61.83 \mathrm{~h} \\
\beta^{-} 100\end{array}$ & & $\beta^{-} 141$ & $\begin{array}{l}\text { AE K } 7.03(1.9) \text {, } \\
\text { CE K } 90.9(3.4)\end{array}$ & $\begin{array}{l}91.266(7.0), \\
93.311(16.1), \\
184.577(48.7)\end{array}$ \\
\hline${ }^{103} \mathrm{Pd}$ & $\begin{array}{l}16.991 \mathrm{~d} \\
\varepsilon 100 \\
\text { (to }{ }^{103 \mathrm{~m}} \mathrm{Rh} \text { ) }\end{array}$ & & & $\begin{array}{l}\text { AE L } 2.39(168), \\
\text { AE K } 17(18.2), \\
\text { CE K } 16.528(9.521), \\
\text { CE L } 36.336(71.237), \\
\text { CE M } 39.121(14.377)\end{array}$ & $\begin{array}{l}39.748(0.0683), \\
357.45(0.0221), \\
20.074(22.4) \text { X-ray } K_{\alpha} \\
20.216(42.5) X \text {-ray } K_{\alpha}\end{array}$ \\
\hline $\begin{array}{l}{ }^{103 \mathrm{~m}} \mathrm{Rh} \\
39.75 \mathrm{keV}\left(\mathrm{J}^{\pi}=7 / 2+\right)\end{array}$ & $56.114 \min$ IT 100 & & & $\begin{array}{l}\text { CE L } 36.343 \text { (70), } \\
\text { CE M } 39.128 \text { (14.3) }\end{array}$ & \\
\hline${ }^{102 \mathrm{~m}} \mathrm{Rh}$ & $3.742 \mathrm{y}$ & & & AE K 16.2 (17.7) & $475.06(95)$ \\
\hline $\begin{array}{l}140.7 \mathrm{keV} \\
\left(\mathrm{J}^{\pi}=6+\right)\end{array}$ & $\begin{array}{l}\text { IT } 0.233 \\
\varepsilon 99.767\end{array}$ & & & & $\begin{array}{l}631.29(56.0), \\
697.49(44.0), \\
766.84(34.0), \\
1046.59(34.0), \\
1112.84(19.0)\end{array}$ \\
\hline${ }^{102 \mathrm{~g}} \mathrm{Rh}$ & $\begin{array}{l}207.3 \mathrm{~d} \\
\varepsilon 78 \\
\beta^{+} 14.7 \\
\beta^{-} 22\end{array}$ & & $\begin{array}{l}\beta^{+} 520 \\
\beta^{-} 390\end{array}$ & AE K 16.2 (10.7) & $475.06(46)$ \\
\hline $\begin{array}{l}{ }^{114 \mathrm{~m}} \mathrm{In} \\
190.27 \mathrm{keV} \\
\left(\mathrm{J}^{\pi}=5+\right)\end{array}$ & $\begin{array}{l}49.51 \mathrm{~d} \\
\text { IT } 96.75 \\
\varepsilon 3.25\end{array}$ & & & $\begin{array}{l}\text { AE L } 2.94(65) \text {, } \\
\text { AE K } 20.1(5.98), \\
\text { CE189.44 (6.71) }\end{array}$ & $190.27(15.56)$ \\
\hline${ }^{114 \mathrm{~g}} \mathrm{In}$ & $\begin{array}{l}71.9 \mathrm{~s} \\
\beta^{-} 99.5 \\
\varepsilon 0.5 \\
\beta^{+} 0.0034\end{array}$ & & $\begin{array}{l}\beta^{-} 777.9 \\
\beta^{+} 200\end{array}$ & $\begin{array}{l}\text { AE L } 2.72(0.43), \\
\text { AE K } 19.3(0.067)\end{array}$ & $1299.83(0.139)$ \\
\hline${ }^{125} \mathrm{I}$ & $\begin{array}{l}59.407 \mathrm{~d} \\
\varepsilon 100\end{array}$ & & & $\begin{array}{l}\text { AE L } 3.19(156.5) \text {, } \\
\text { AE K } 22.7(19.8) \text {, } \\
\text { CE K 3.6787 (78.1), } \\
\text { CE L } 30.5533(10.7)\end{array}$ & $\begin{array}{l}35.492(6.68) \\
27.472(73.1) \text { X-ray } K_{\alpha} \\
27.202(39.6) \text { X-ray } K_{\alpha}\end{array}$ \\
\hline${ }^{169 \mathrm{~g}} \mathrm{Yb}$ & $\begin{array}{l}32.018 \mathrm{~d} \\
\varepsilon 100\end{array}$ & & & $\begin{array}{l}\text { AE L } 5.67(161.8), \\
\text { AE K } 40.9(10.6), \\
\text { CE K } 50.3896(34.3), \\
\text { CE L 53.0047 (7.03), } \\
\text { CE K } 71.133(6.16), \\
\text { CE L } 99.663(5.46), \\
\text { CE K } 117.8235(10.9) \text {, } \\
\text { CE K } 138.527(12.86)\end{array}$ & $\begin{array}{l}49.773(52.5) \mathrm{X} \text {-ray } \mathrm{K}_{\alpha} \\
50.742(91.6) \mathrm{X} \text {-ray } \mathrm{K}_{\alpha} \\
63.120(43.6) \mathrm{X} \text {-ray } \mathrm{K}_{\beta}\end{array}$ \\
\hline${ }^{177 g} \mathrm{Yb}$ & $\begin{array}{l}1.911 \mathrm{~h} \\
\beta^{-} 100\end{array}$ & & $\beta^{-} 423$ & $\begin{array}{l}\text { CE K } 58.31(4.6) \\
\text { CE K } 75.30(1.43) \\
\text { CE K } 87.08(1.8)\end{array}$ & $\begin{array}{l}121.62(3.05) \\
150.40(18.0) \\
1080.20(5.08)\end{array}$ \\
\hline${ }^{177 g} \mathrm{Lu}$ & $\begin{array}{l}6.6443 \mathrm{~d} \\
\beta^{-} 100\end{array}$ & & $\beta^{-} 148.8$ & $\begin{array}{l}\text { AU L } 11.23(8.64) \\
\text { CE K } 47.6(5.02) \\
\text { CE L } 103.38(6.76) \\
\text { CE M } 111.28(1.68) \\
\text { CE K } 143.016(0.57)\end{array}$ & $\begin{array}{l}71.6418(0.164), \\
112.9498(6.23), \\
136.7245(0.0465), \\
208.3662(10.41), \\
249.6742(0.1997), \\
321.3159(0.2186)\end{array}$ \\
\hline
\end{tabular}


Table 2 (continued)

\begin{tabular}{|c|c|c|c|c|c|}
\hline $\begin{array}{l}\text { Product or isomer, } \\
\text { excitation energy, isomer } \\
\text { spin } J^{\pi}\end{array}$ & $\begin{array}{l}\text { Half life and decay mode } \\
(\%)\end{array}$ & $\mathrm{E}_{\alpha, \max }(\mathrm{keV})$ & $\begin{array}{l}<\mathrm{E}_{\beta-}>\text { or } \\
<\mathrm{E}_{\beta+}> \\
(\mathrm{keV})\end{array}$ & $\begin{array}{l}\text { Main electrons auger }(\mathrm{AE}) \text {, } \\
\text { conversion }(\mathrm{CE}) \mathrm{E}_{\mathrm{e}}(\mathrm{keV}) \\
\text { and } \mathrm{I}_{\mathrm{e}}(\%) \text { in parentheses }\end{array}$ & $\begin{array}{l}\text { Main gamma lines } \mathrm{E}_{\gamma}(\mathrm{keV}) \\
\text { and } \mathrm{I}_{\gamma}(\%) \text { in parentheses } \\
\text { X-ray are indicated }\end{array}$ \\
\hline $\begin{array}{l}{ }^{177 m} \mathrm{Lu} \\
970.176 \mathrm{keV} \\
\left(\mathrm{J}^{\pi}=23 / 2-\right)\end{array}$ & $\begin{array}{l}160.4 \mathrm{~d} \\
\text { IT } 22.7 \\
\beta^{-} 77.3\end{array}$ & & $\beta^{-} 40.39$ & $\begin{array}{l}\text { AE L } 6.180(126.1) \\
\text { AE K } 44.80(5.9) \\
\text { CE K } 40.00(33.9) \\
\text { CE K } 47.60(17.2) \\
\text { CE K } 63.15(24.4) \\
\text { CE K } 87.93(15.2) \\
\text { CE L } 101.68(23.2) \\
\text { CE M } 102.76(1.64) \\
\text { CE N } 112.41(1.34) \\
\text { CE L } 117.23(4.67) \\
\text { CE K } 138.75(5.61) \\
\text { CE L } 142.01(2.78) \\
\text { CE K } 149.08(2.36) \\
\text { CE K } 163.13(4.15) \\
\text { CE L } 217.21(1.91)\end{array}$ & $\begin{array}{l}105.3589(12.68), \\
112.9498(21.4), 128.5027 \\
\quad(16.04), \\
153.2842(16.54), 174.3988 \\
(12.47), 204.1050(13.51), \\
208.3662(55.4), \\
228.4838(35.9), 281.7868 \\
(13.97), 327.6829(18.43), \\
378.5036(29.40), \\
418.5388(21.72)\end{array}$ \\
\hline${ }^{186 \mathrm{~g}} \mathrm{Re}$ & $\begin{array}{l}3.7186 \mathrm{~d} \\
\beta^{-92.53} \\
\varepsilon 7.47\end{array}$ & & $\beta^{-} 346.7$ & & $137.16(9.47)$ \\
\hline${ }^{192 \mathrm{~g}} \mathrm{Ir}$ & $\begin{array}{l}73.829 \mathrm{~d} \\
\beta^{-} 95.24\end{array}$ & & $\beta^{-} 178.9$ & & $\begin{array}{l}295.96(28.71), \\
308.45(29.70), \\
316.51(82.86), \\
468.07(47.84), \\
604.41(8.216), \\
612.46(5.34), \\
884.54(0.29)\end{array}$ \\
\hline${ }^{210}$ At & $\begin{array}{l}8.1 \mathrm{~h} \\
\alpha 0.175 \\
\varepsilon 99.825\end{array}$ & 5524.0 & & & $\begin{array}{l}245.3(79), \\
1181.4(99), \\
1436.7(29.0), \\
1483.3(46.5), \\
1599.5(13.4)\end{array}$ \\
\hline${ }^{210} \mathrm{Po}$ & $\begin{array}{l}138.376 \mathrm{~d} \\
\alpha 100\end{array}$ & 5304.3 & & & $803.06(0.00103)$ \\
\hline${ }^{211} \mathrm{At}$ & $\begin{array}{l}7.214 \mathrm{~h} \\
\alpha 41.80 \\
\varepsilon 58.20\end{array}$ & 5869.5 & & & $\begin{array}{l}669.78(0.0037) \\
742.72(0.001)\end{array}$ \\
\hline $\begin{array}{l}{ }^{211 \mathrm{~m}} \mathrm{Po} \\
1462 \mathrm{keV} \\
\left(\mathrm{J}^{\pi}=25 / 2+\right)\end{array}$ & $\begin{array}{l}25.3 \mathrm{~s} \\
\alpha 99.984 \\
\text { IT } 0.016\end{array}$ & 8883 & & & $\begin{array}{l}363.0(0.016) \\
1064.9(0.015)\end{array}$ \\
\hline${ }^{211} \mathrm{Po}$ & $\begin{array}{l}0.516 \mathrm{~s} \\
\alpha 100\end{array}$ & 7450.3 & & & $\begin{array}{l}569.65(0.535), \\
897.8(0.551)\end{array}$ \\
\hline
\end{tabular}

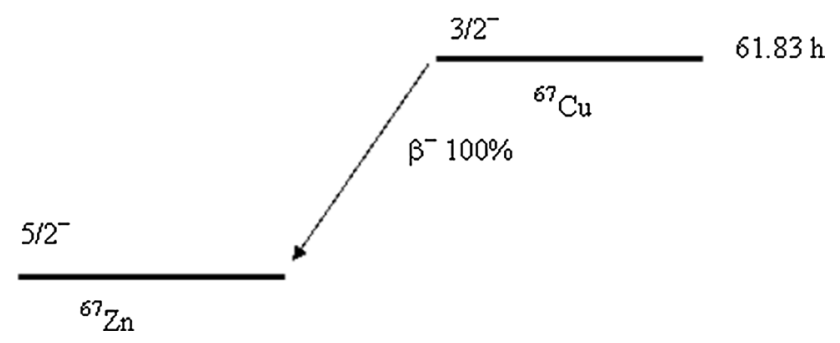

Fig. $1{ }^{67} \mathrm{Cu}$ decay scheme excluded due to systematic errors in that energy range (information from authors). The selected data vs the Padé fit are shown in Fig. 3.

\section{${ }^{70} \mathrm{Zn}(p, a){ }^{67} \mathrm{Cu}$ reaction}

A total of 3 data sets were found in literature: [23, 28, 30] (Fig. 4). None of these sets are new and were already evaluated in TRS 473 [2]. The data in Schwarzbach [28] are only relative and were normalized at low energies, but as the resulting values are very different from the TENDL predictions they were excluded. 


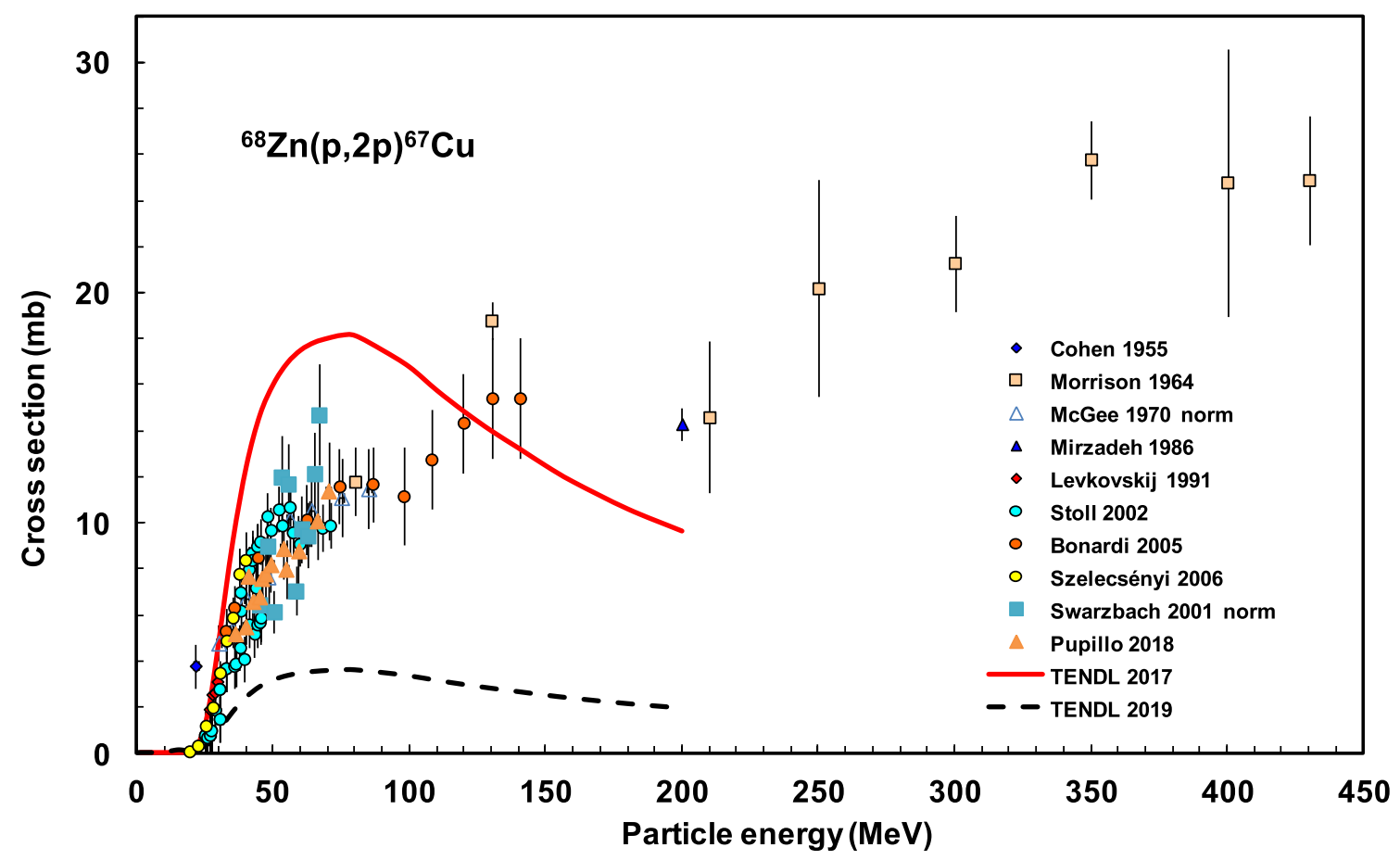

Fig. $2{ }^{68} \mathrm{Zn}(p, 2 p){ }^{67} \mathrm{Cu}$ reaction: all experimental data and TENDL predictions

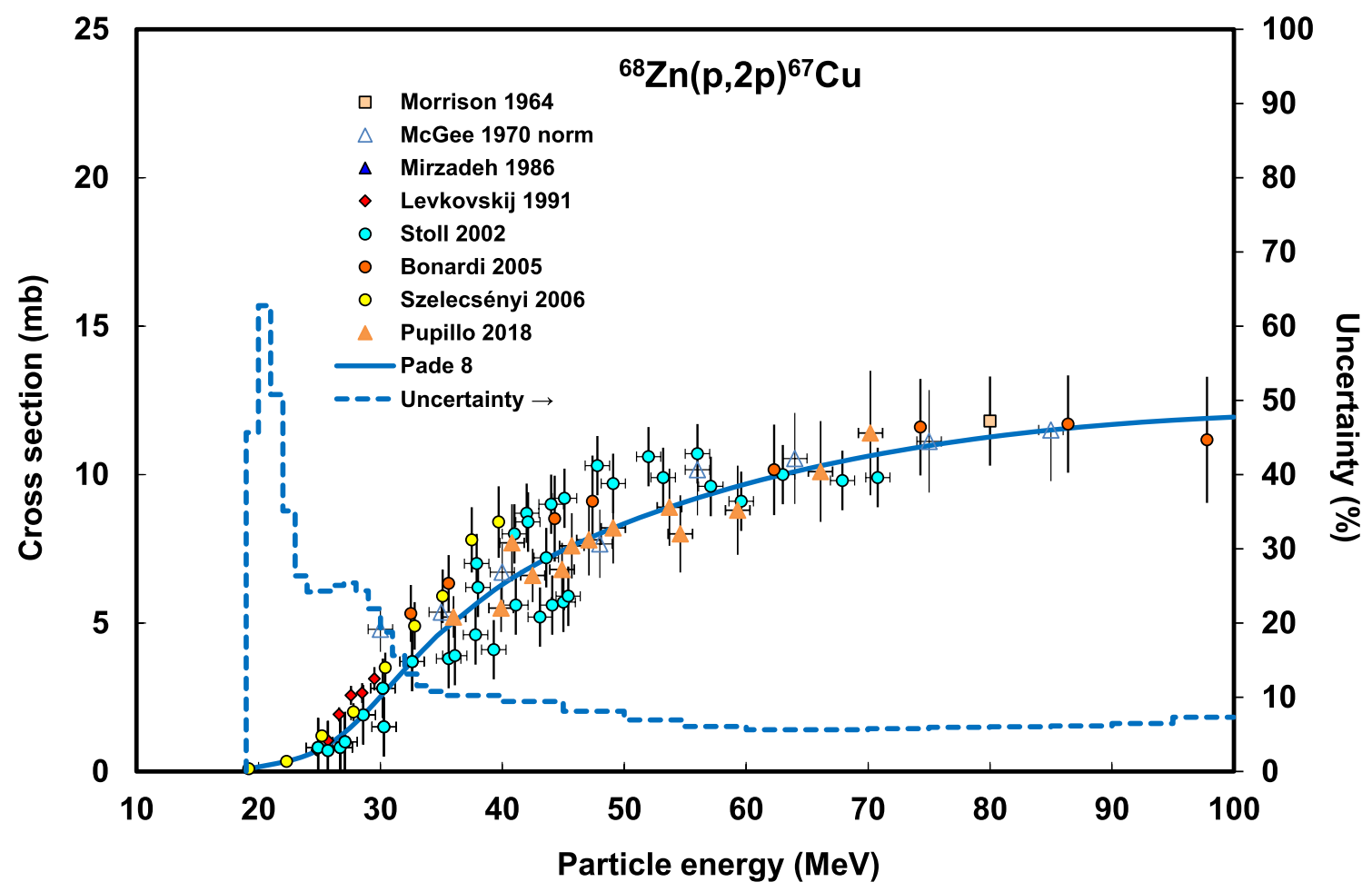

Fig. $3{ }^{68} \mathrm{Zn}(p, 2 p){ }^{67} \mathrm{Cu}$ reaction: selected experimental works and Padé fit (solid line) with total derived uncertainties, including $4 \%$ systematic uncertainty (dashed line, right hand scale) 


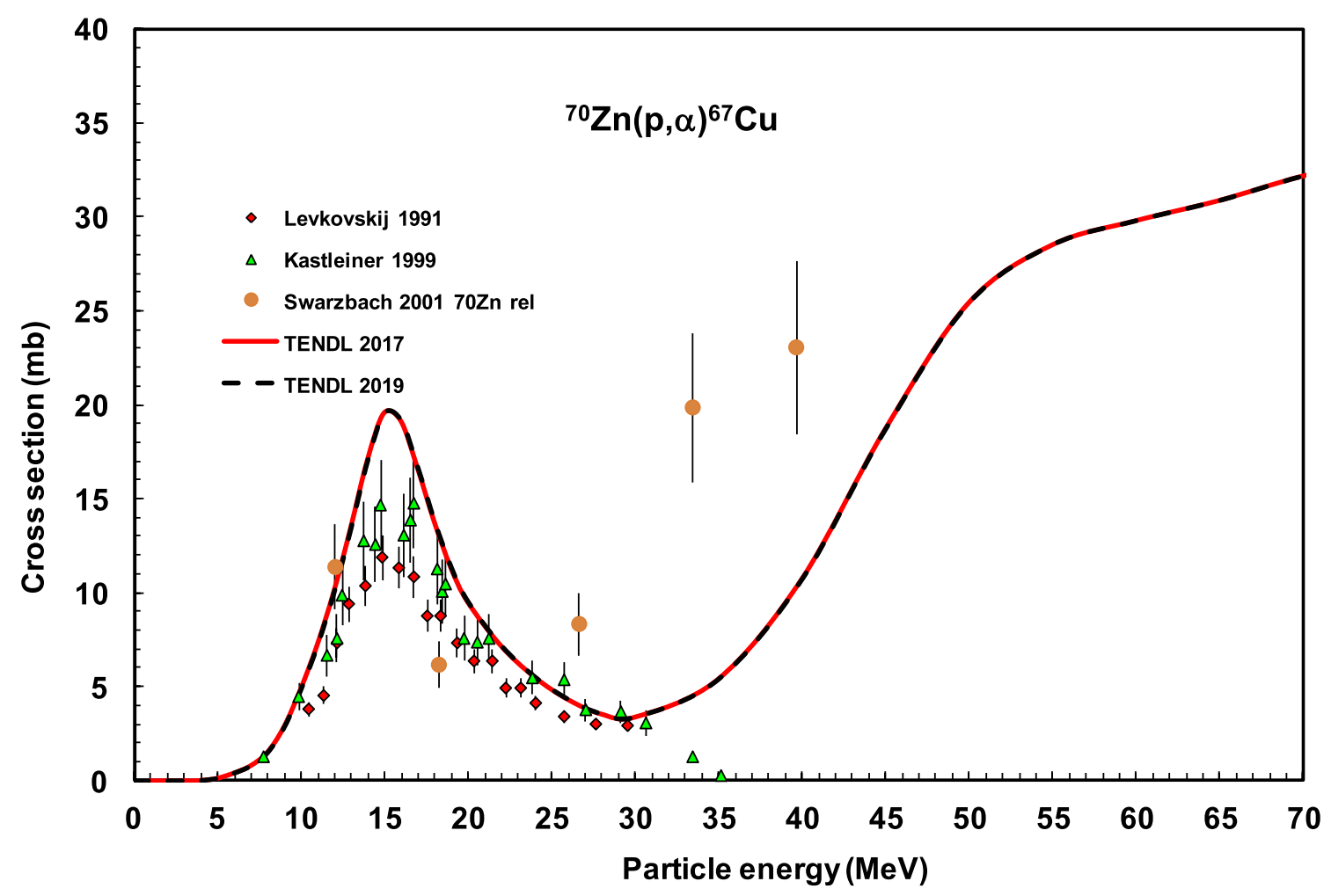

Fig. $4{ }^{70} \mathrm{Zn}(p, \alpha){ }^{67} \mathrm{Cu}$ reaction: all experimental data and TENDL predictions

Fig. $5{ }^{70} \mathrm{Zn}(p, \alpha){ }^{67} \mathrm{Cu}$ reaction: selected experimental works (with uncertainties) and Padé fit with derived uncertainties (dashed line, right hand scale)

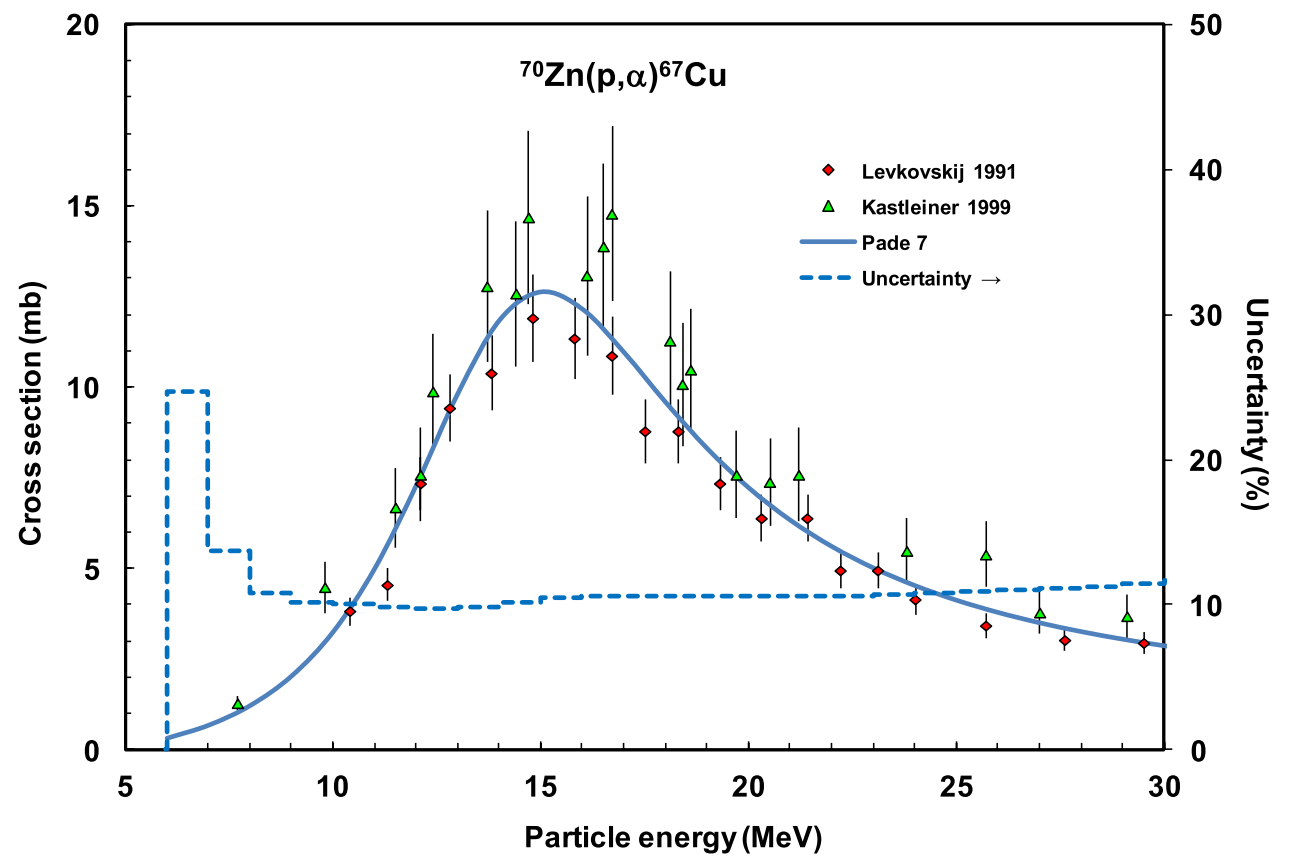


The two last, discrepant, points of Kastleiner et al [30] were excluded (large difference from TENDL predictions showing rising cross sections at this energy) as shown in Fig. 5. Fit made till $30 \mathrm{MeV}$.

\section{${ }^{\text {nat }} \mathrm{Zn}(p, x){ }^{67} \mathrm{Cu}$ reaction}

This reaction on natural targets was not evaluated earlier. A total of four data sets can be derived from literature: [23, 25, $28,30]$ and are compared with TENDL evaluations in Fig. 6.
Schwarzbach [28] data (see remark on normalisation above) were deselected as they are scattered and contradicting the Bonardi [25] data.

Levkovskij [23] and Kastleiner [30] data, measured on ${ }^{70} \mathrm{Zn}$, were normalised to ${ }^{\text {nat }} \mathrm{Zn}$ below the $(p, 2 p)$ threshold and were included. Levkovskij [23] data were corrected due to outdated monitor reaction data. The selected and corrected data vs the Padé fit are shown in Fig. 7.
Fig. $6{ }^{\text {nat }} \mathrm{Zn}(p, \mathrm{x})^{67} \mathrm{Cu}$ reaction: all experimental data and TENDL predictions
Fig. $7{ }^{\text {nat }} \mathrm{Zn}(p, \mathrm{x})^{67} \mathrm{Cu}$ reaction: selected experimental works (with uncertainties) and Padé fit with derived uncertainties (dashed line, right hand scale).
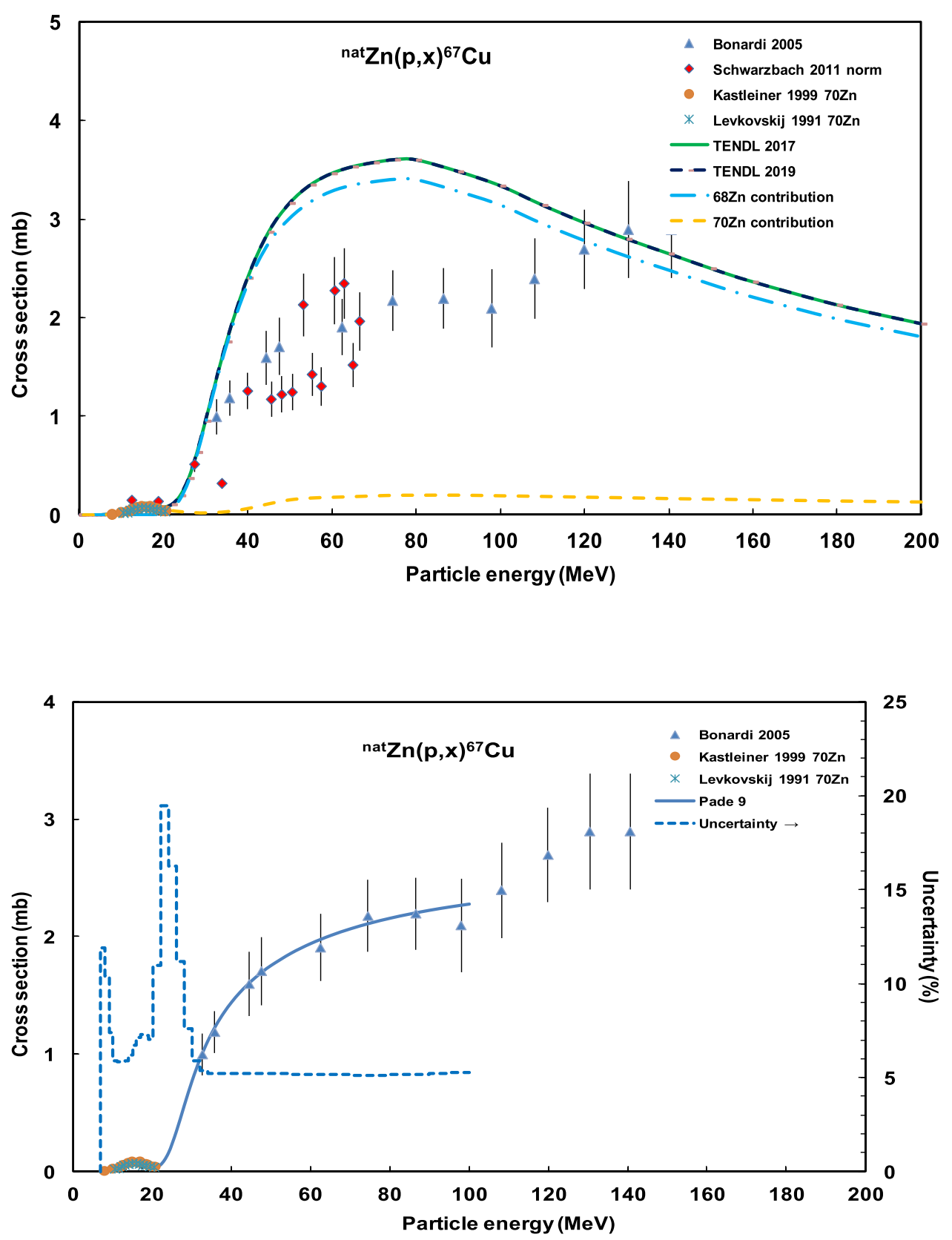
Fig. $8{ }^{\text {nat }} \mathrm{Zn}(d, \mathrm{x}){ }^{67} \mathrm{Cu}$ reaction: all experimental data and TENDL predictions

Fig. $9{ }^{\text {nat }} \mathrm{Zn}(d, \mathrm{x}){ }^{67} \mathrm{Cu}$ reaction: selected experimental works (with uncertainties) and Padé fit with derived uncertainties (dashed line, right hand scale)
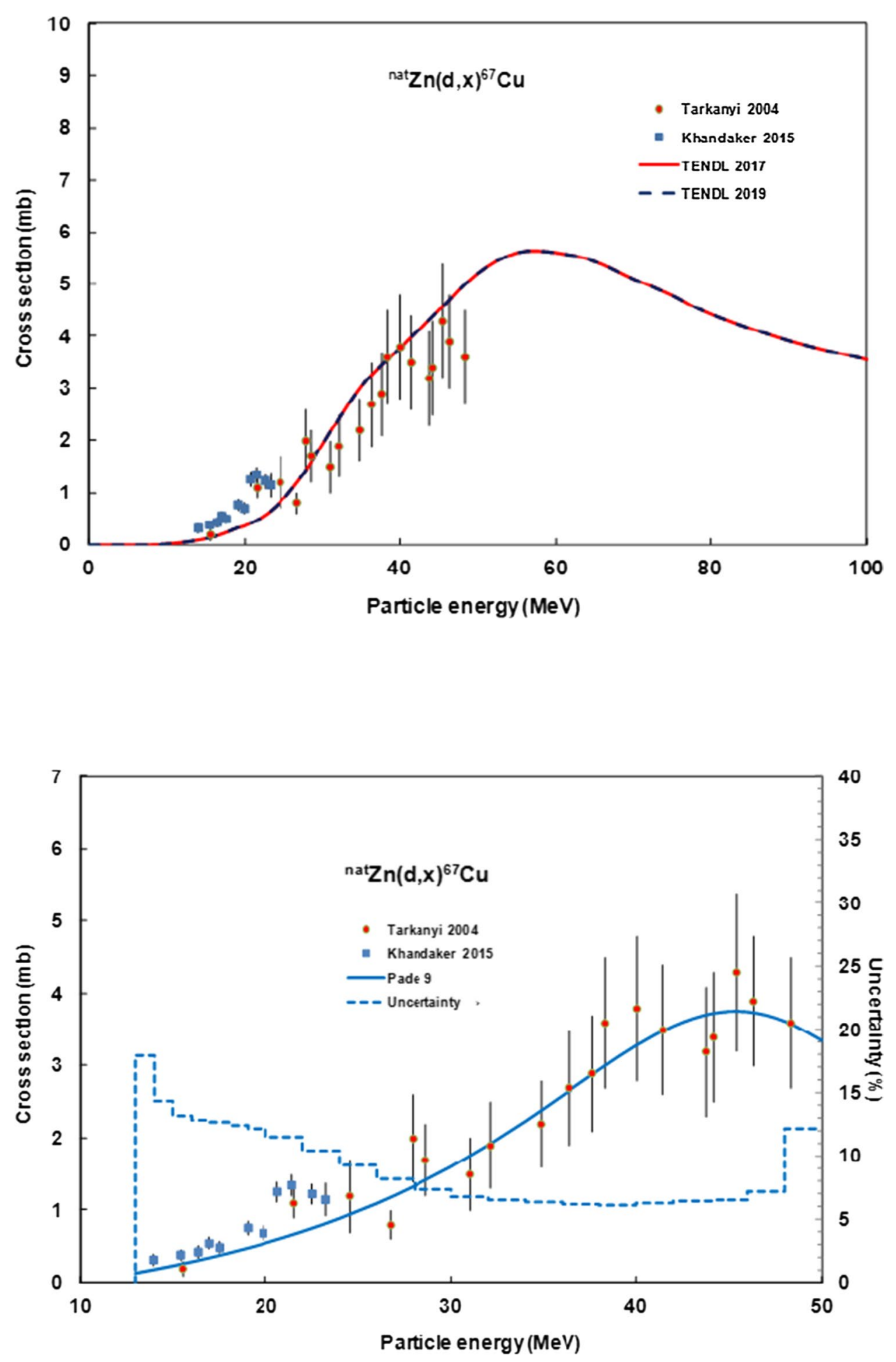


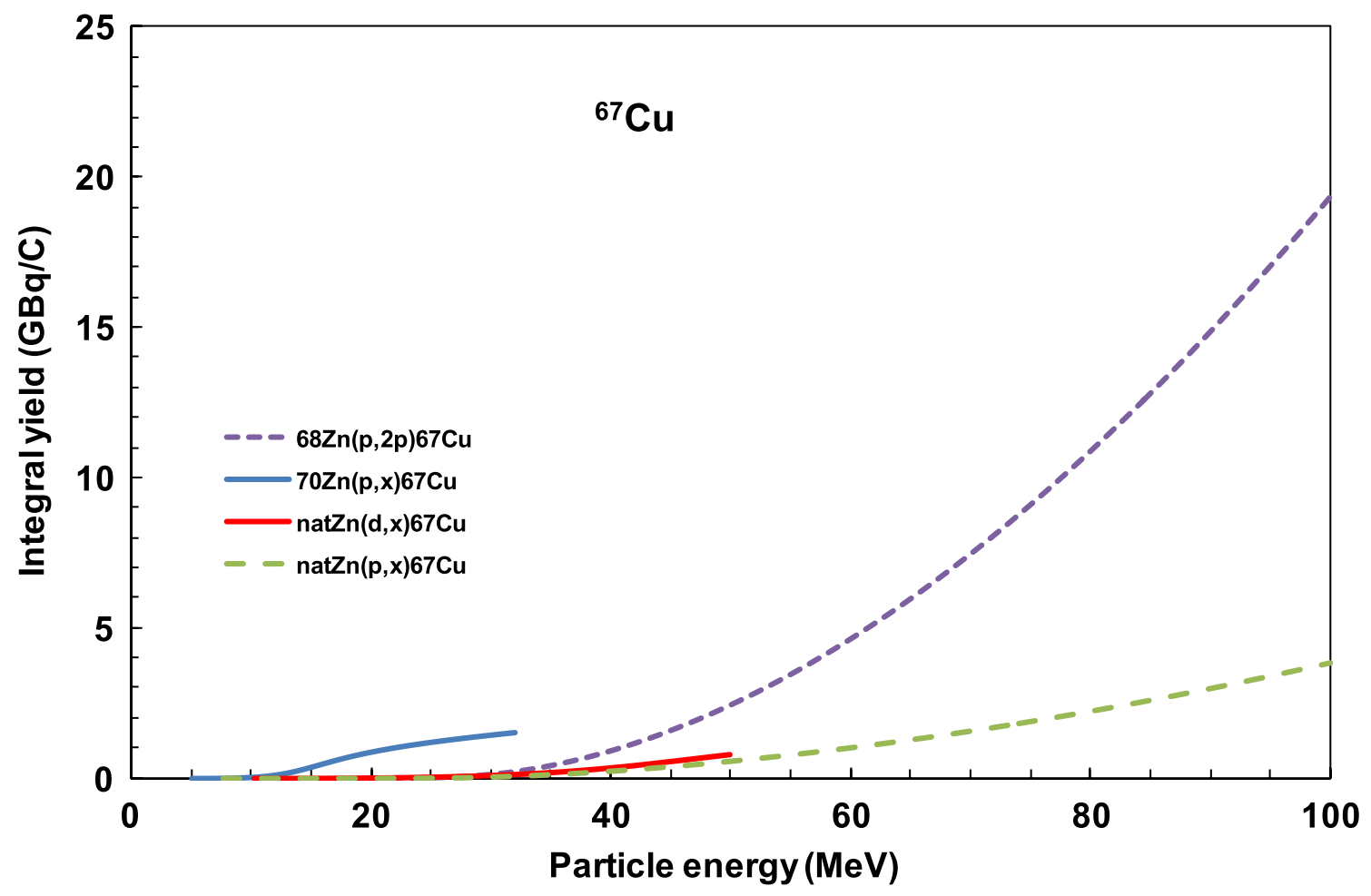

Fig. 10 Yield calculated from the recommended cross sections for ${ }^{67} \mathrm{Cu}$ production

Fig. 11 The ${ }^{103} \mathrm{Pd}$ and ${ }^{103 \mathrm{~m}} \mathrm{Rh}$ decay scheme

Fig. 12 The ${ }^{102 \mathrm{~m}} \mathrm{Rh}$ and ${ }^{102 g} \mathrm{Rh}$ decay scheme

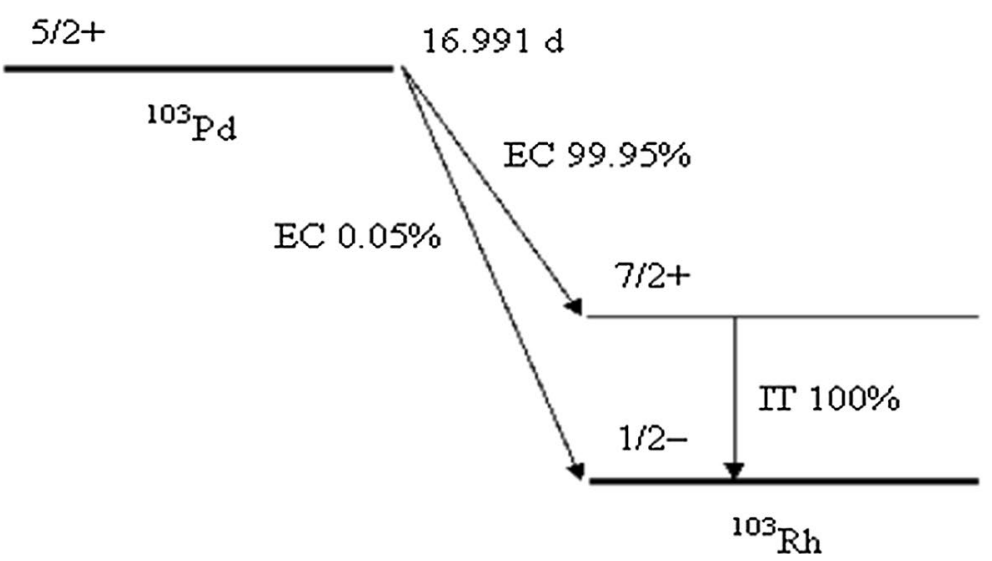

$56.114 \mathrm{~min}$

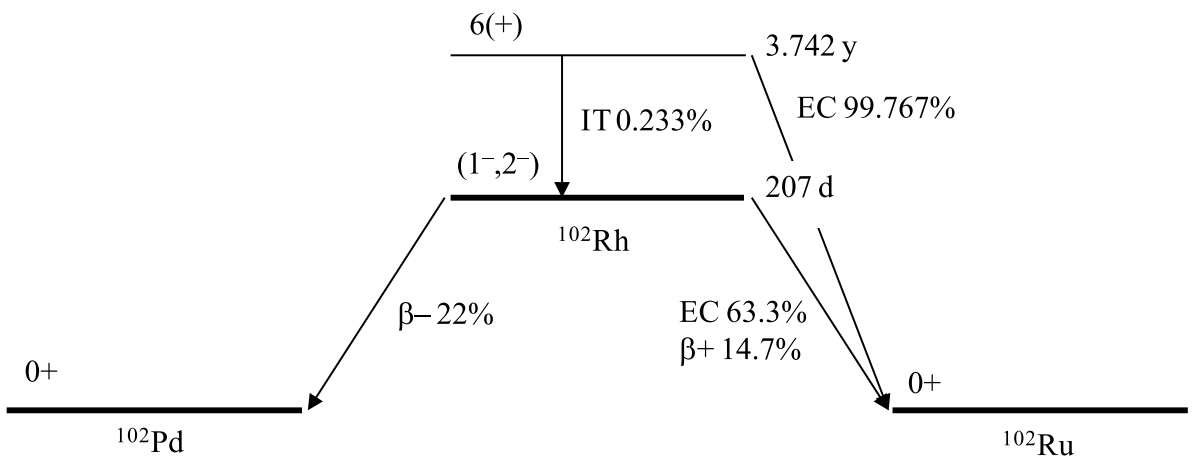




\section{${ }^{\text {nat }} \mathrm{Zn}(\mathrm{d}, \mathrm{x}){ }^{67} \mathrm{Cu}$ reaction}

A total of 2 data sets were found in literature: Tárkányi [31] and Khandaker [32] and are compared with TENDL evaluations in Fig. 8. Both sets were selected and fitted (Fig. 9). This reaction was not evaluated earlier.

\section{Integral yields for production of ${ }^{67} \mathrm{Cu}$}

The integral yields calculated on the basis of fitted crosssections for production of ${ }^{67} \mathrm{Cu}$ are collected in Fig. 10 .

\section{${ }^{103} \mathrm{Pd}$ and ${ }^{102} \mathrm{Rh}$ production}

Palladium-103 $\left(\mathrm{T}_{1 / 2}=16.991 \mathrm{~d}\right)$ decaying $100 \%$ by electron capture, accompanied by emission of Auger electrons and low energy X-rays, is extensively used in the treatment of prostate cancer and ocular melanoma. Applied mostly in brachytherapy form.

Rhodium-102 (metastable and ground state) is an important radioisotopic impurity generated during production of ${ }^{103} \mathrm{Pd}$.

The simplified decay schemes of ${ }^{103} \mathrm{Pd}$ and ${ }^{103 \mathrm{~m}} \mathrm{Rh}$ are shown in Fig. 11, and those for the co-produced ${ }^{102 \mathrm{~m}} \mathrm{Rh}$ and ${ }^{102 g} \mathrm{Rh}$ in Fig. 12.

The ${ }^{103} \mathrm{Rh}(p, \mathrm{n}){ }^{103} \mathrm{Pd},{ }^{103} \mathrm{Rh}(d, 2 \mathrm{n}){ }^{103} \mathrm{Pd},{ }^{103} \mathrm{Rh}(p, \mathrm{x}){ }^{102 \mathrm{~m}} \mathrm{Rh}$, ${ }^{102 \mathrm{~g}} \mathrm{Rh},{ }^{103} \mathrm{Rh}(d, \mathrm{x}){ }^{102 \mathrm{~m}} \mathrm{Rh},{ }^{102 \mathrm{~g}} \mathrm{Rh}$ production routes were evaluated.

\section{Cross sections for production of ${ }^{103} \mathrm{Pd}$ and ${ }^{102 m, 9}$ Rh}

${ }^{103} \mathrm{Rh}(\mathrm{p}, \mathrm{n}){ }^{103} \mathrm{Pd}$ reaction

A total of 9 data sets were found in literature: [33-41], which are compared to TENDL evaluations in Fig. 13. The work by Bramblett [36] is to be considered new as it was not included in the previous evaluation.

The set of Mukhammedov [39] was de-selected because of the differences in shape compared with all other excitation functions just above the threshold energy.

The highest energy point of Albert [34] is outlying and was not considered for the fitting.

It was mentioned in an earlier publication [2] that a systematic difference in cross sections was found depending on if X-lines, or $\gamma$-lines were used for the activity measurement. This discrepancy could not be explained by a recent unpublished review of ${ }^{103} \mathrm{Pd}$ decay data although for X-lines absolute intensities are calculated, while $\gamma$-ray abundances are measured. For the present report we used cross sections derived from $\mathrm{X}$-ray measurement, except for the datasets of $[34,35,38]$ that rely on neutron measurements.

The uncertainty for data of Sudar [41] was increased up to $10 \%$ (selected data vs. Padé fit are shown in Fig. 14).

\section{${ }^{103} \mathrm{Rh}(\mathrm{p}, \mathrm{x}){ }^{102 \mathrm{~m}, \mathrm{~g}} \mathrm{Rh}$ reaction}

For formation of the ground and metastable state of ${ }^{102} \mathrm{Rh}$ by proton induced reactions on ${ }^{103} \mathrm{Rh}$, the two data sets found in literature were used for fitting: [40, 42]. The data
Fig. $13{ }^{103} \mathrm{Rh}(p, \mathrm{n}){ }^{103} \mathrm{Pd}$ reaction: all experimental data and TENDL predictions

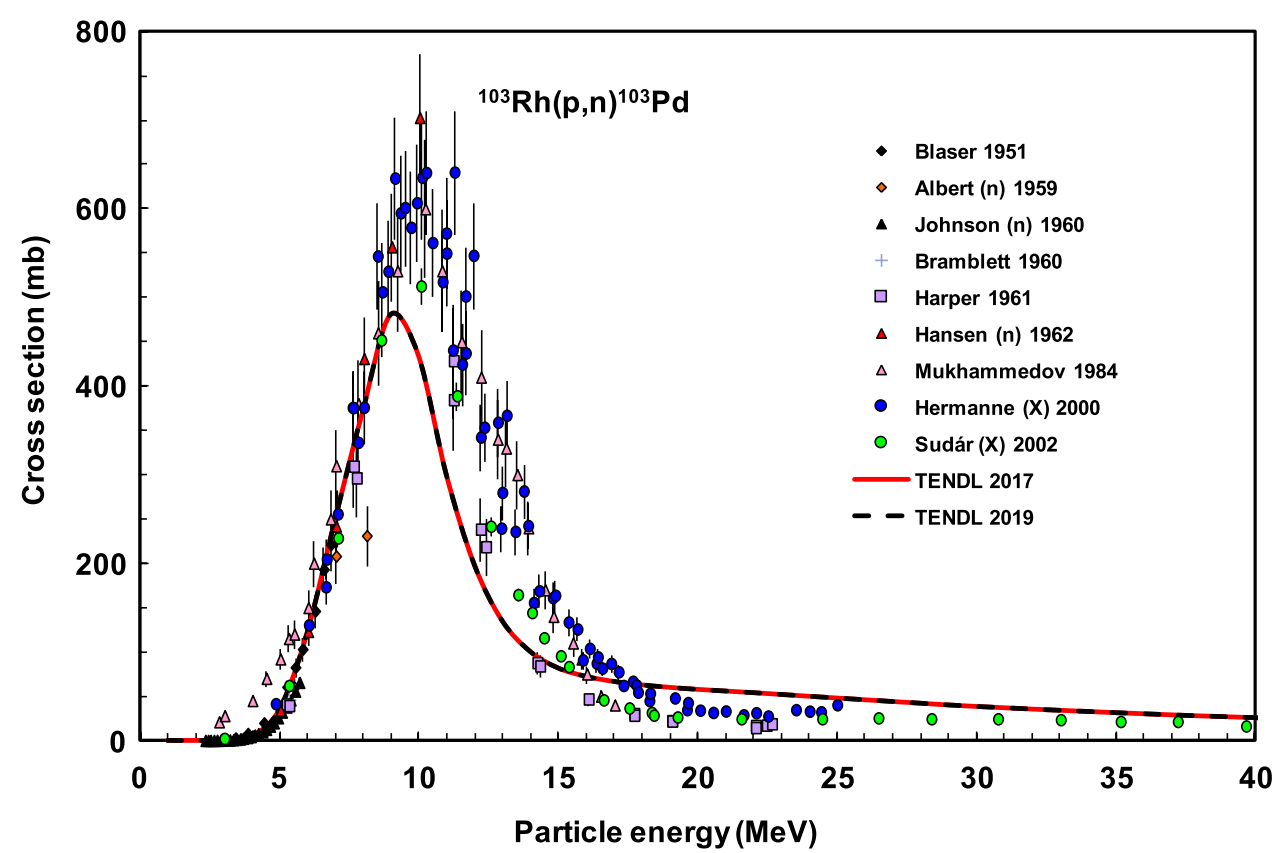


Fig. $14{ }^{103} \operatorname{Rh}(p, \mathrm{n}){ }^{103} \mathrm{Pd}$ reaction: selected experimental works (with uncertainties) and Padé fit with derived uncertainties (dashed line, right hand scale)

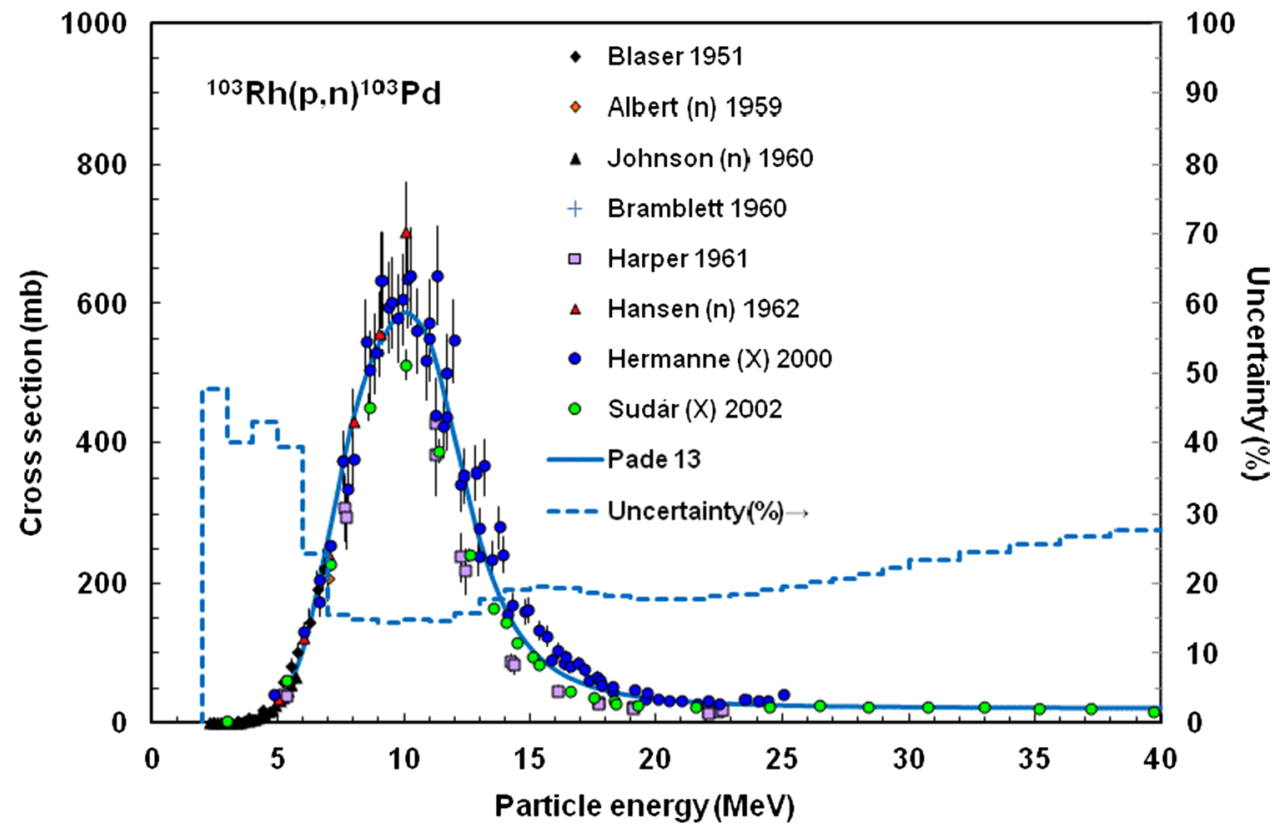

Fig. $15{ }^{103} \mathrm{Rh}(p, \mathrm{x})^{102 \mathrm{~m}} \mathrm{Rh}$ reaction: all experimental data and TENDL predictions

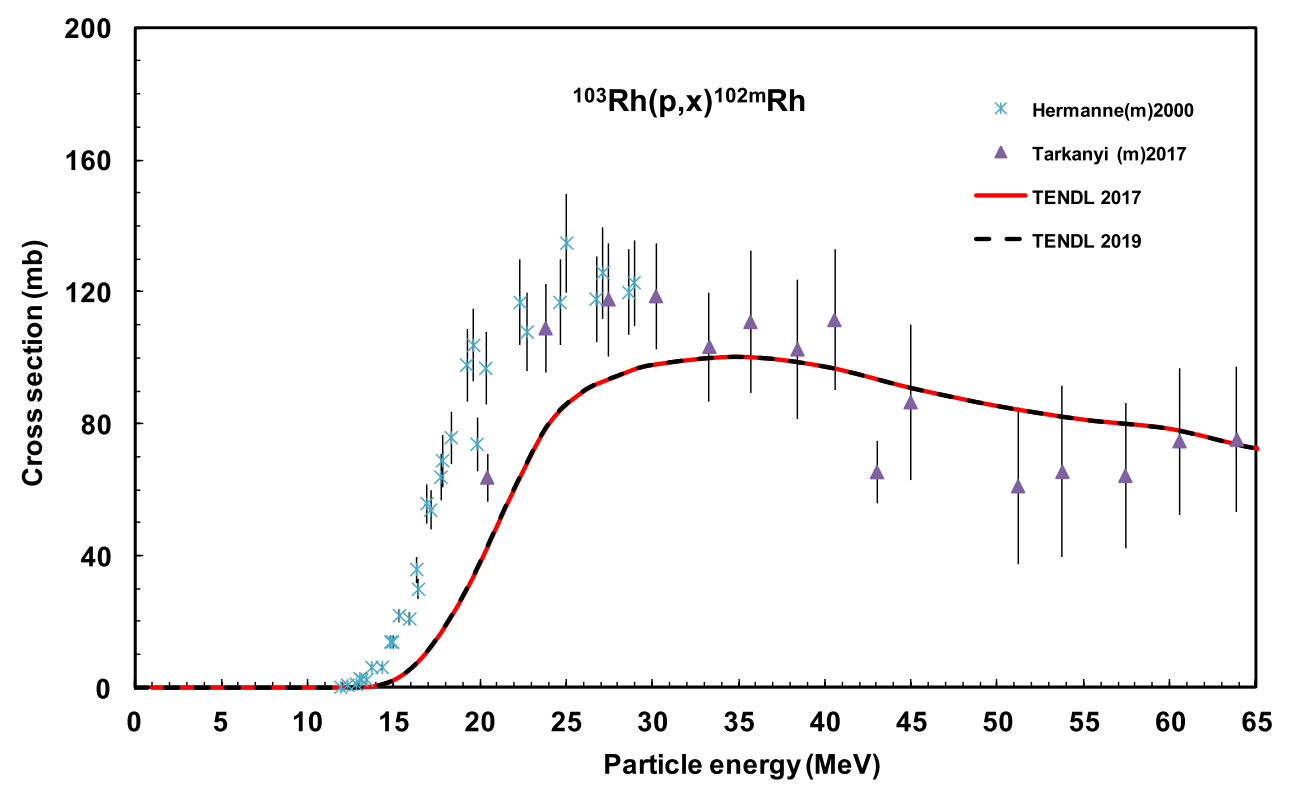

by Tárkányi [42], both for production of ${ }^{102 \mathrm{~m}} \mathrm{Rh}$ and ${ }^{102 \mathrm{~g}} \mathrm{Rh}$, are new. All data and the fitted data vs the Padé fit are shown in Figs. 15 and 16, respectively.

\section{${ }^{103} \mathrm{Rh}(\mathrm{p}, \mathrm{x}){ }^{102 \mathrm{~g}} \mathrm{Rh}$ reaction}

Two data sets were found in the literature published by [40] and are compared with TENDL evaluations in Fig. 17. Tárkányi 40 data have large uncertainties in the overlapping high energy region and were normalized to Hermanne [42] data by a factor of 0.7 before the fit was undertaken. Corrected data are shown in Fig. 18 versus the Padé fit.

\section{${ }^{103} \mathrm{Rh}(\mathrm{d}, 2 \mathrm{n}){ }^{103} \mathrm{Pd}$ reaction}

For formation of ${ }^{103} \mathrm{Pd}$ by deuteron induced reactions on ${ }^{103} \mathrm{Rh}$, the two data sets found in literature were used for fitting: [43-45] (Fig. 19). The set of Tárkányi [45] is new and was not considered in the earlier evaluation. The data reported in Ditrói [46] are identical to those in Tárkányi [45] and were excluded from the compilation. In the earlier evaluation the X-ray data were selected. In the last unpublished review of decay data, a small change was made for $\gamma$-ray probability. The Tárkányi data [45] relying on $\gamma$-measurements are systematically lower than the 
Fig. $16{ }^{103} \mathrm{Rh}(\mathrm{p}, \mathrm{x}){ }^{102 \mathrm{~m}} \mathrm{Rh}$ reaction: selected experimental works (with uncertainties) and Padé fit with derived uncertainties (dashed line, right hand scale)

Fig. $17{ }^{103} \mathrm{Rh}(\mathrm{p}, \mathrm{x}){ }^{102 \mathrm{~g}} \mathrm{Rh}$ reaction: all experimental data and TENDL predictions
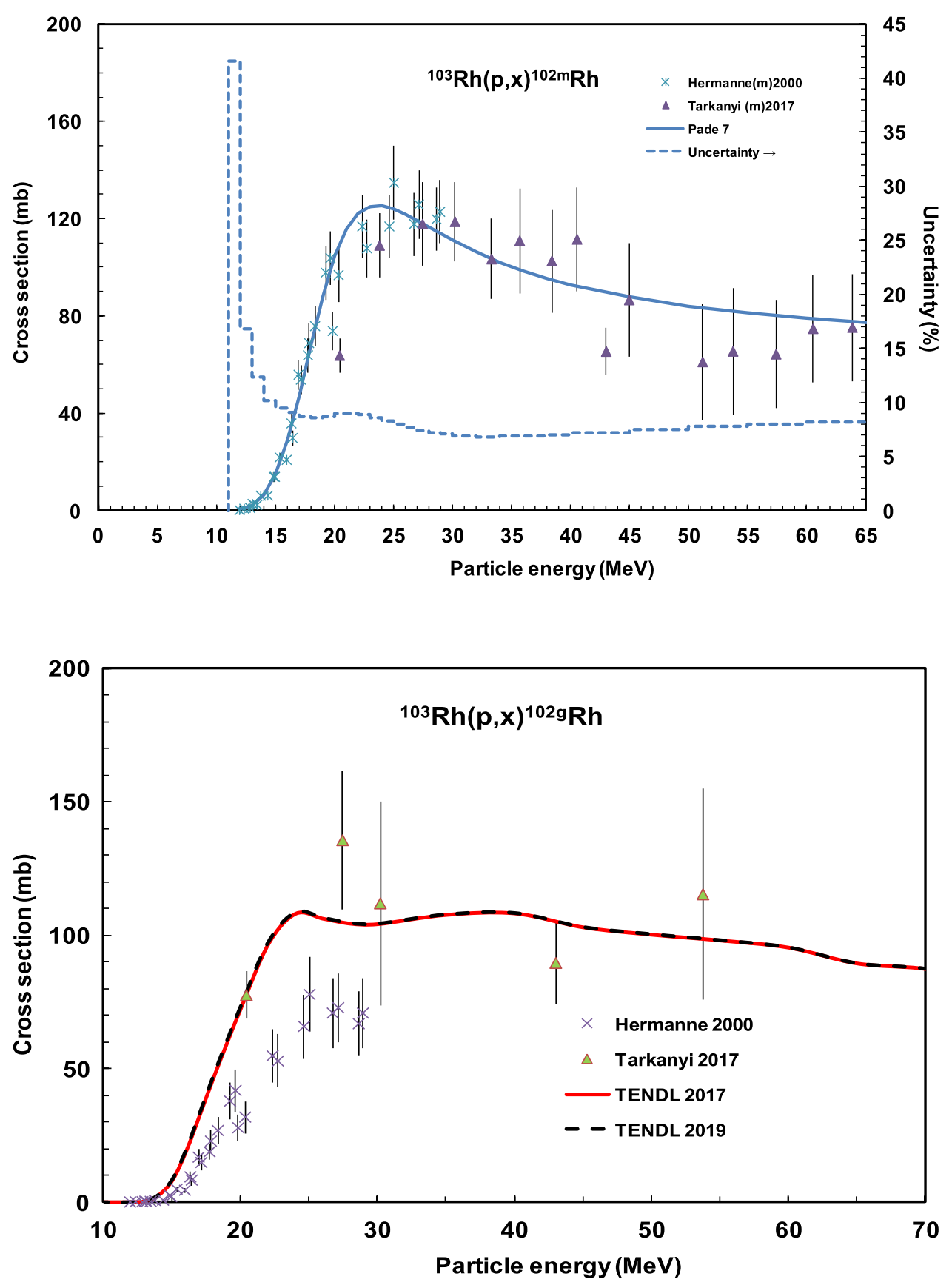

Hermanne [43, 44] values based on X-ray measurements and were hence multiplied by 1.2 according to ratio shown in case of protons for the ${ }^{103} \mathrm{Rh}(p, \mathrm{n}){ }^{103} \mathrm{Pd}$ reaction.

Hermanne [43, 44] X-ray data and the Tárkányi [45] corrected gamma data were selected and used for fitting as shown in Fig. 20.

\section{${ }^{103} \mathrm{Rh}(\mathrm{d}, \mathrm{x}){ }^{102 \mathrm{~m}} \mathrm{Rh},{ }^{102 g} \mathrm{Rh}$ reactions}

A total of 3 data sets were found in literature for formation of the ground and metastable state of ${ }^{102} \mathrm{Rh}$ by deuteron irradiation of ${ }^{103} \mathrm{Rh}$ : [43, 44, 46, 47]. The values reported in Hermanne [47] and Ditrói [46] data are new.

A few low energy points of Ditrói [46] below the threshold were deselected.

The collected and the selected data vs the Padé fit for production of ${ }^{102 \mathrm{~m}} \mathrm{Rh}$ are shown in Figs. 21 and 22, and for production of ${ }^{102 \mathrm{~g}} \mathrm{Rh}$ in Figs. 23 and 24, respectively. 
Fig. $18{ }^{103} \mathrm{Rh}(\mathrm{p}, \mathrm{x}){ }^{102 g} \mathrm{Rh}$ reaction: selected experimental works (with uncertainties) and Padé fit with derived uncertainties (dashed line, right hand scale)

Fig. $19{ }^{103} \mathrm{Rh}(d, 2 \mathrm{n}){ }^{103} \mathrm{Pd}$ reaction: all experimental data and TENDL predictions
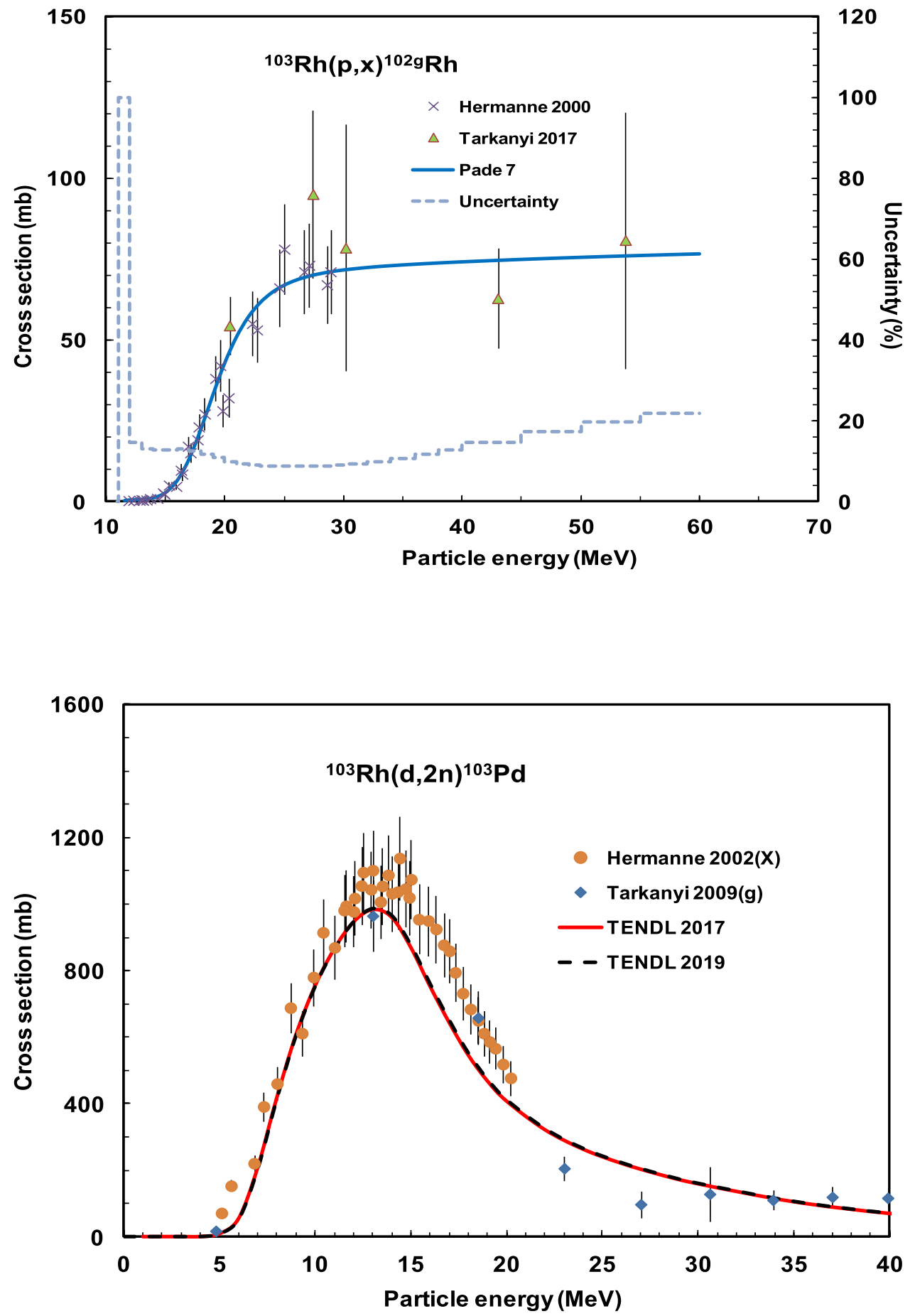

\section{Integral yields for production of ${ }^{103} \mathrm{Pd}$, ${ }^{102 m_{R h}}$ and ${ }^{1029} \mathrm{Rh}$}

The deduced integral yields for the $(p, n)$ and $(d, 2 \mathrm{n})$ reactions leading to ${ }^{103} \mathrm{Pd}$ are shown in Fig. 25.

Four calculated integral yields of the ${ }^{103} \mathrm{Rh}(\mathrm{p}, \mathrm{x}){ }^{102 \mathrm{~g}} \mathrm{Rh}$, ${ }^{103} \mathrm{Rh}(\mathrm{p}, \mathrm{x}){ }^{102 \mathrm{~m}} \mathrm{Rh},{ }^{103} \mathrm{Rh}(d, \mathrm{x}){ }^{102 \mathrm{~m}} \mathrm{Rh}$ and ${ }^{103} \mathrm{Rh}(d, \mathrm{x}){ }^{102 \mathrm{~g}}$ $\mathrm{Rh}$ reactions are shown in Fig. 26.

\section{$114 \mathrm{~m}$ In production}

The radionuclide ${ }^{114 \mathrm{~m}} \mathrm{In}\left(\mathrm{T}_{1 / 2}=49.51 \mathrm{~d}\right)$, being a longer-lived analogue of ${ }^{111} \mathrm{In}$, is of potential interest in Auger and conversion electron therapy for longer lasting therapeutic studies with use of its compounds of appropriately slow kinetics.

The decay scheme and the decay data are shown in Fig. 27 and Table 2. 


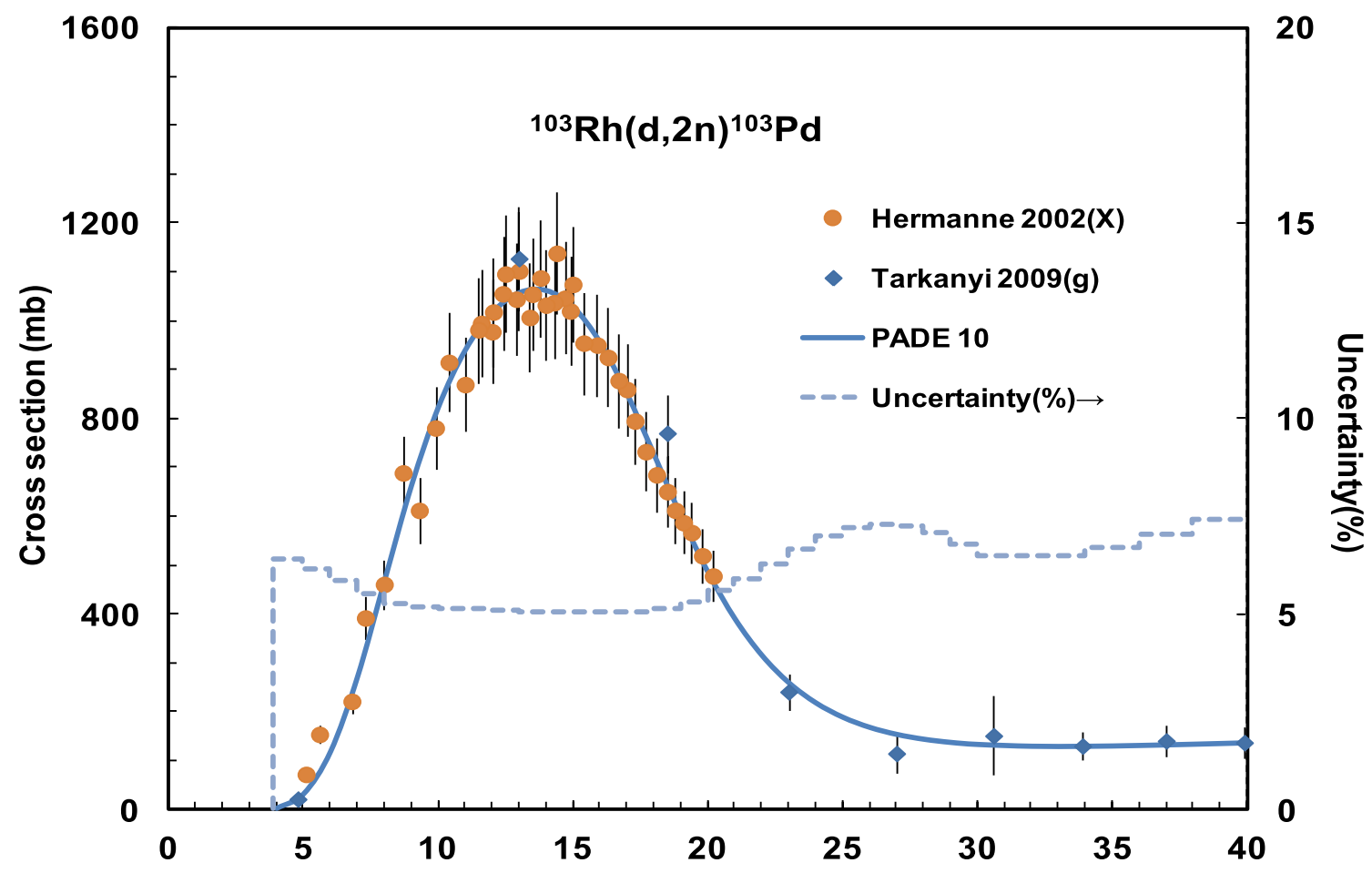

Fig. $20{ }^{103} \mathrm{Rh}(d, 2 \mathrm{n}){ }^{103} \mathrm{Pd}$ reaction: selected experimental works (with uncertainties) and Padé fit with derived uncertainties (dashed line, right hand scale)

Fig. $21{ }^{103} \mathrm{Rh}(d, \mathrm{x})^{102 \mathrm{~m}} \mathrm{Rh}$ reaction: all experimental data and TENDL predictions

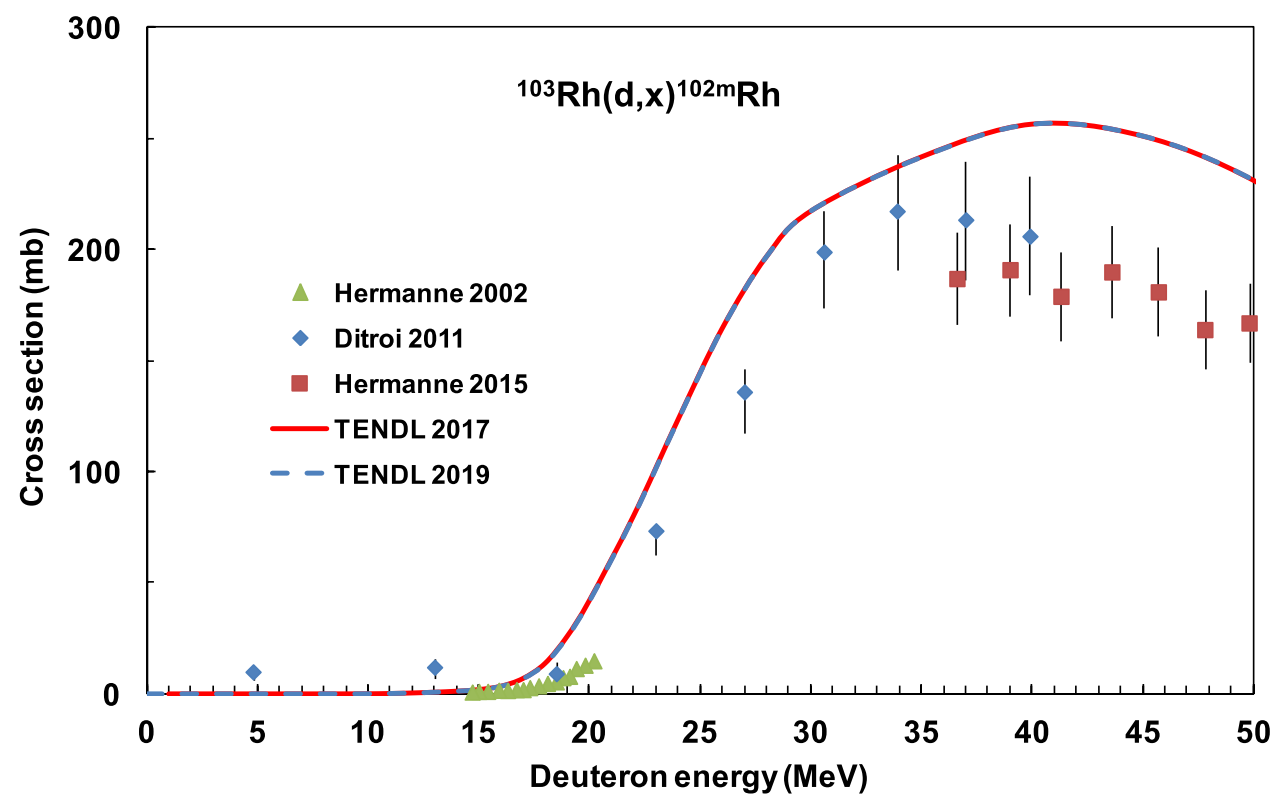

\section{Evaluated nuclear reactions}

The ${ }^{114} \mathrm{Cd}(p, \mathrm{n}){ }^{114 \mathrm{~m}} \mathrm{In}, \quad{ }^{114} \mathrm{Cd}(d, 2 \mathrm{n}){ }^{114 \mathrm{~m}} \mathrm{In}$ and ${ }^{116} \mathrm{Cd}(p, 3 \mathrm{n}){ }^{114 \mathrm{~m}}$ In reactions were evaluated.

\section{${ }^{114} \mathrm{Cd}(p, n){ }^{114 \mathrm{~m}}$ In reaction}

A total of 17 data sets were found in literature: [48-62] (Fig. 28). Two sets are new as they were not included in the previous evaluation: Hermanne [57] and Zarubin [62].

Five datasets were de-selected: Zaitseva [55] (obtained on ${ }^{\text {nat }} \mathrm{Cd}$ target, shows a systematic shift to the higher energies), 
Fig. $22{ }^{103} \mathrm{Rh}(d, \mathrm{x}){ }^{102 \mathrm{~m}} \mathrm{Rh}$ reaction: selected experimental works (with uncertainties) and Padé fit with derived uncertainties (dashed line, right hand scale)

Fig. $23{ }^{103} \mathrm{Rh}(d, \mathrm{x}){ }^{102 \mathrm{~g}} \mathrm{Rh}$ reaction: all experimental data and TENDL predictions
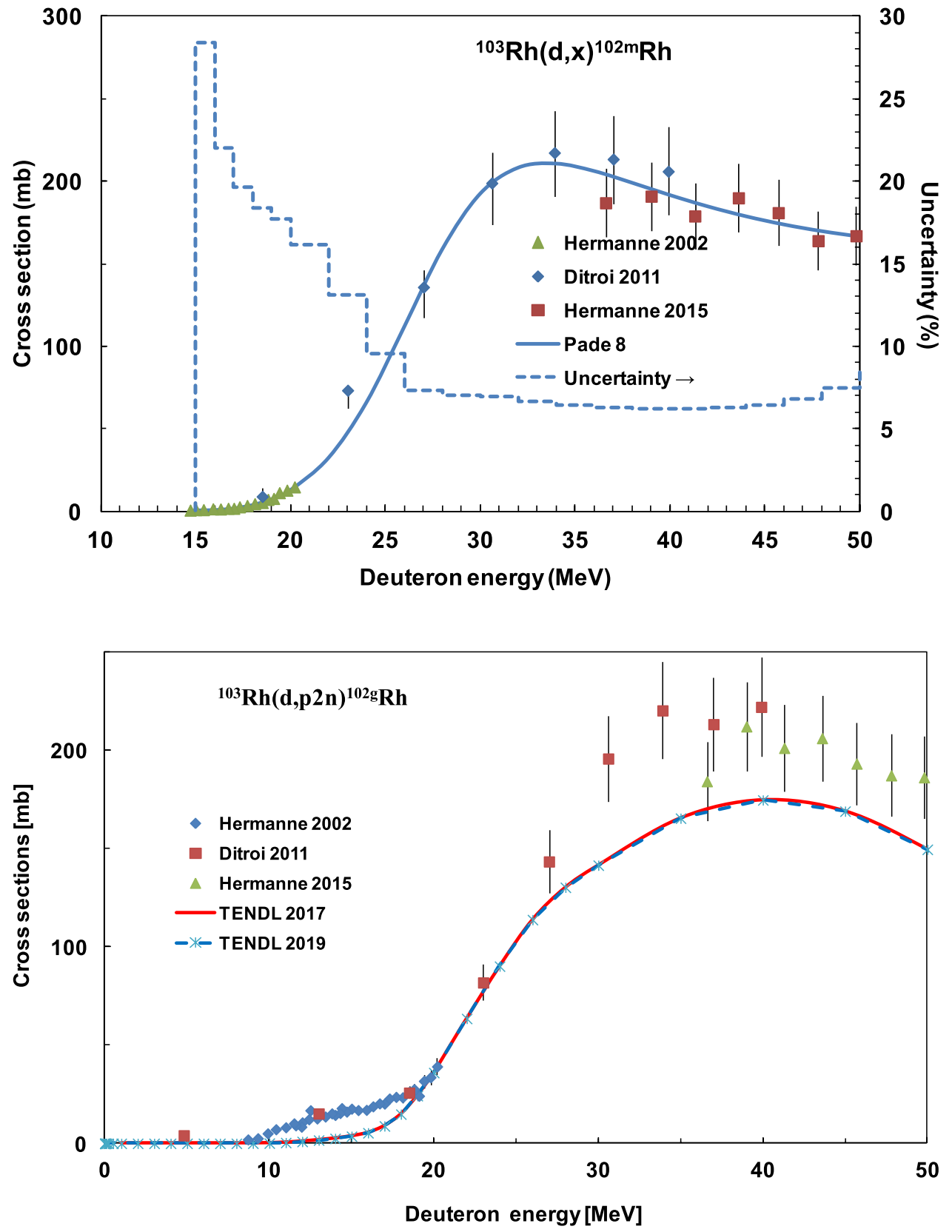

Abramovich [53] (refer to sum of metastable + ground state cross sections), Nieckarz [51] (high energy measurements), Mirzaei [56] (data are theoretical results obtained from ALICE code, no experimental data for ${ }^{114 \mathrm{~m}} \mathrm{In}$ ), and Said [59] (measured on enriched target, the large deviation from other sets is probably caused by an unreliable target thickness determination).

The collected and the selected data vs the Padé fit for the ${ }^{114} \mathrm{Cd}(p, \mathrm{n}){ }^{114 \mathrm{~m}}$ In reaction are shown in Figs. 28 and 29, respectively.

\section{${ }^{114} \mathrm{Cd}(\mathrm{d}, 2 \mathrm{n}){ }^{114 \mathrm{~m}}$ In reaction}

A total of 5 data sets were found in literature: [56, 63-65] (Fig. 30). No new data were found since the last evaluation. The set of Tárkányi [65] was corrected by a factor of 0.9 after re-analysing and using the $\mathrm{Cu}+\mathrm{d}$ monitor reactions instead of the $\mathrm{Fe}+\mathrm{d}$ reactions. The data of Mirzaei [56] were deselected. The absolute cross-section values are too small comparing to Tárkányi [65] and to Nassiff [63]. The absolute cross-section values are also too small for the simultaneously measured ${ }^{111}$ In. Two data points of Nassiff [63] above $17 \mathrm{MeV}$ were deselected. 


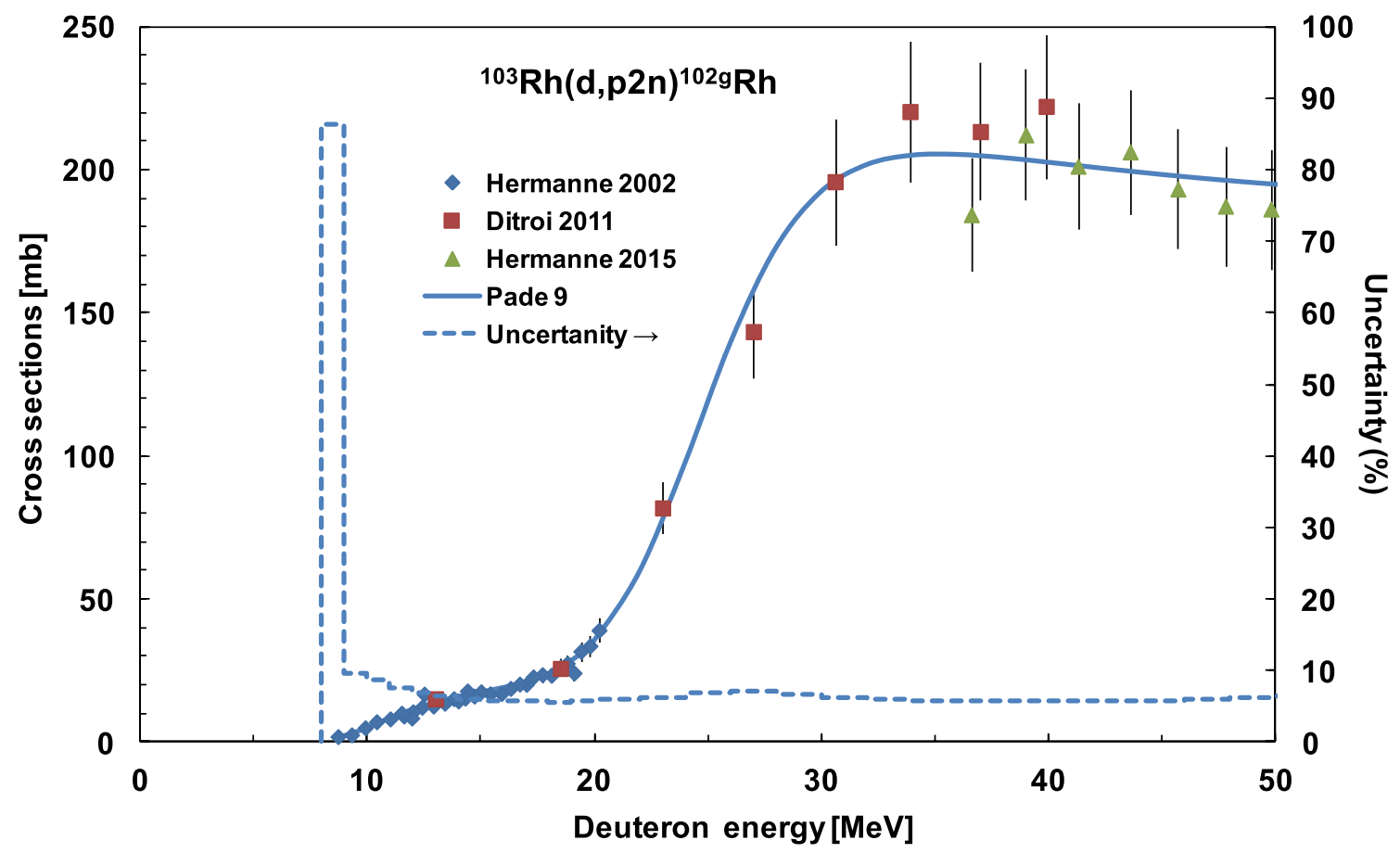

Fig. $24{ }^{103} \mathrm{Rh}(d, \mathrm{x}){ }^{102 g} \mathrm{Rh}$ reaction: selected experimental works (with uncertainties) and Padé fit with derived uncertainties (dashed line, right hand scale)

Fig. 25 Yields calculated from the recommended cross sections for ${ }^{103} \mathrm{Pd}$ production

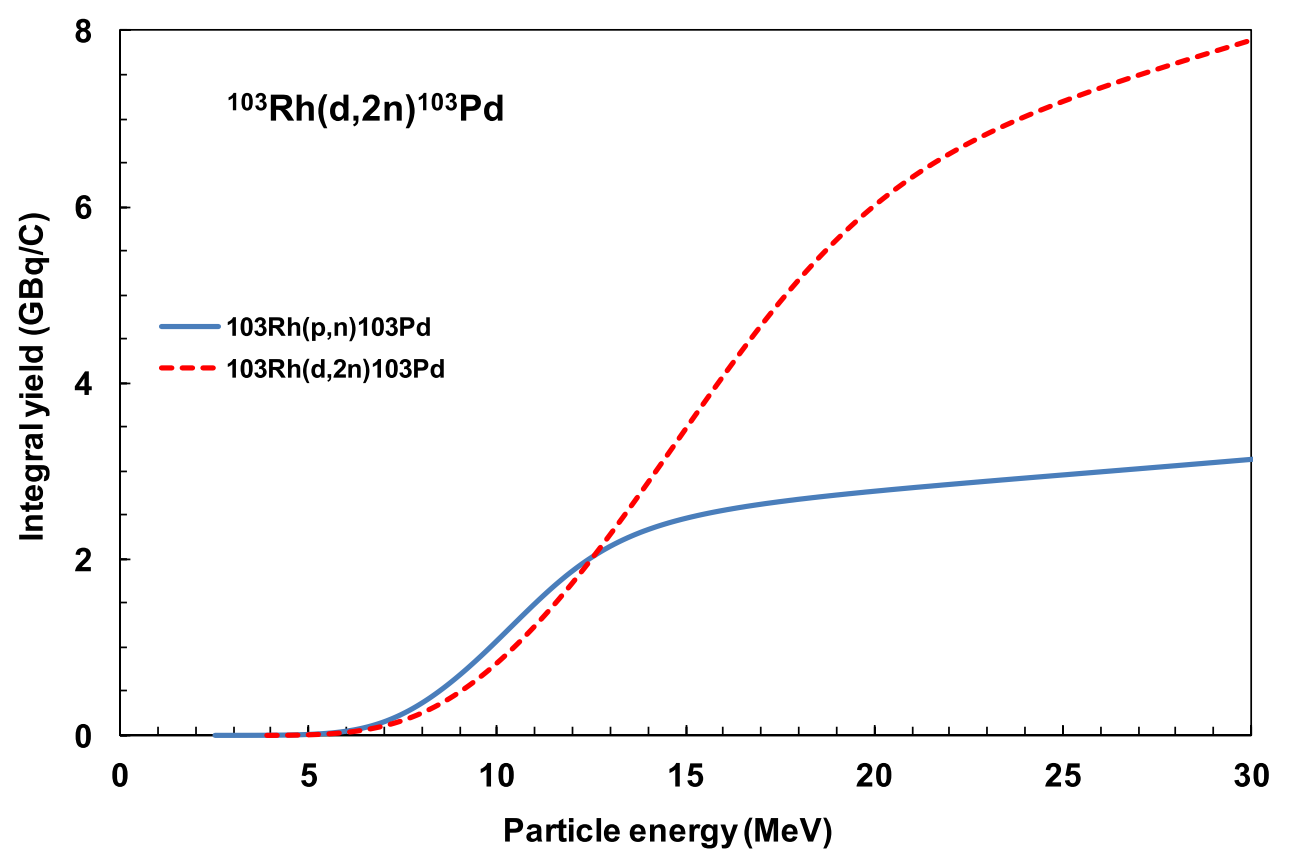

The data measured on ${ }^{\text {nat }} \mathrm{Cd}$ target of Tárkányi [60] contains the contribution from the ${ }^{113} \mathrm{Cd}(d, \mathrm{n})^{114 \mathrm{~m}}$ In reaction. According to the Alice IPPE calculation this contribution can be neglected (estimated ${ }^{113} \mathrm{Cd}(d, \mathrm{n})^{114 \mathrm{~m}+\mathrm{g}}$ In is around $5-10 \%$ in the important low energy range, for ${ }^{114 \mathrm{~m}}$ In alone is even smaller). No correction was done for this contribution considering that the data measured on ${ }^{114} \mathrm{Cd}$ targets and derived from ${ }^{\text {nat }} \mathrm{Cd}$ targets show excellent agreement and the uncertainty on the absolute values is in both cases in the $12-15 \%$ range.

As the threshold for ${ }^{116} \mathrm{Cd}(\mathrm{d}, 4 \mathrm{n}){ }^{114} \mathrm{In}$ is $19.6 \mathrm{MeV}$, we used normalized data obtained on ${ }^{\text {nat }} \mathrm{Cd}$ up to $20.7 \mathrm{MeV}$. The collected and the selected data vs the Padé fit for the 
Fig. 26 Yield calculated from the recommended cross sections for ${ }^{103} \mathrm{Rh}(\mathrm{p}, \mathrm{x}){ }^{102 \mathrm{~m}, \mathrm{~g}} \mathrm{Rh}$ and

${ }^{103} \mathrm{Rh}(d, \mathrm{x}){ }^{102 \mathrm{~m}, \mathrm{~g}} \mathrm{Rh}$ reactions
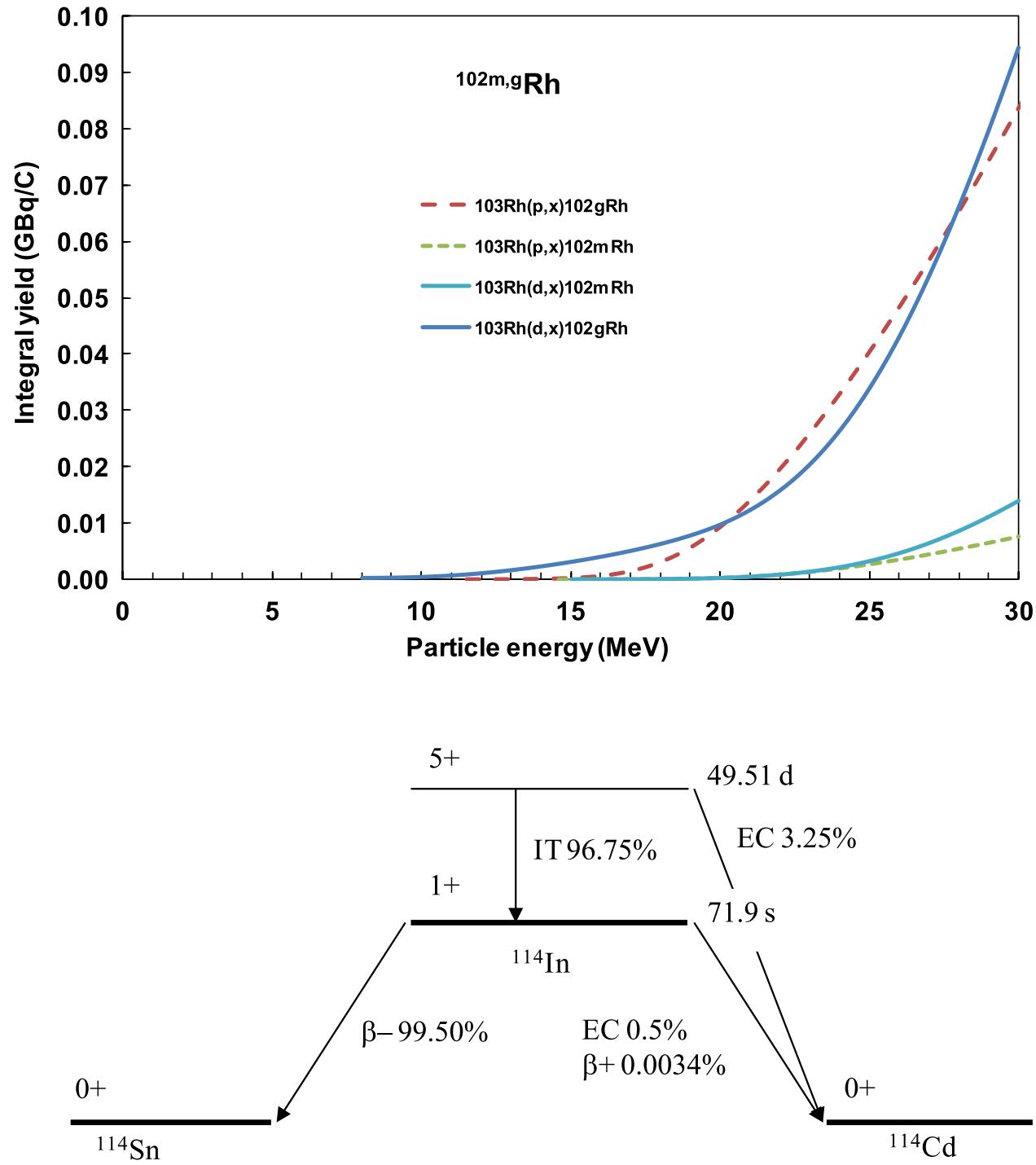

Fig. $28{ }^{114} \mathrm{Cd}(p, \mathrm{n})^{114 \mathrm{~m}}$ In reaction: all experimental data and TENDL predictions

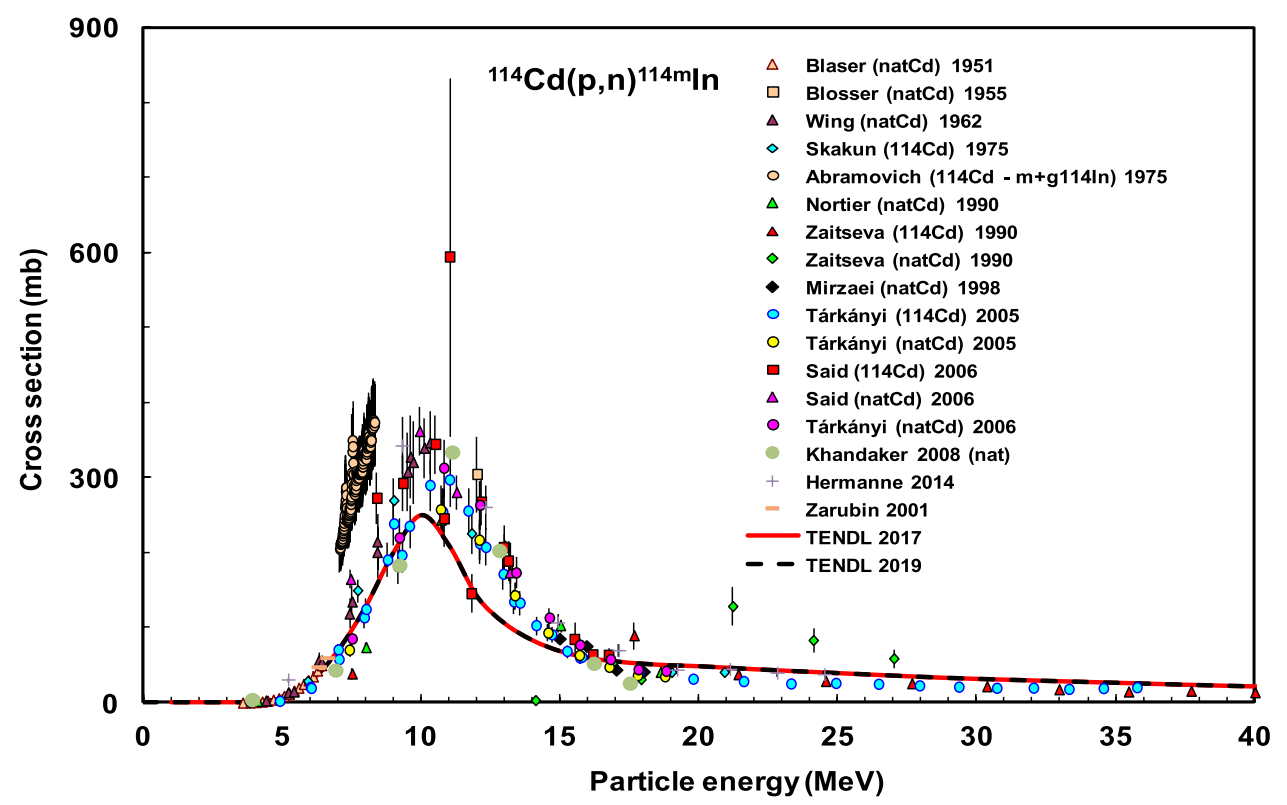


Fig. $29{ }^{114} \mathrm{Cd}(p, \mathrm{n}){ }^{114 \mathrm{~m}}$ In reaction: selected experimental works (with uncertainties) and Padé fit with derived uncertainties (dashed line, right hand scale)

Fig. $30{ }^{114} \mathrm{Cd}(d, 2 \mathrm{n})^{114 \mathrm{~m}}$ In reaction: all experimental data and TENDL predictions
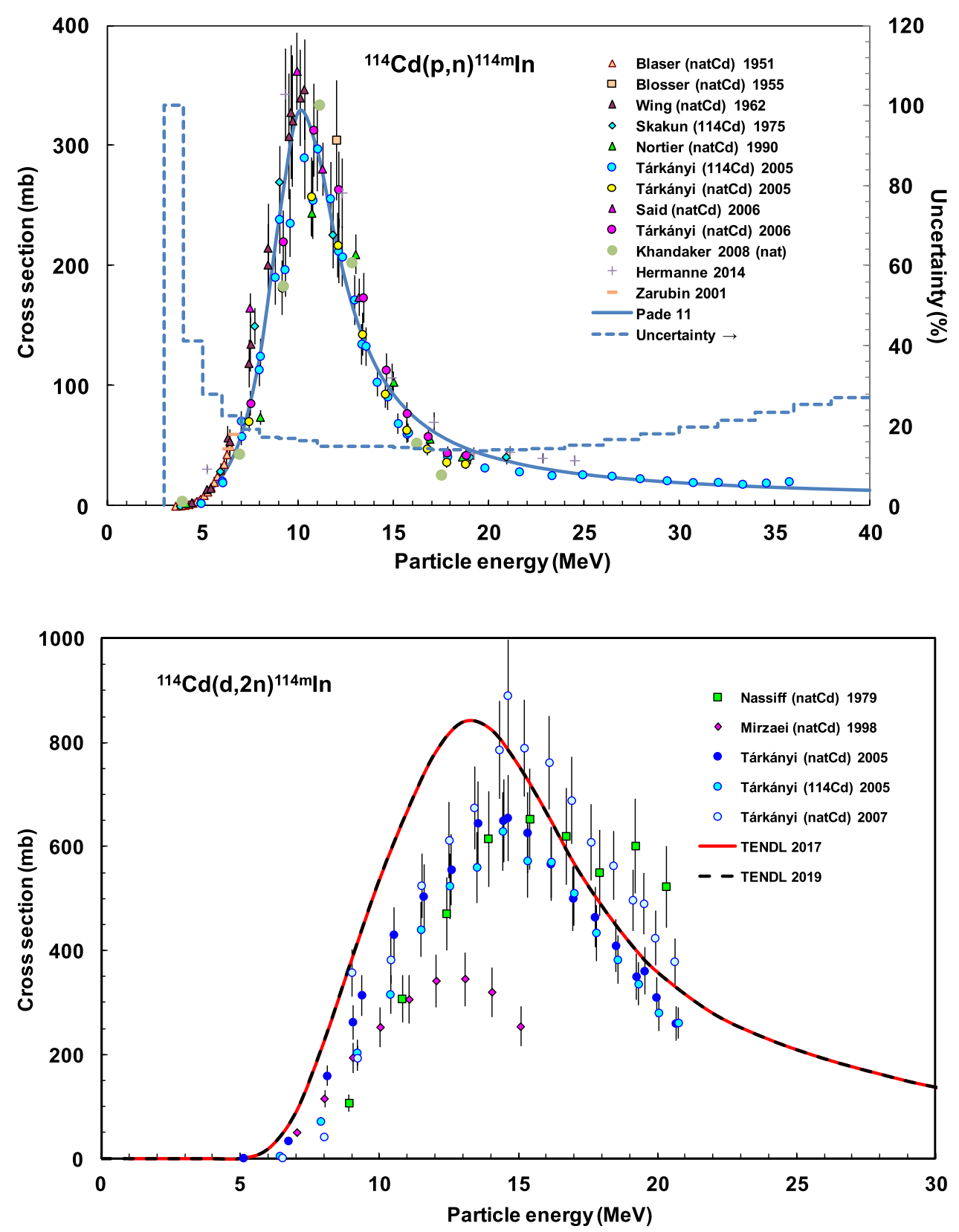

${ }^{114} \mathrm{Cd}(d, 2 \mathrm{n}){ }^{114 \mathrm{~m}}$ In reaction are shown in Figs. 30 and 31, respectively.

\section{${ }^{116} C d(p, 3 n){ }^{114 m}$ In reaction}

A total of 3 data sets were found in literature: [51, 64, 66]. The sets of Nieckarz [51] and Hermanne [66] are new and were not used in the previous evaluation as shown in Fig. 32. All data were selected and fitted and are shown vs the Padé fit in Fig. 33.

\section{$114 \mathrm{~m}$ In yields}

Calculated integral yields of the ${ }^{114} \mathrm{Cd}(p, \mathrm{n}){ }^{114 \mathrm{~m}} \mathrm{In}$, ${ }^{114} \mathrm{Cd}(d, 2 \mathrm{n}){ }^{114 \mathrm{~m}} \mathrm{In}$ and ${ }^{116} \mathrm{Cd}(p, 3 \mathrm{n}){ }^{114 \mathrm{~m}} \mathrm{In}$ reactions are shown in Fig. 34.

\section{${ }^{125}$ I production}

The long-lived iodine isotope ${ }^{125} \mathrm{I}\left(\mathrm{T}^{1 / 2}=59.41 \mathrm{~d}\right)$ is an intense Auger electron emitter. It is commonly used in radio-immunoassay. 


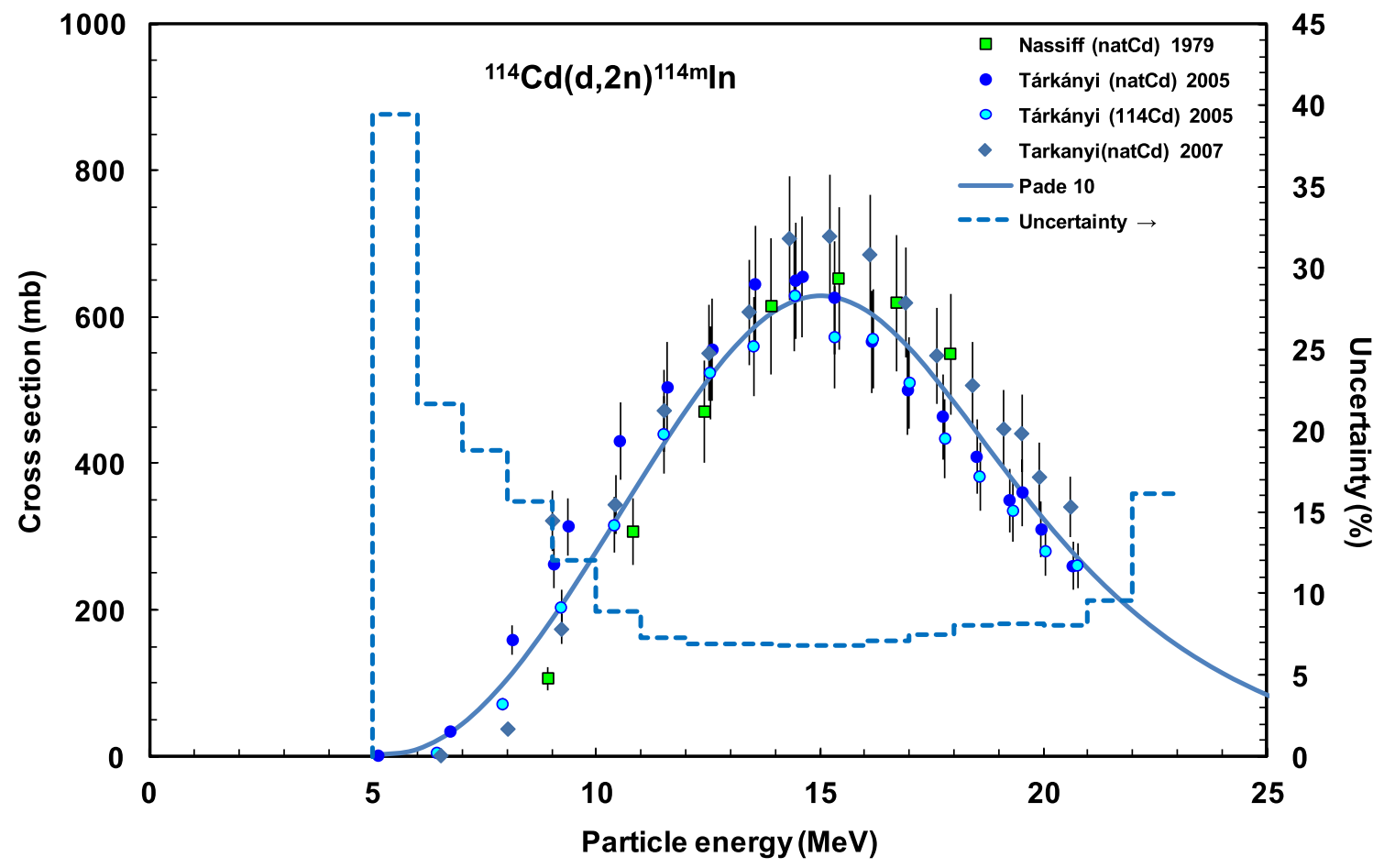

Fig. $31{ }^{114} \mathrm{Cd}(d, 2 \mathrm{n}){ }^{114 \mathrm{~m}}$ In reaction: selected experimental works (with uncertainties) and Padé fit with derived uncertainties (dashed line, right hand scale)

Fig. $32{ }^{116} \mathrm{Cd}(p, 3 \mathrm{n}){ }^{114 \mathrm{~m}}$ In reaction: all experimental data and TENDL predictions

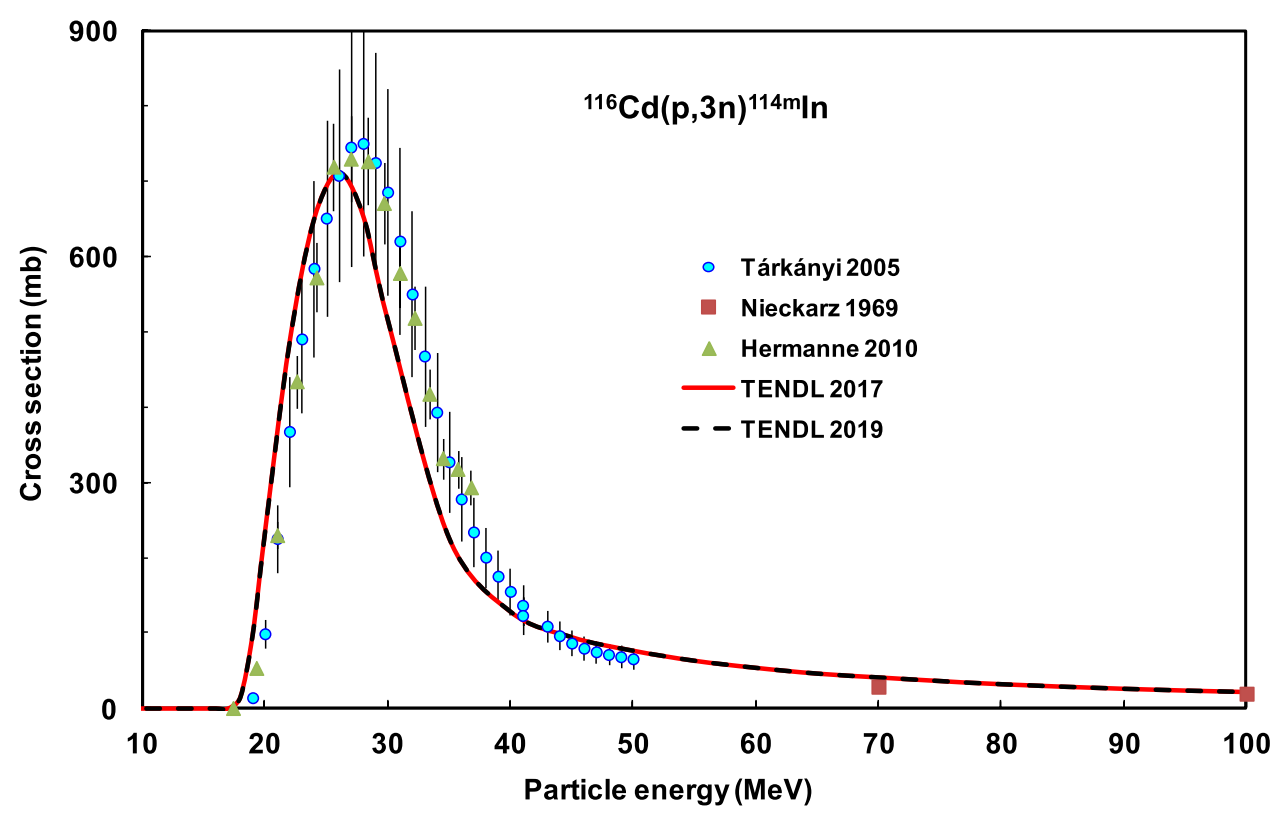


Fig. $33{ }^{116} \mathrm{Cd}(p, 3 \mathrm{n}){ }^{114 \mathrm{~m}} \mathrm{In}$ reaction: selected experimental works (with uncertainties) and Padé fit with derived uncertainties (dashed line, right hand scale)

Fig. 34 Yield calculated from the recommended cross sections for ${ }^{114} \mathrm{Cd}(p, \mathrm{n})^{114 \mathrm{~m}} \mathrm{In}$, ${ }^{114} \mathrm{Cd}(d, 2 \mathrm{n}){ }^{114 \mathrm{~m}} \mathrm{In}$ and

${ }^{116} \mathrm{Cd}(p, 3 \mathrm{n}){ }^{114 \mathrm{~m}}$ In reactions
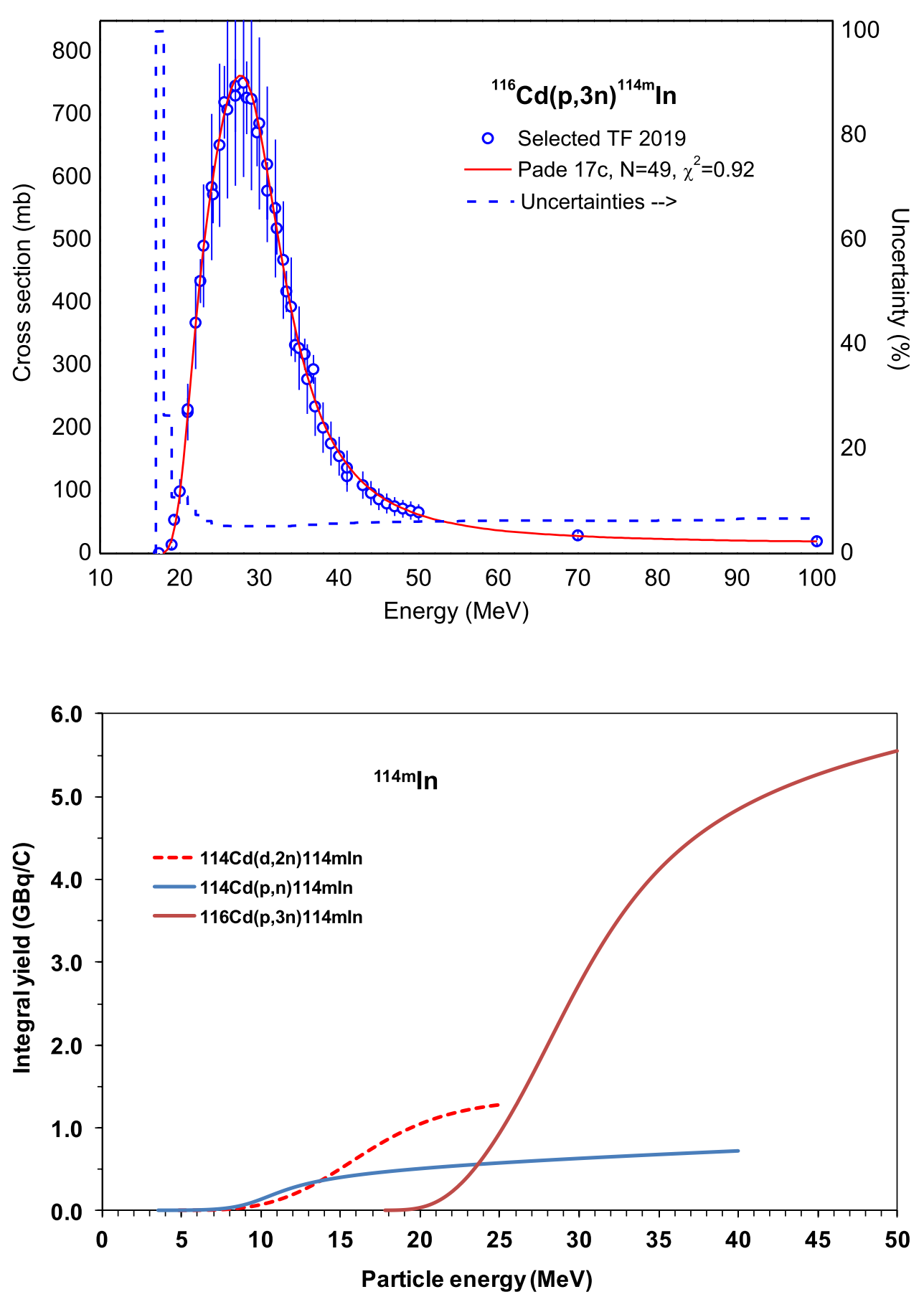

The decay scheme and the decay data are shown in Fig. 35 and Table 2.

The ${ }^{125} \mathrm{Te}(p, \mathrm{n}){ }^{125} \mathrm{I}$ and ${ }^{124} \mathrm{Te}(d, \mathrm{n}){ }^{125} \mathrm{I}$ production routes were evaluated.

\section{${ }^{125} \mathrm{Te}(\mathrm{p}, \mathrm{n})^{125} \mathrm{I}$ reaction}

A total of five data sets were found in literature: [67-71] (see Fig. 36).
Three datasets are new and were not used in the previous evaluation [2]: [68-70].

The single discrepant data point of Zweit [68] was deselected due to its low cross-section value.

The lowest energy outlying data point of Al-Azony [70] was removed. The selected data and the Padé fit are shown in Fig. 37. 
Fig. $35{ }^{125}$ I decay scheme

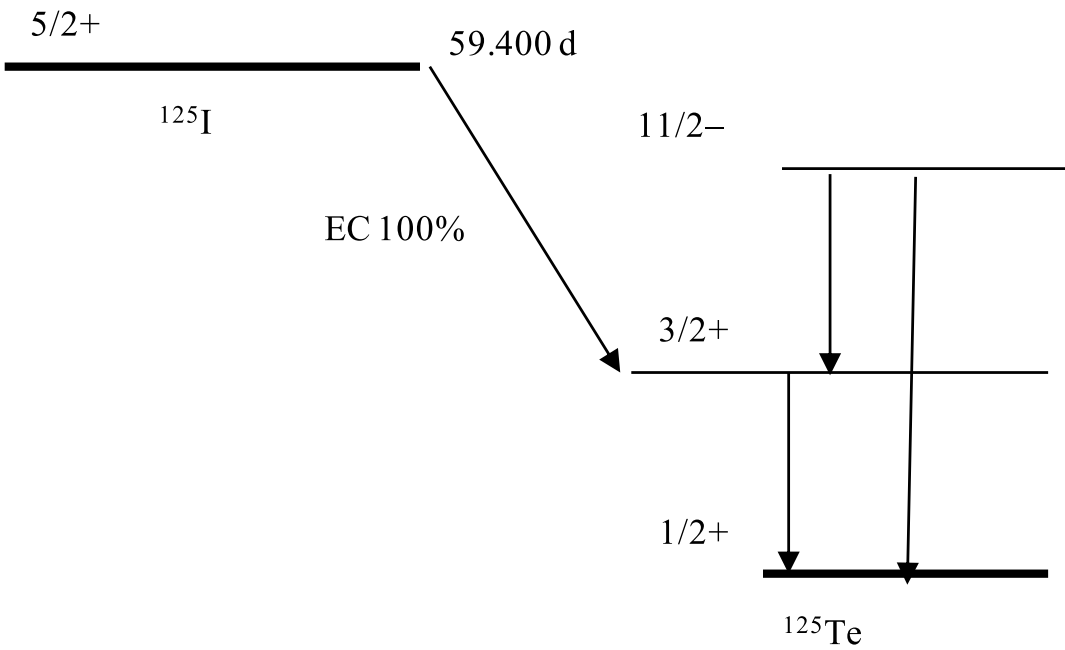

$57.40 \mathrm{~d}$

Fig. $36{ }^{125} \mathrm{Te}(p, \mathrm{n})^{125} \mathrm{I}$ reaction: all experimental data and TENDL predictions

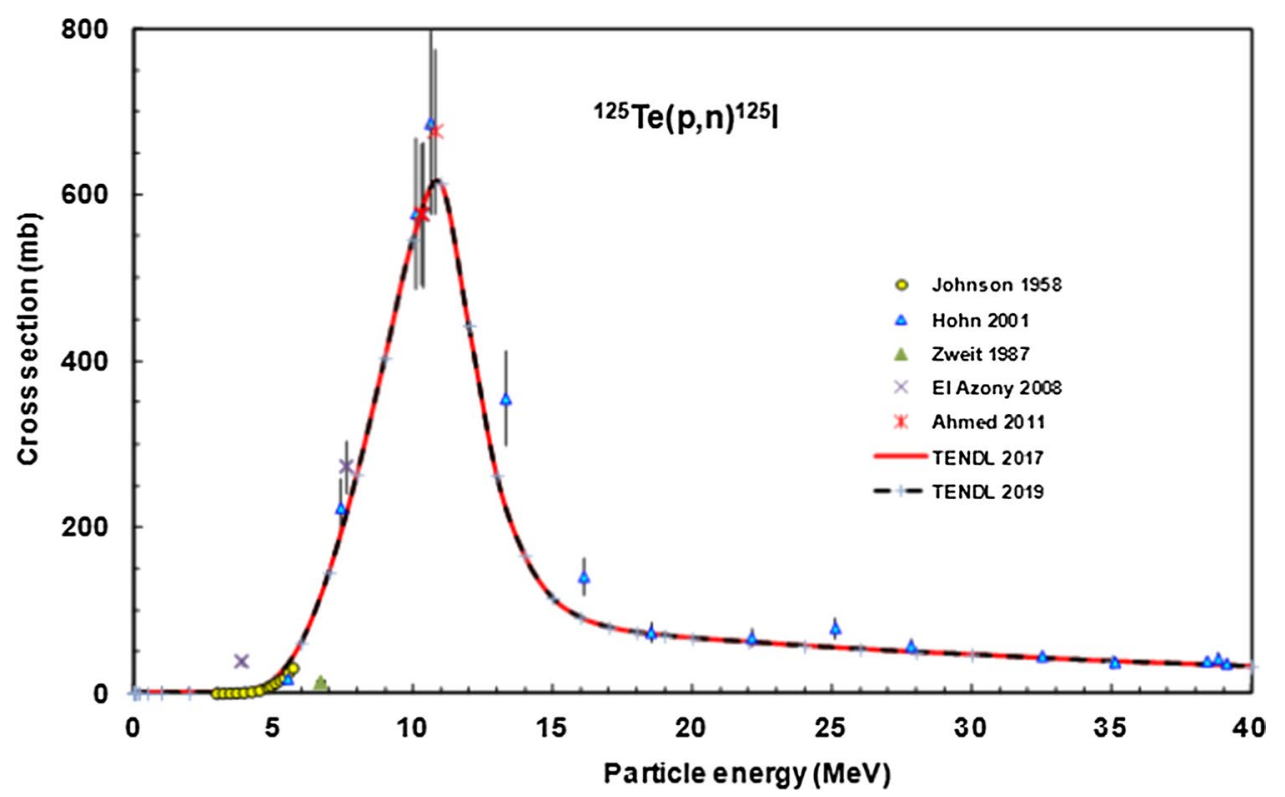

\section{${ }^{124} \mathrm{Te}(\mathrm{d}, \mathrm{n}){ }^{125}$ I reaction}

Three data sets measured by Bastian [72] on highly enriched ${ }^{124} \mathrm{Te}$ and by Zaidi [73] and Hermanne [74] on tellurium target with natural isotopic composition were found in literature (Fig. 38). Zaidi [73] and Hermanne [74] data were not considered relevant here due to the low threshold (3.2 MeV) of the contaminating ${ }^{125} \mathrm{Te}(d, 2 \mathrm{n}){ }^{125} \mathrm{I}$ reaction, so those data are not shown in Fig. 38. Selected data are shown vs the Padé fit in Fig. 39.

\section{Integral yields for production of ${ }^{125}$ I}

Calculated integral yields of the ${ }^{125} \mathrm{Te}(p, \mathrm{n}){ }^{125} \mathrm{I}$ and ${ }^{124} \mathrm{Te}(\mathrm{d}$, $n)^{125}$ I reactions are shown in Fig. 40.

\section{${ }^{169} \mathrm{Yb}$ production}

${ }^{169} \mathrm{Yb}$ emits a low-energy photon spectrum, evaluated for use in high dose rate brachytherapy.

The decay scheme and the decay data are shown in Fig. 41 and Table 2.

The ${ }^{169} \mathrm{Tm}(p, \mathrm{n}){ }^{169} \mathrm{Yb}$ and ${ }^{169} \mathrm{Tm}(d, 2 \mathrm{n}){ }^{169} \mathrm{Yb}$ reactions were evaluated.

\section{Cross sections for production of ${ }^{169} \mathrm{Yb}$}

\section{${ }^{169} \mathrm{Tm}(p, n){ }^{169} \mathrm{Yb}$ reaction}

Four data sets measured by [75-78] were found in literature. Two of them are new and were not considered in the 
Fig. $37{ }^{125} \mathrm{Te}(p, \mathrm{n}){ }^{125}$ I reaction: selected experimental works (with uncertainties) and Padé fit with derived uncertainties (dashed line, right hand scale)

Fig. $38{ }^{124} \mathrm{Te}(d, \mathrm{n}){ }^{125} \mathrm{I}$ reaction: all experimental data and TENDL predictions
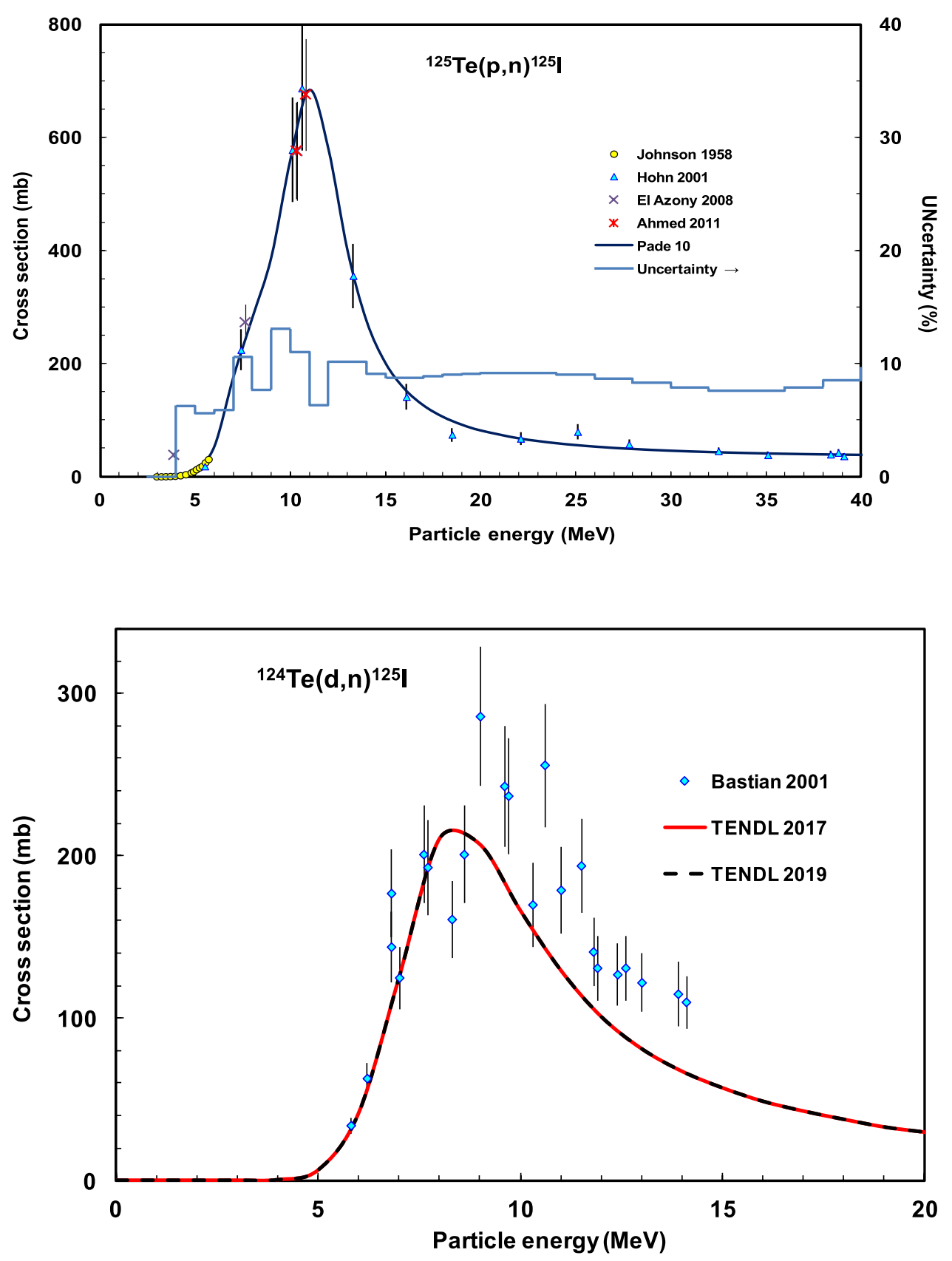

previous evaluation: [77, 78]. All data sets were selected and compared with TENDL predictions in Fig. 42.

The data in Spahn [76] were normalized considering the systematic trend of the other selected datasets. Two outlying data points of Birattari [75] near the maximum were excluded from the figure and uncertainties were increased up to $10 \%$. The fitted data versus the Padé fit are shown in Fig. 43.

\section{${ }^{169} \operatorname{Tm}(d, 2 \mathrm{n}){ }^{169} \mathrm{Yb}$ reaction}

A total of four data sets were found in literature: [79-83] and are compared to TENDL libraries in Fig. 44. The results of [80-83] are new as they were not considered in the earlier evaluation. All data sets were selected for fitting without changes and are shown vs the Padé fit in Fig. 45. 
Fig. $39{ }^{124} \mathrm{Te}(d, \mathrm{n}){ }^{125}$ I reaction: selected experimental works (with uncertainties) and Padé fit with derived uncertainties (dashed line, right hand scale)

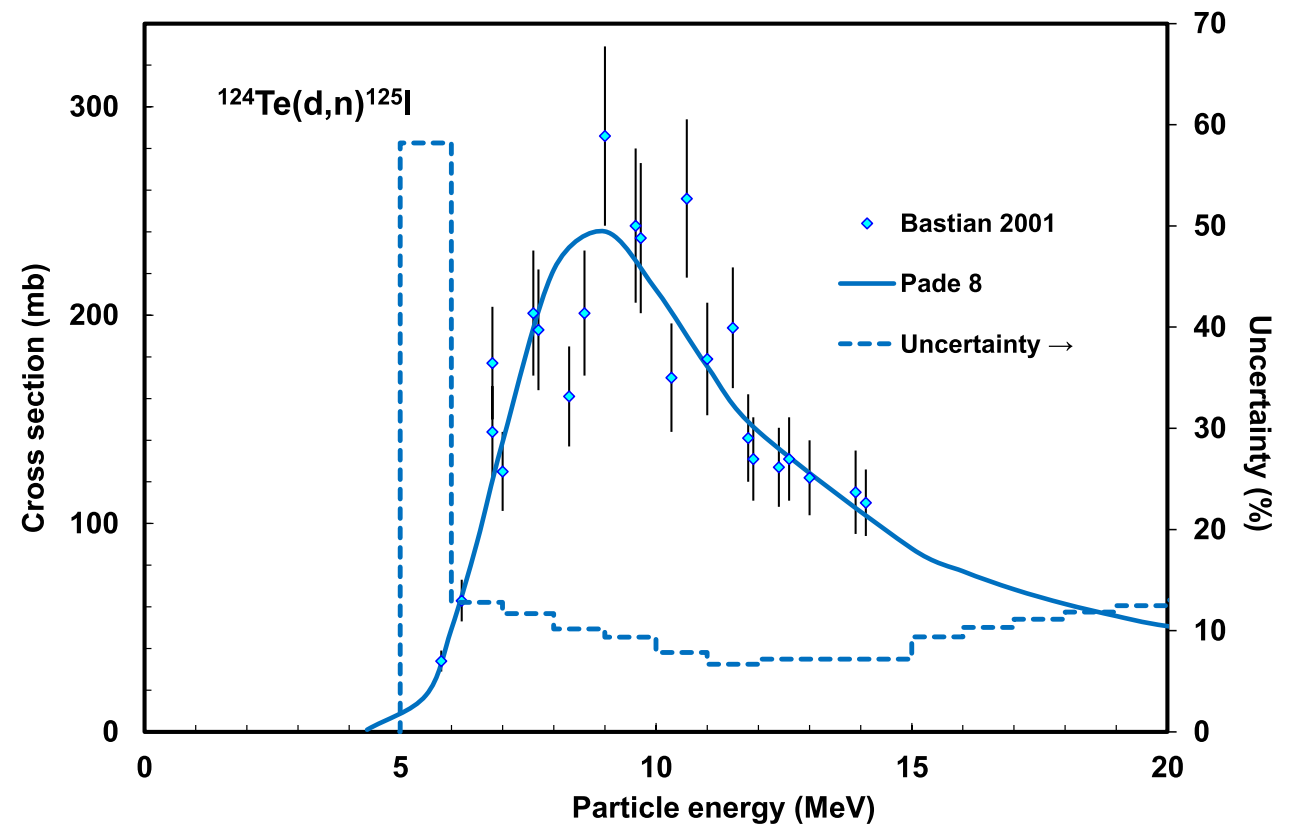

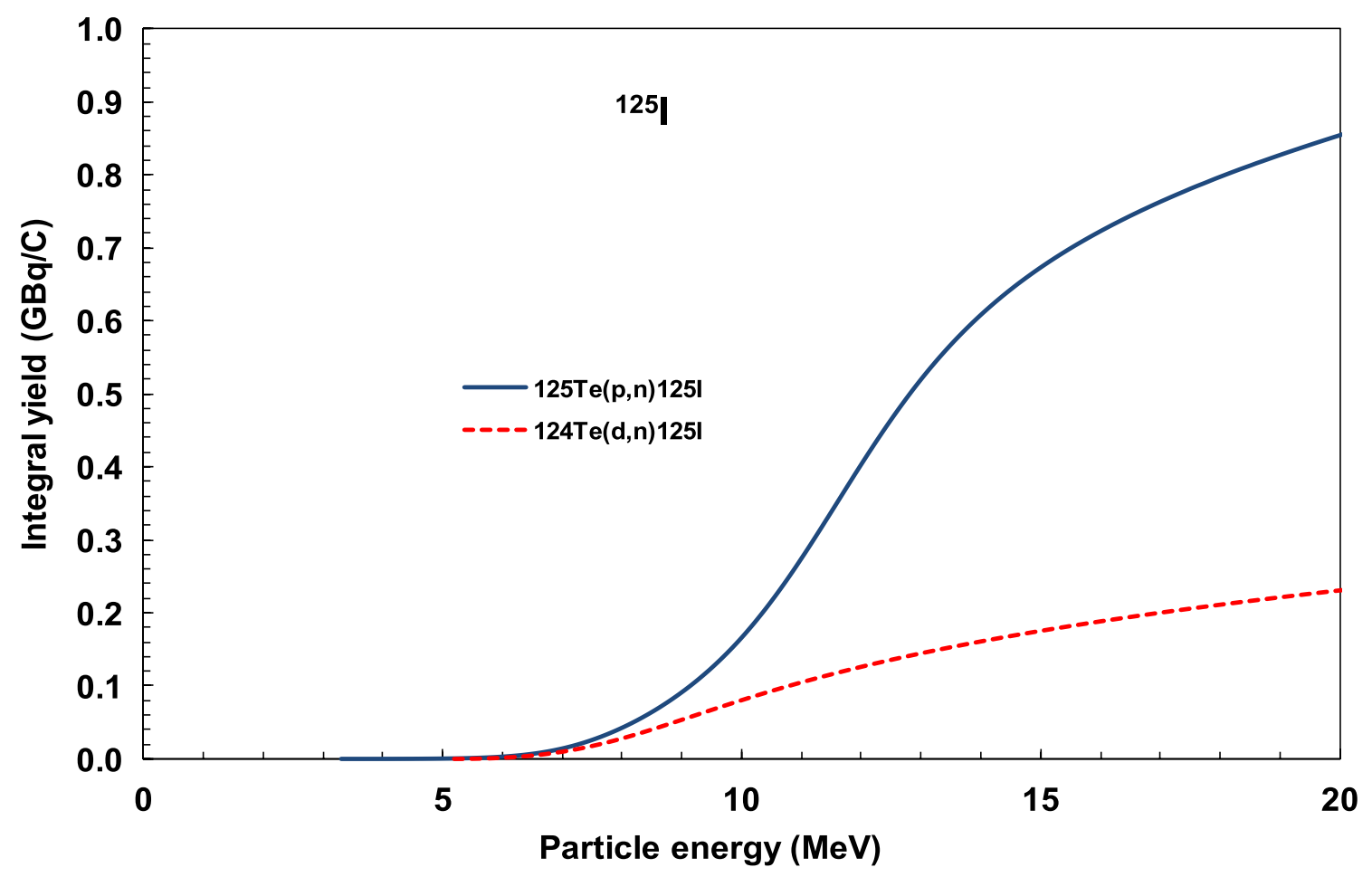

Fig. 40 Yield calculated from the recommended cross sections for ${ }^{125} \mathrm{Te}(p, \mathrm{n}){ }^{125} \mathrm{I}$ and ${ }^{124} \mathrm{Te}(d, \mathrm{n}){ }^{125} \mathrm{I}$ reactions

\section{Integral yields for production of ${ }^{169} \mathrm{Yb}$}

Calculated integral yields of the ${ }^{169} \mathrm{Tm}(p, \mathrm{n}){ }^{169} \mathrm{Yb}$ and ${ }^{169} \mathrm{Tm}(d, 2 \mathrm{n}){ }^{169} \mathrm{Yb}$ reactions are shown in Fig. 46.

\section{${ }^{177 g}$ Lu production}

The ground state of ${ }^{177} \mathrm{Lu}$ is one of the most important novel therapeutic $\beta^{-}$emitters that also emits low energy gammas for imaging and localization with gamma cameras (a 
Fig. $41{ }^{169 g} \mathrm{Yb}$ decay scheme

Fig. $42{ }^{169} \mathrm{Tm}(p, \mathrm{n}){ }^{169} \mathrm{Yb}$ reaction: all experimental data and TENDL predictions

Fig. $43{ }^{169} \mathrm{Tm}(p, n){ }^{169} \mathrm{Yb}$ reaction: selected experimental works (with uncertainties) and Padé fit with derived uncertainties (dashed line, right hand scale)

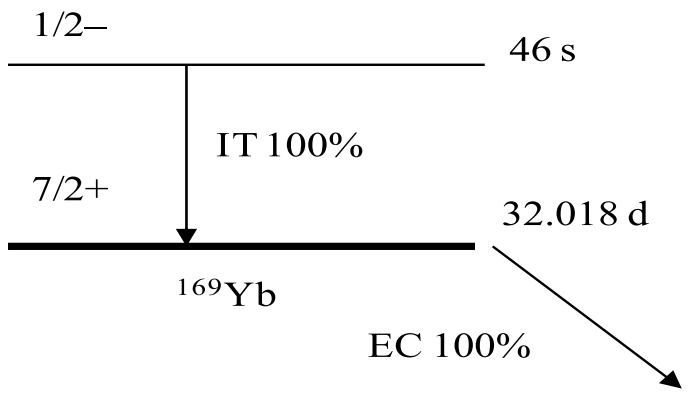

$1 / 2+$

${ }^{169} \mathrm{Tm}$

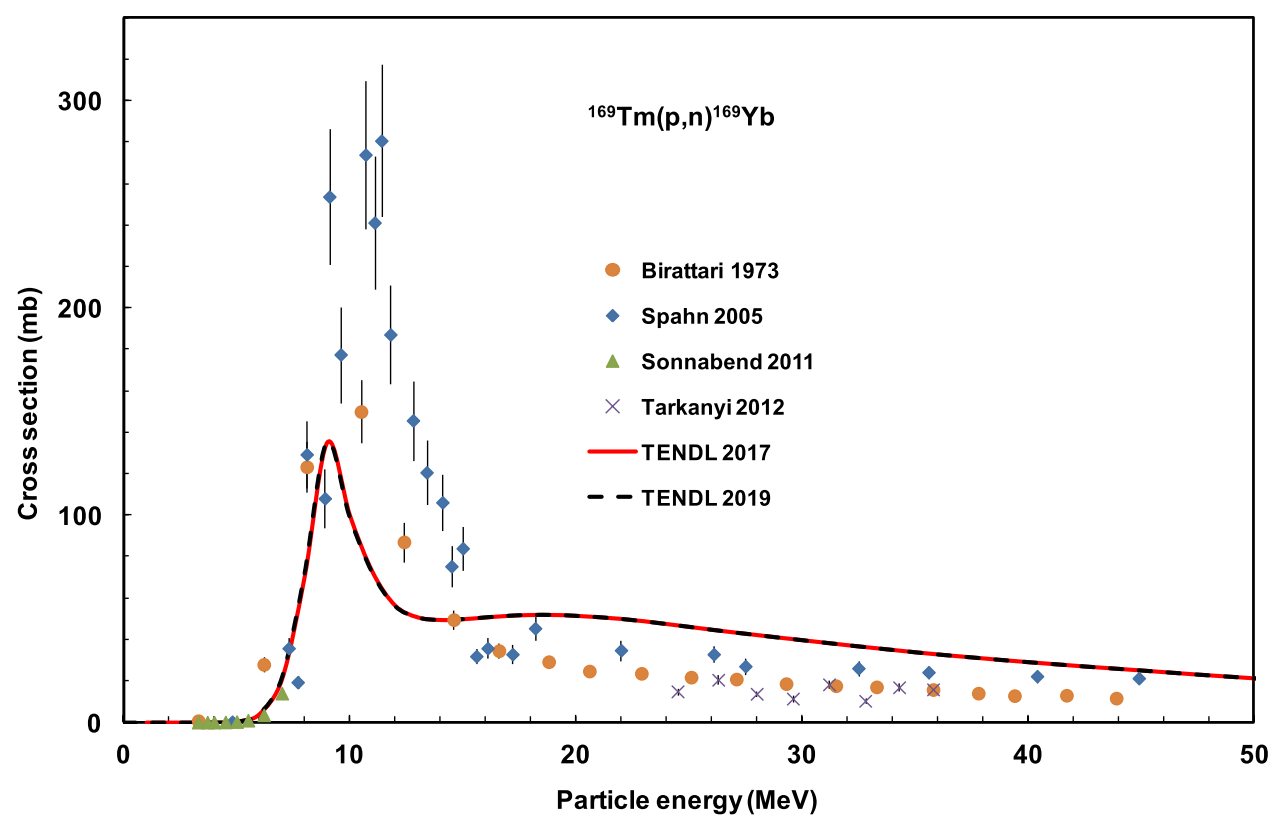


Fig. $44{ }^{169} \mathrm{Tm}(d, 2 \mathrm{n}){ }^{169} \mathrm{Yb}$ reaction: all experimental data and TENDL predictions
Fig. $45{ }^{169} \mathrm{Tm}(d, 2 \mathrm{n}){ }^{169} \mathrm{Yb}$ reaction: selected experimental works (with uncertainties) and Padé fit with derived uncertainties (dashed line, right hand scale)
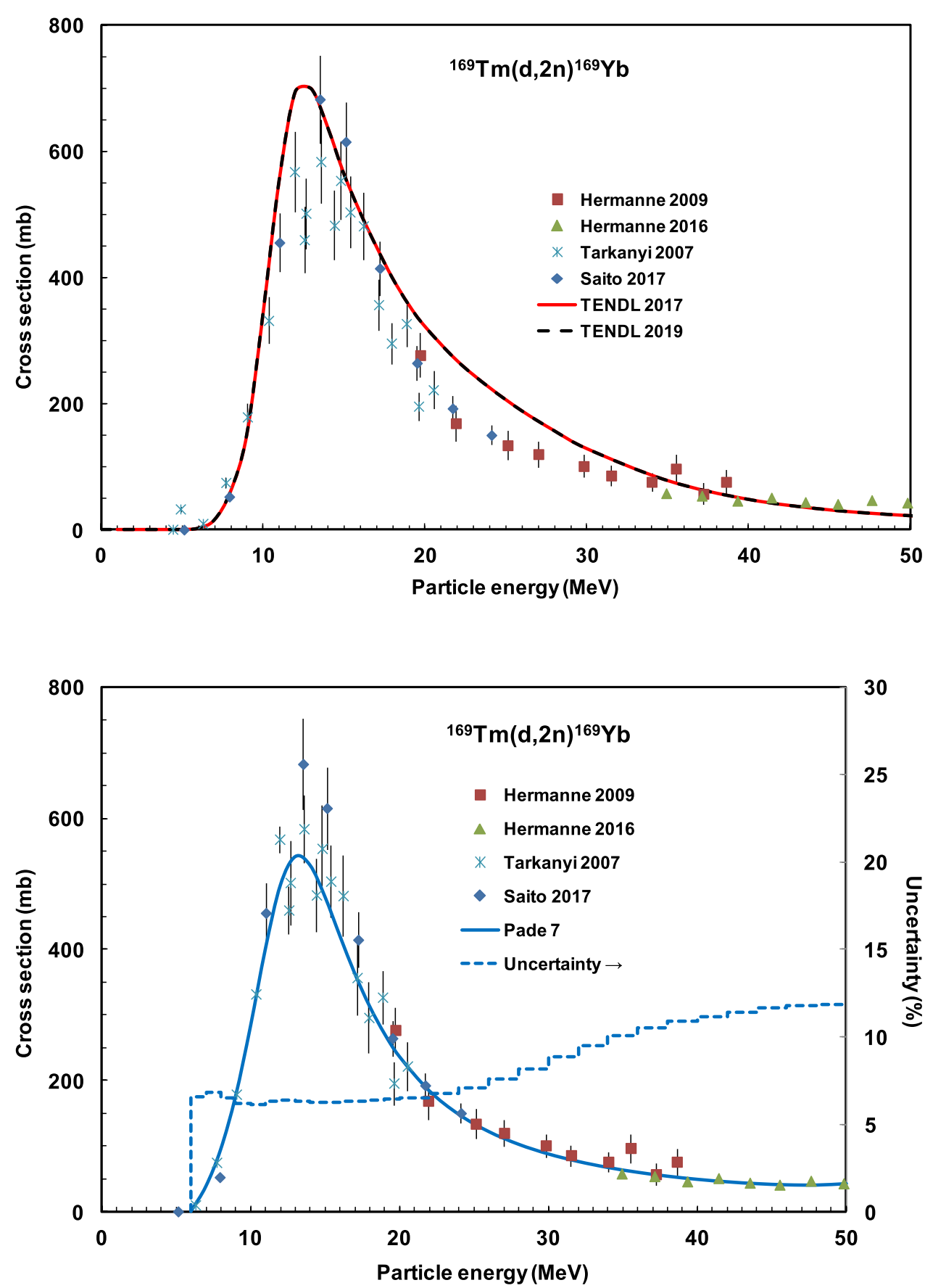

theranostic radioisotope).

The simplified decay scheme and the decay data are shown in Fig. 47 and collected in Table 2.

The ${ }^{176} \mathrm{Yb}(d, p){ }^{177} \mathrm{Yb}->{ }^{177 \mathrm{~g}} \mathrm{Lu}$ and ${ }^{176} \mathrm{Yb}(d, \mathrm{n}){ }^{177 \mathrm{~g}} \mathrm{Lu}$ reactions were evaluated.

\section{${ }^{176} \mathrm{Yb}(d, p){ }^{177} \mathrm{Yb}$ reaction}

A total of 4 data sets were found in literature for formation of the parent radionuclide ${ }^{177} \mathrm{Yb}$ : [84-87] and are compared to TENDL evaluations in Fig. 48. The data sets of
Tárkányi [85] and Khandaker [87] are new. All data series were selected for fitting and are compared versus the Padé fit in Fig. 49.

\section{${ }^{176} \mathrm{Yb}(d, \mathrm{x}){ }^{177 g}$ Lu reaction}

A total of 5 data sets were found in literature: [84, 85, 87-89]. The results by [85-88] are new as they were published after the earlier evaluation. All available data are compared to TENDL libraries in Fig. 50. 
Fig. 46 Yield calculated from the recommended cross sections for ${ }^{169} \mathrm{Tm}(p, \mathrm{n}){ }^{169} \mathrm{Yb}$ and

${ }^{169} \mathrm{Tm}(d, 2 \mathrm{n}){ }^{169} \mathrm{Yb}$ reactions

Fig. $47{ }^{177} \mathrm{Yb},{ }^{177 \mathrm{~m}} \mathrm{Lu}$ and

${ }^{177 g}$ Lu decay schemes
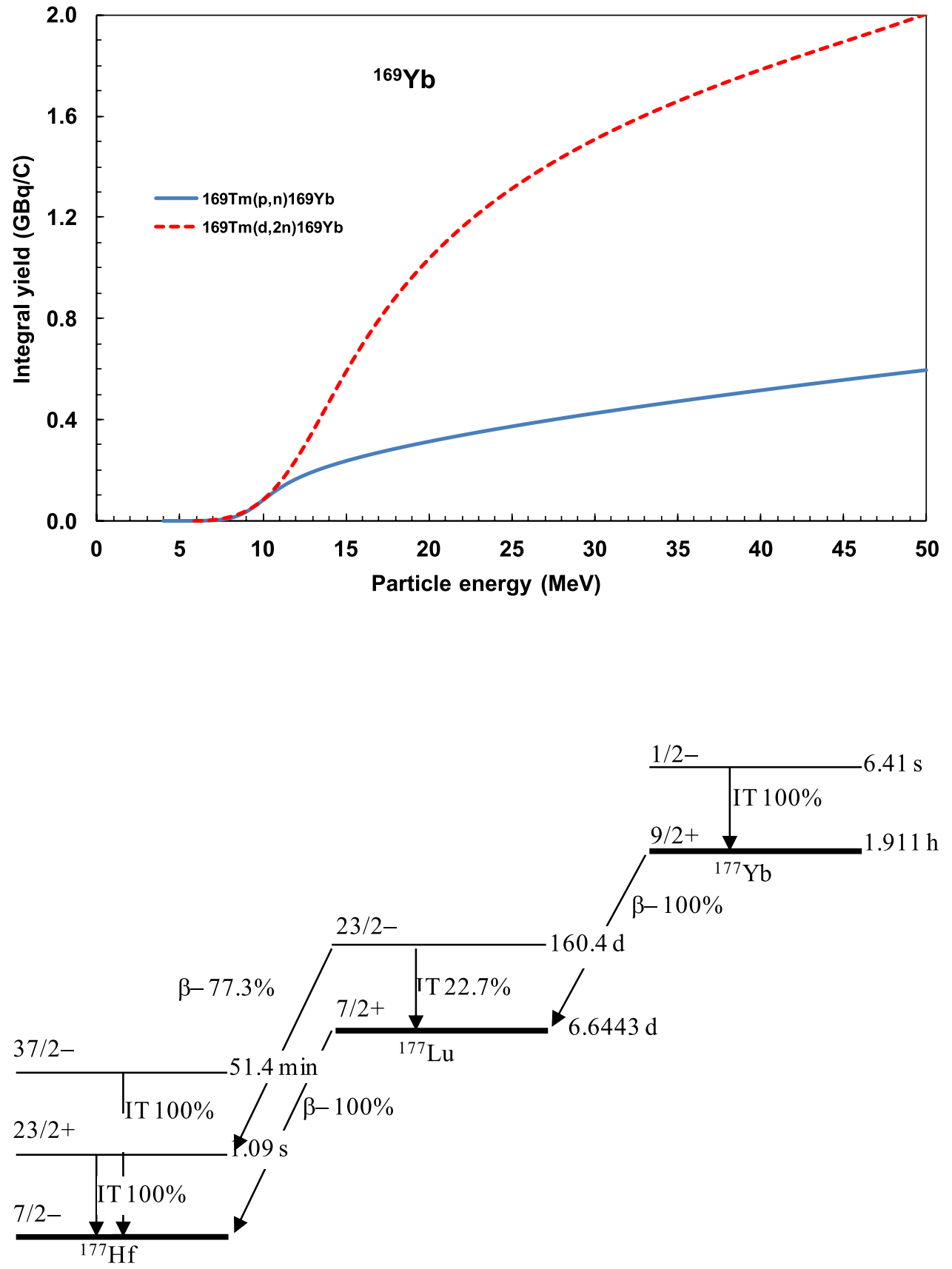

The data sets of Tarkanyi $[85,86]$ are deselected as they are significantly different within the uncertainty limits of the three other datasets that agree very well. The selected data are compared with the Padé fit in Fig. 51.
Integral yields for production of ${ }^{177} \mathrm{Yb}$ and ${ }^{1779}$ Lu

Calculated integral yields of the ${ }^{176} \mathrm{Yb}(d, p){ }^{177} \mathrm{Yb}$ and ${ }^{176} \mathrm{Yb}(d, \mathrm{x}){ }^{177 \mathrm{~g}} \mathrm{Lu}$ reactions are shown in Fig. 52. 
Fig. $48{ }^{176} \mathrm{Yb}(d, p){ }^{177} \mathrm{Yb}$ reaction: all experimental data and TENDL predictions
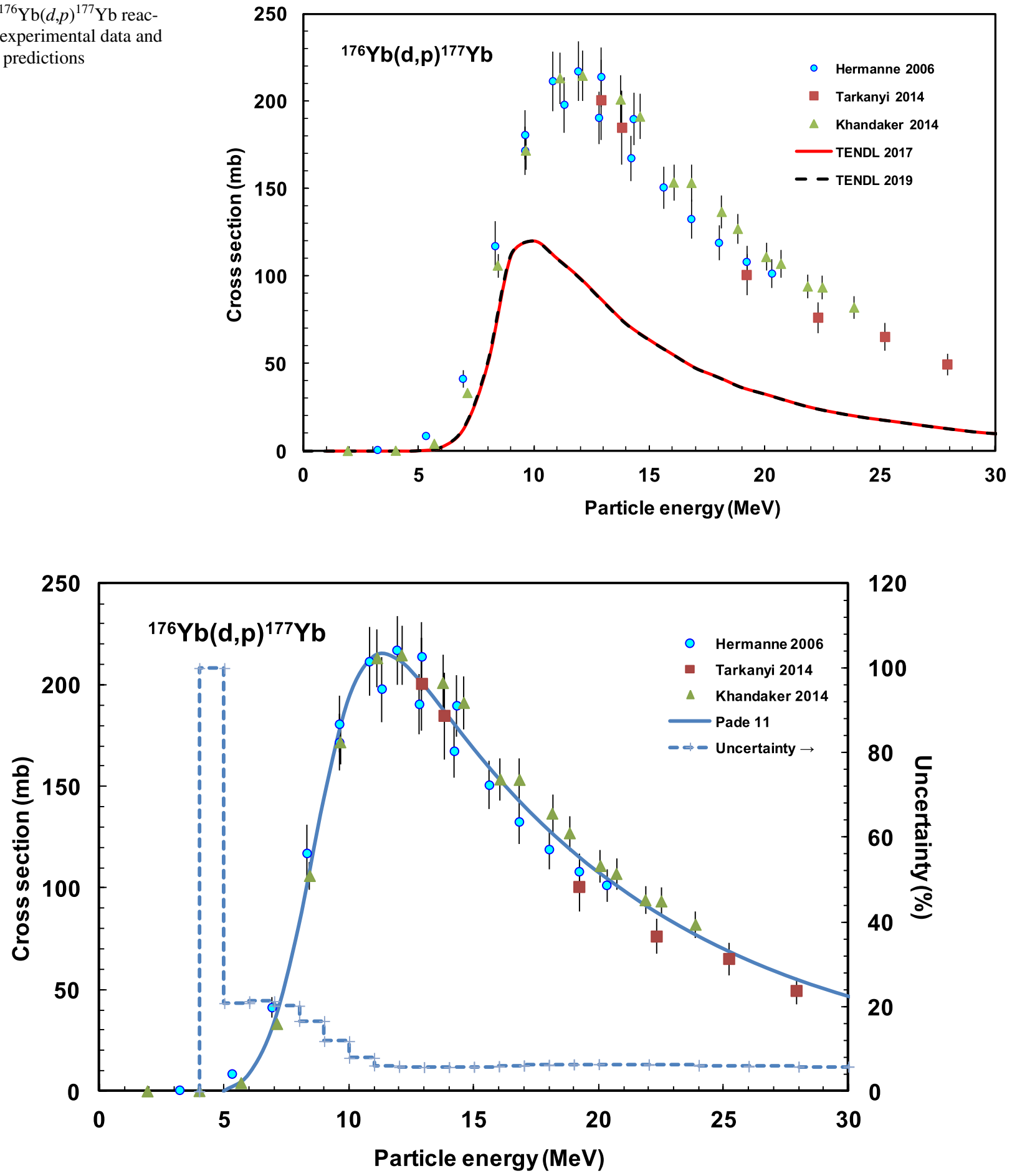

Fig. $49{ }^{176} \mathrm{Yb}(d, p){ }^{177} \mathrm{Yb}$ reaction: selected experimental works (with uncertainties) and Padé fit with derived uncertainties (dashed line, right hand scale)

\section{${ }^{1869} \operatorname{Re}$ production}

The radionuclide ${ }^{186 g}$ Re provides both high-abundance $\beta^{-}$particle emissions to deliver high doses, and low-energy $\gamma$-rays suitable for imaging.

The simplified decay scheme and the decay data are presented on Fig. 53 and Table 2.

The ${ }^{186} \mathrm{~W}(p, \mathrm{n}){ }^{186 \mathrm{~g}} \mathrm{Re}$ and ${ }^{186} \mathrm{~W}(d, 2 \mathrm{n}){ }^{186 \mathrm{~g}} \mathrm{Re}$ reactions were evaluated. 
Fig. $50{ }^{176} \mathrm{Yb}(d, \mathrm{x}){ }^{177 \mathrm{~g}} \mathrm{Lu}$ reaction: all experimental data and TENDL predictions

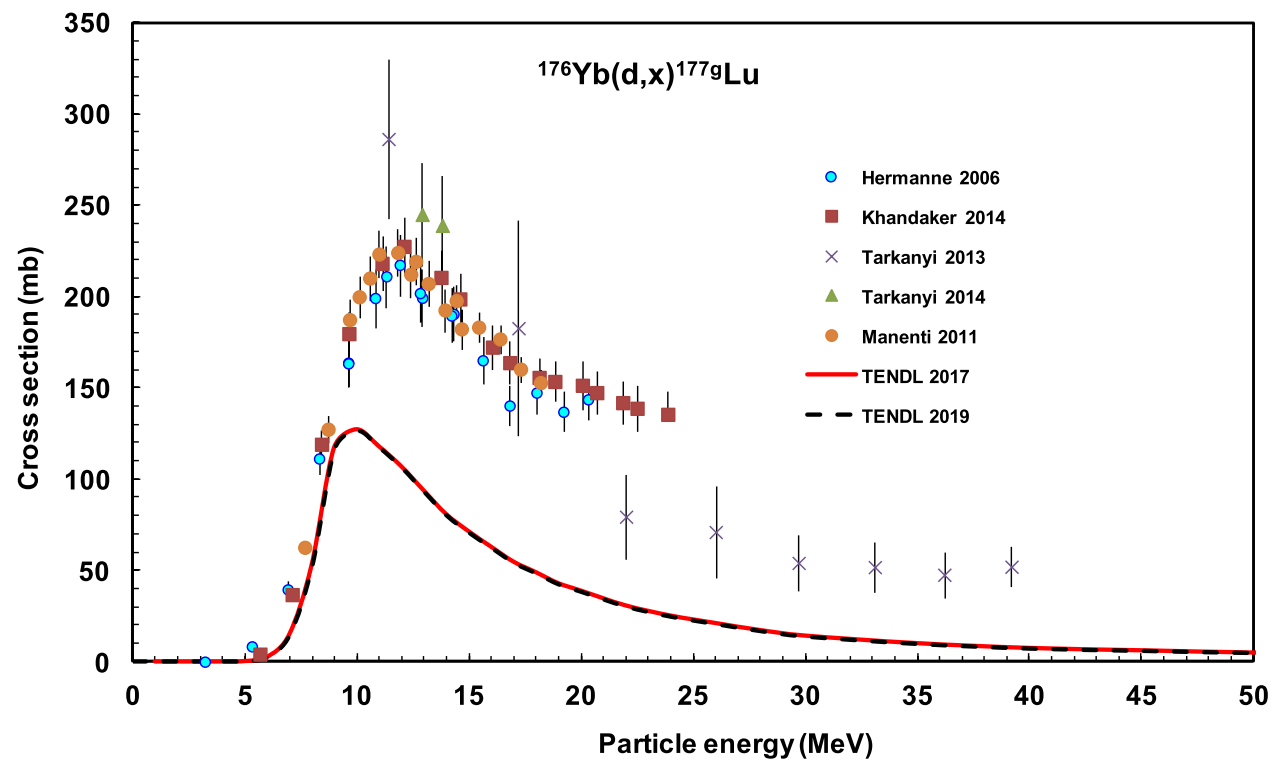

Fig. $51{ }^{176} \mathrm{Yb}(d, \mathrm{x}){ }^{177 \mathrm{~g}} \mathrm{Lu}$ reaction selected experimental works (with uncertainties) and Padé fit with derived uncertainties (dashed line, right hand scale)

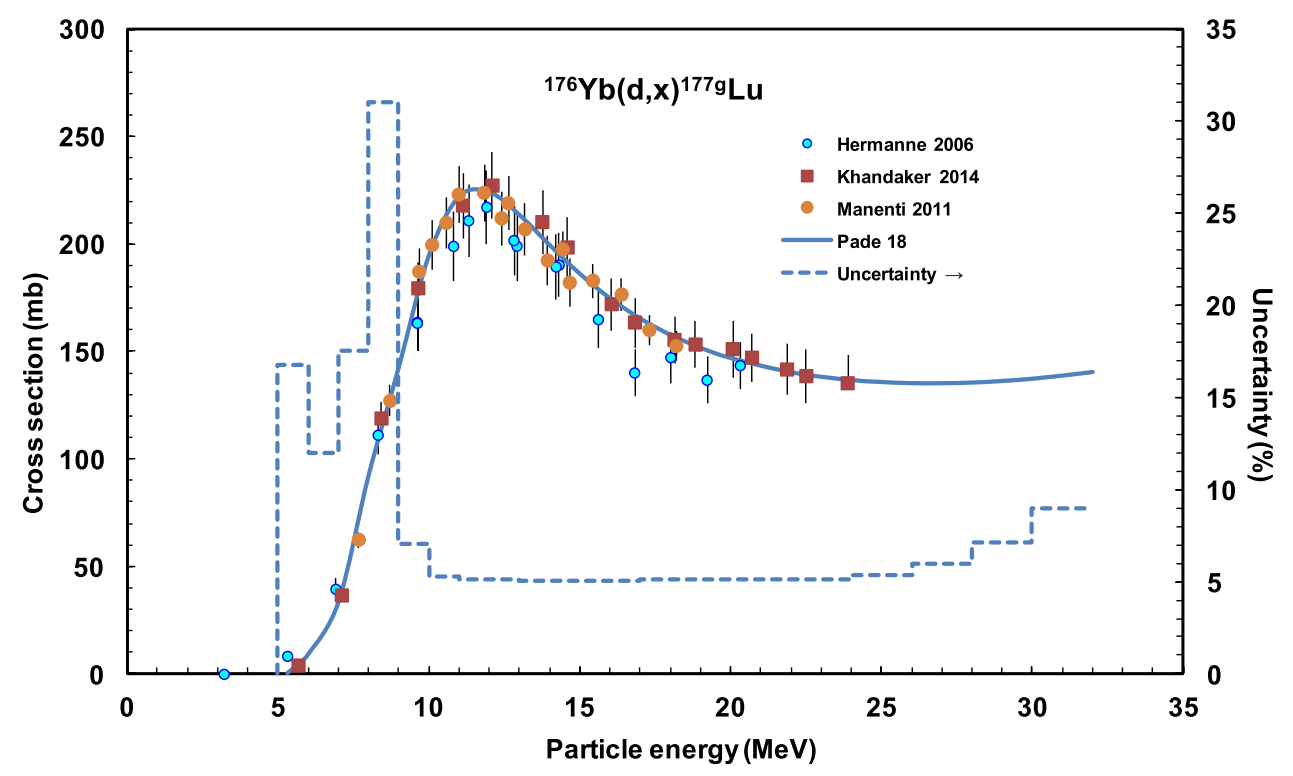

\section{${ }^{186} \mathrm{~W}(p, n){ }^{186 g}$ Re reaction}

A total of 11 data sets were found in literature: [90-102] and are compared with TENDL libraries in Fig. 54.

Four sets are new and were reported after the last evaluation: [98-101].

The reason of large systematic disagreements was not found during detailed investigation of the reported experimental methods and data evaluation methods. Systematic behavior of the excitation functions in the same atomic mass range was also studied. The data by Shigeta [90], Zhang [92], Khandaker [98], and Tarkanyi [94] were deselected as they show too high or too low cross-section values, respectively. Lapi data [97] were normalized at the maximum to get more data points to fit near the maximum. Selected data vs the Padé fit are compared in Fig. 55.

\section{${ }^{186} W(d, 2 n){ }^{186 g}$ Re reaction}

A total of 11 data sets were found in literature: [103-114] which are compared with TENDL evaluations in Fig. 56.

Three datasets are new since the last evaluation: [112-114].

Three sets were deselected: Manenti [104] and Duchemin [106] (unusual shape, too high cross-section values) and Alekseev [110] (shifted in energy).

The too low cross-section point at $15.7 \mathrm{MeV}$ of Zhenlan [105] was not taken into account for fitting. The selected data and the Padé fit are shown in Fig. 57. 
Fig. 52 Yield calculated from the recommended cross sections for ${ }^{176} \mathrm{Yb}(d, p){ }^{177} \mathrm{Yb}$ and

${ }^{176} \mathrm{Yb}(d, \mathrm{x}){ }^{177} \mathrm{Lu}$ reactions
Fig. $53^{186 \mathrm{~m}, \mathrm{~g}}$ Re decay scheme

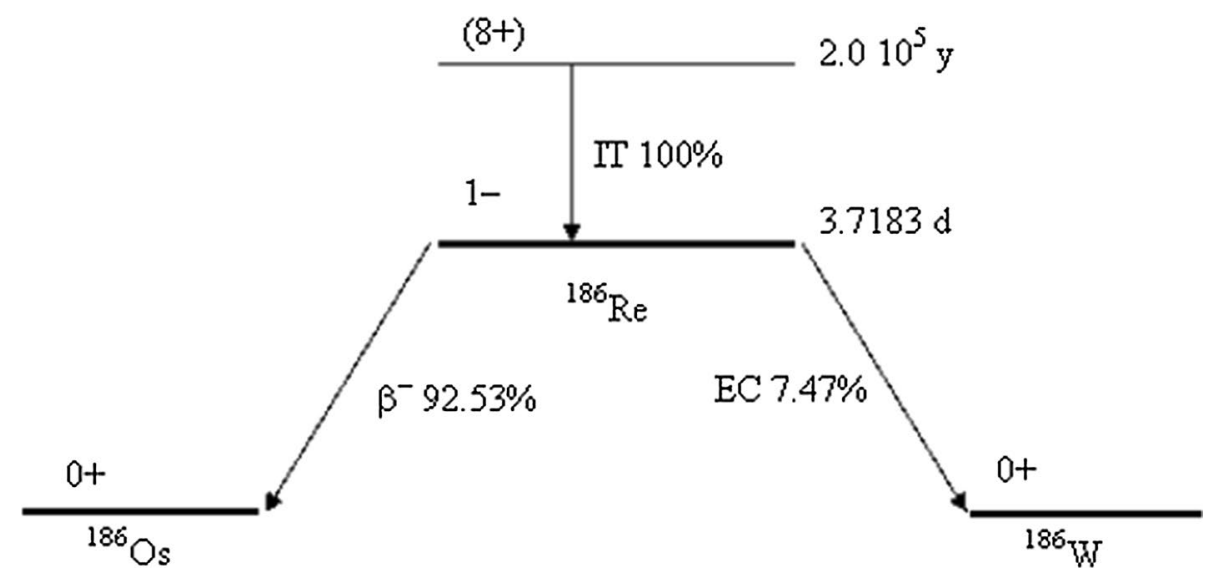

\section{Integral yields for production of ${ }^{186} \mathrm{Re}$}

Calculated integral yields of the ${ }^{186} \mathrm{~W}(p, \mathrm{n})^{186 \mathrm{~g}} \mathrm{Re}$ and ${ }^{186} \mathrm{~W}(d, 2 \mathrm{n}){ }^{186 g} \mathrm{Re}$ reactions are shown in Fig. 58.

\section{${ }^{192}$ Ir production}

The ${ }^{192}$ Ir has good decay properties for therapy (high intensity beta radiation and long half-life), but it emits undesirable high-energy gammas difficult for shielding. It is commonly used in brachytherapy. The simplified decay scheme and the decay data are presented in Fig. 59 and Table 2.
The reactions ${ }^{192} \mathrm{Os}(p, \mathrm{n}){ }^{192 \mathrm{~m} 1+\mathrm{g}} \mathrm{Ir}$ and ${ }^{192} \mathrm{Os}(d, 2 \mathrm{n}){ }^{192 \mathrm{~m} 1+\mathrm{g}} \mathrm{Ir}$ were evaluated.

\section{Cross sections for production of ${ }^{192 \mathrm{~m} 1+\mathrm{g}} / \mathrm{r}$ ${ }^{192} \mathrm{Os}(\mathrm{p}, \mathrm{n})^{192 \mathrm{~m} 1+\mathrm{g} I \mathrm{Ir} \text { reaction }}$}

A total of four data sets were found in literature: [115-118] and were compared with TENDL evaluations in Fig. 60. The two sets by Szelecsenyi and Hermanne [117, 118] are new since the last evaluation. All data sets were selected and fitted and are compared vs the Padé fit in Fig. 61. 


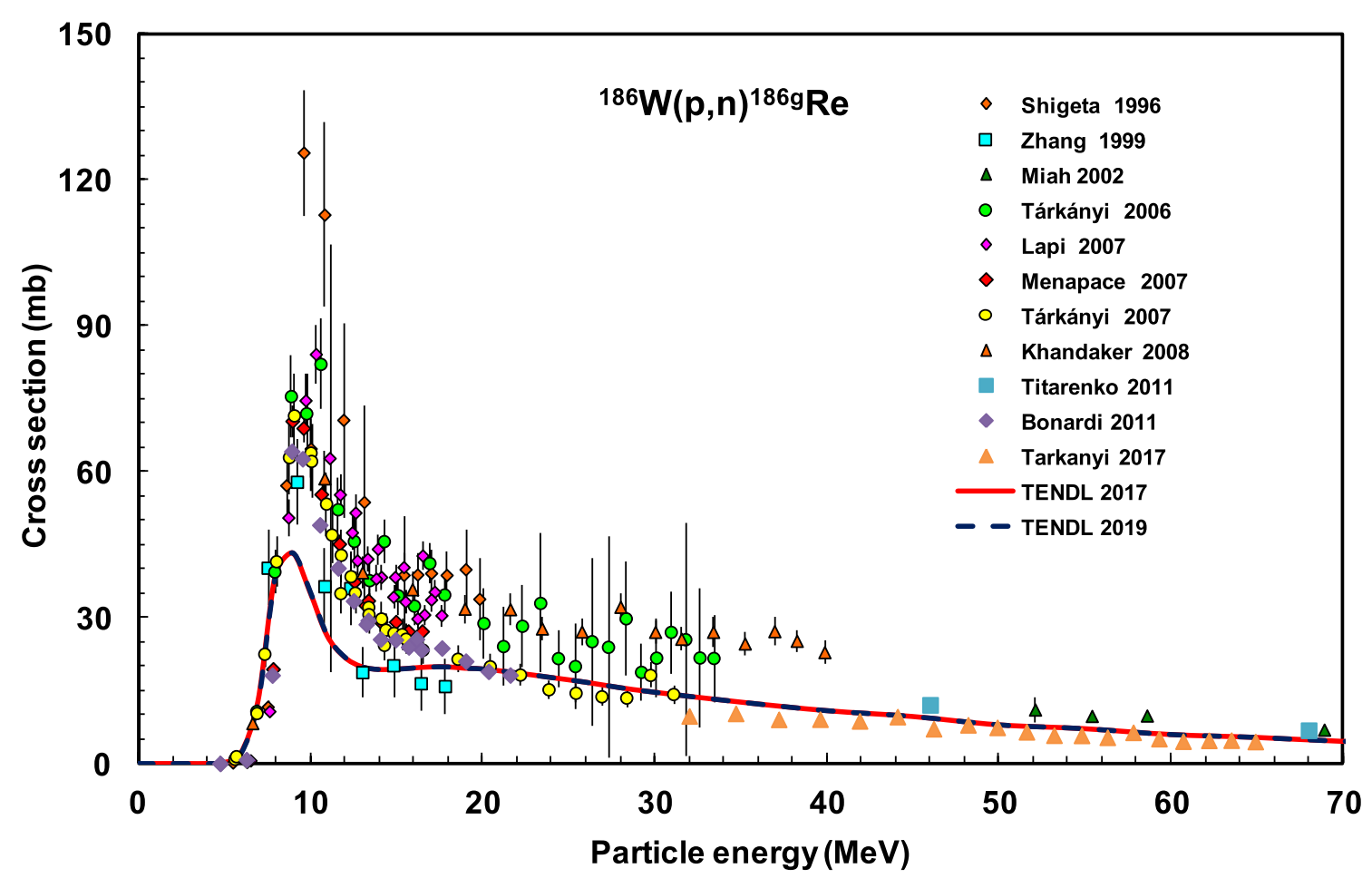

Fig. $54{ }^{186} \mathrm{~W}(p, \mathrm{n}){ }^{186 g} \mathrm{Re}$ reaction: all experimental data and TENDL predictions

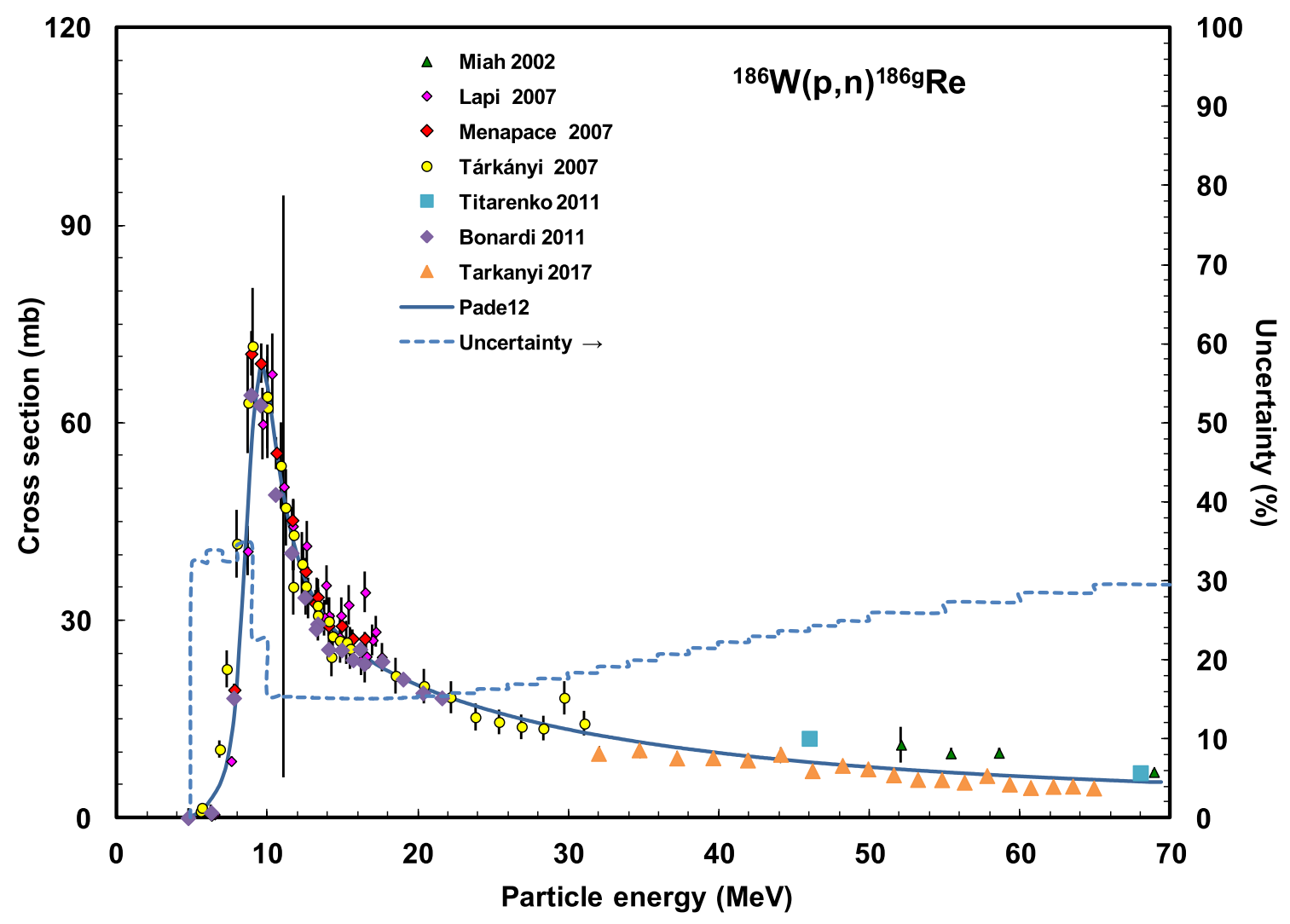

Fig. $55{ }^{186} \mathrm{~W}(p, \mathrm{n})^{186 g} \mathrm{Re}$ reaction: selected experimental works (with uncertainties) and Padé fit with derived uncertainties (dashed line, right hand scale) 


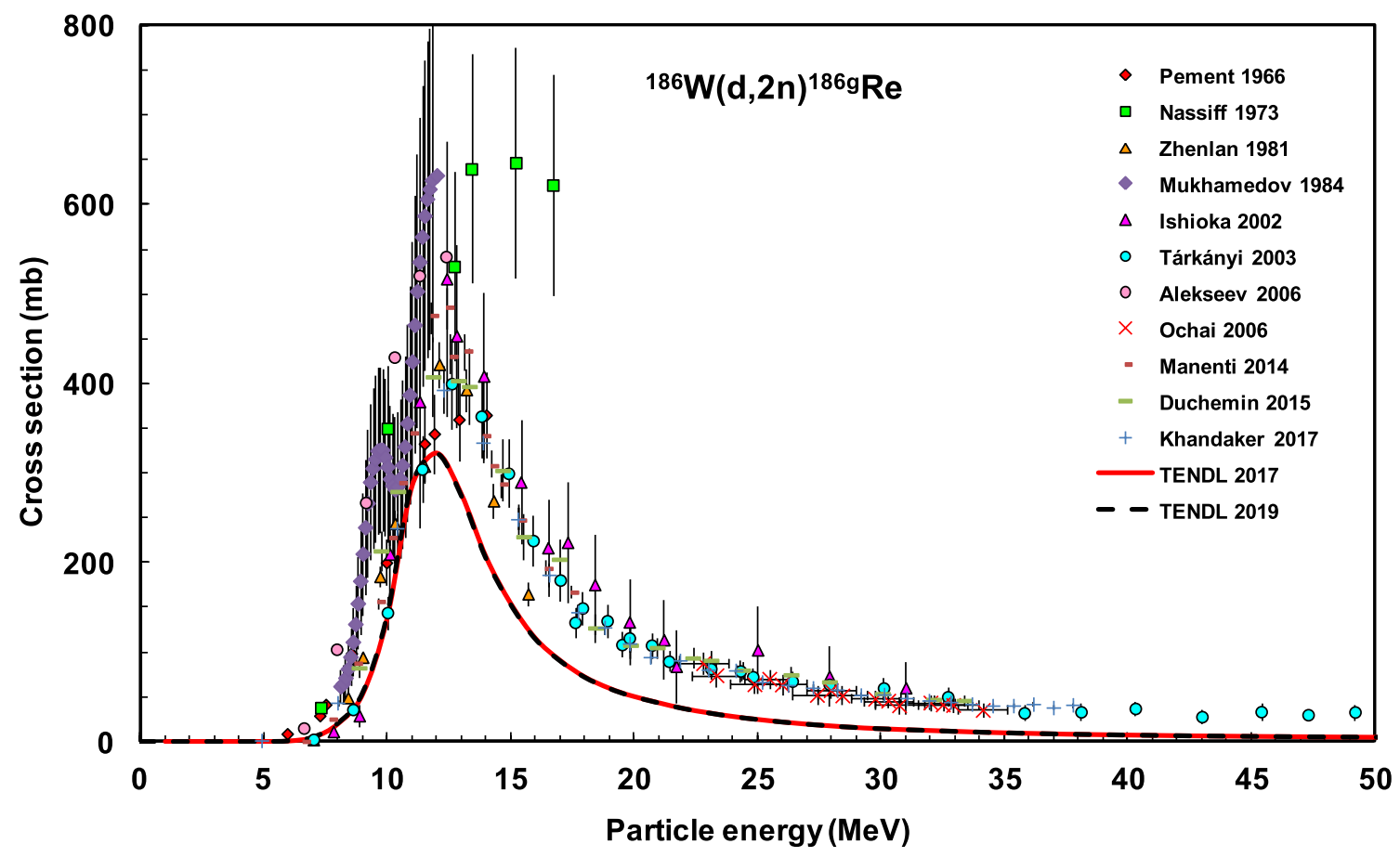

Fig. $56{ }^{186} \mathrm{~W}(d, 2 \mathrm{n}){ }^{186 g}$ Re reaction: all experimental data and TENDL predictions

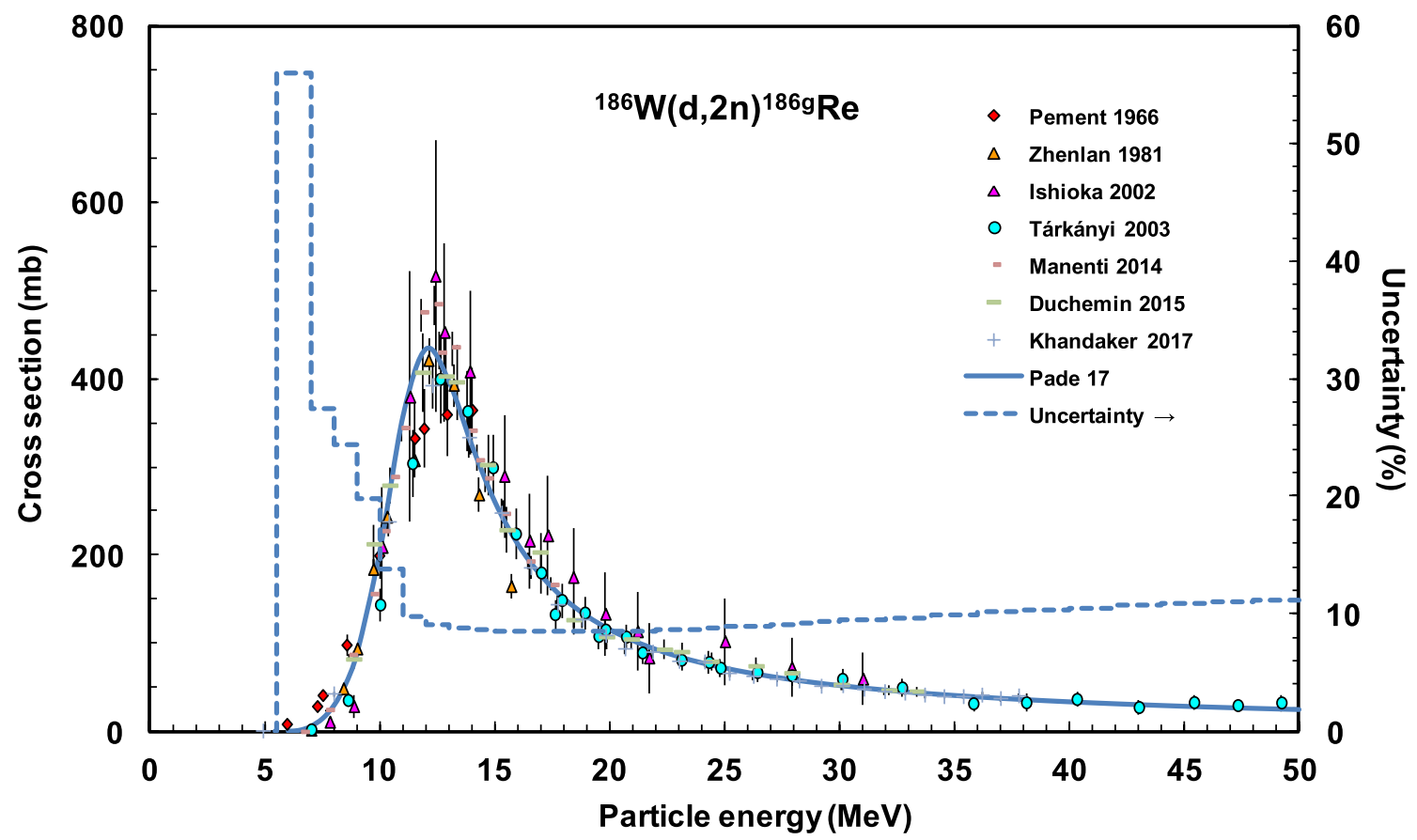

Fig. $57{ }^{186} \mathrm{~W}(d, 2 \mathrm{n}){ }^{186 g}$ Re reaction: selected experimental works (with uncertainties) and Padé fit with derived uncertainties (dashed line, right hand scale) 


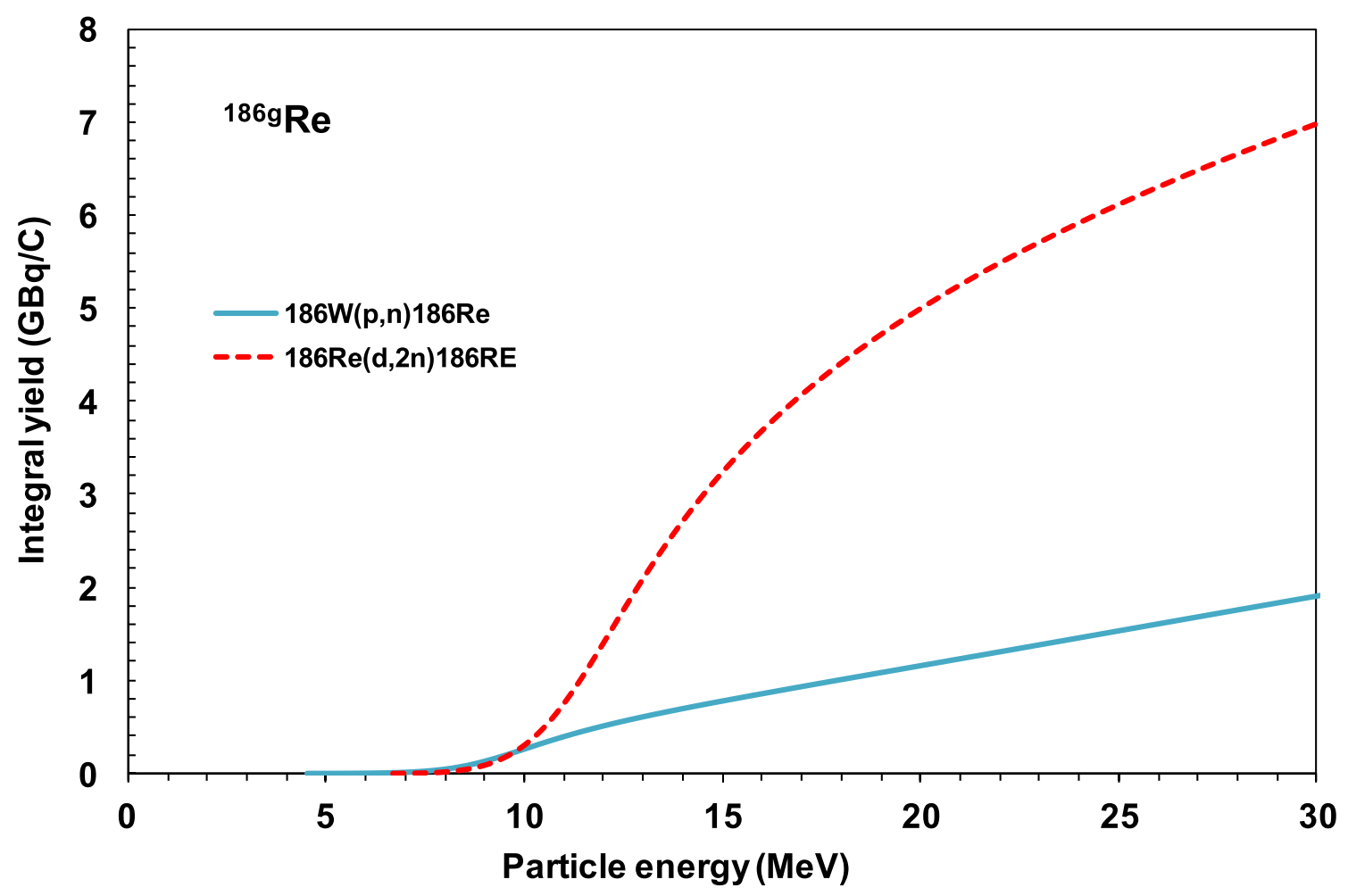

Fig. 58 Yield calculated from the recommended cross sections for ${ }^{186} \mathrm{~W}(p, \mathrm{n}){ }^{186} \mathrm{Re}$ and ${ }^{186} \mathrm{~W}(d, 2 \mathrm{n}){ }^{186} \mathrm{Re}$ reactions

Fig. 59. ${ }^{192 \mathrm{~m}}$ Ir and ${ }^{192 \mathrm{~g}}$ Ir decay scheme

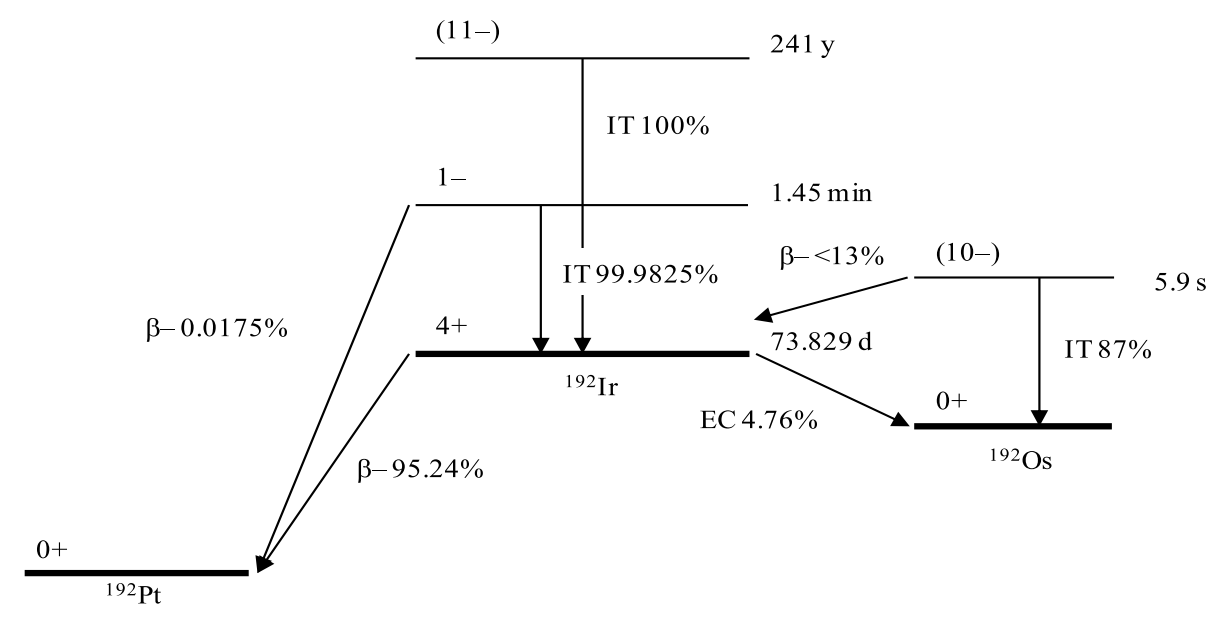

\section{${ }^{192} \mathrm{Os}(d, 2 \mathrm{n}){ }^{192 \mathrm{~m} 1+\mathrm{g} / \mathrm{r} \text { reaction }}$}

Two experimental data sets were published and compared to TENDL evaluations in Fig. 62. Both datasets were selected for fitting: $[119,120]$ Fitted data versus the Padé fit are shown in Fig. 63.

The data series of Hermanne [120] is new and was not included into the earlier evaluation.

\section{Integral yields for production of $192 \mathrm{~m} 1+\mathrm{g} / \mathrm{r}$}

Calculated integral yields of the ${ }^{192} \mathrm{Os}(p, \mathrm{n}){ }^{192 \mathrm{~m} 1+\mathrm{g}} \mathrm{Ir}$ and ${ }^{192} \mathrm{Os}(d, 2 \mathrm{n}){ }^{192 \mathrm{~m} 1+\mathrm{g}}$ Ir reactions are shown in Fig. 64. 
Fig. $60{ }^{192} \mathrm{Os}(p, \mathrm{n})^{192 \mathrm{~m} 1+\mathrm{g}}$ Ir reaction: all experimental data and TENDL predictions
Fig. $61{ }^{192} \mathrm{Os}(p, \mathrm{n})^{192 \mathrm{~m} 1+\mathrm{g}} \mathrm{Ir}$ reaction: selected experimental works (with uncertainties) and Padé fit with derived uncertainties (dashed line, right hand scale)
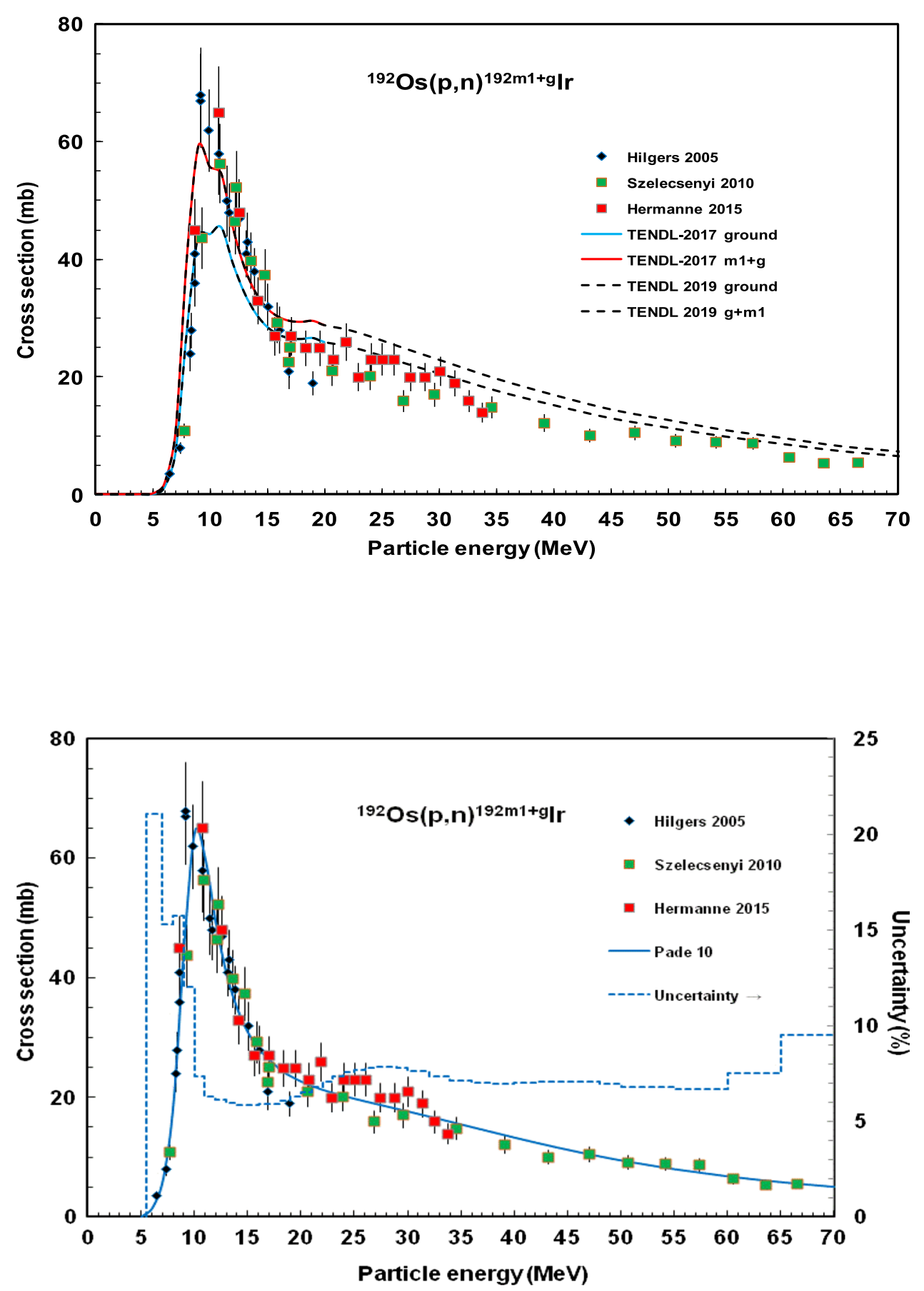

\section{${ }^{211}$ At production}

${ }^{211} \mathrm{At}$ is one of the most promising $\alpha$-particle emitting radionuclides for targeted radionuclide therapy using short penetration, high linear energy transfer and great biological effectiveness of the $\alpha$-particles. ${ }^{210} \mathrm{At}$ is an impurity that leads to production of radio-toxic ${ }^{210} \mathrm{Po}$. The decay schemes of ${ }^{211}$ At and ${ }^{210}$ At are shown in Figs. 65 and 66 and their decay data are collected in Table 2.

The ${ }^{209} \operatorname{Bi}(\alpha, 2 n){ }^{211}$ At and ${ }^{209} \operatorname{Bi}(\alpha, 3 n){ }^{210}$ At reactions were evaluated. 
Fig. $62{ }^{192} \mathrm{Os}(d, 2 \mathrm{n}){ }^{192 \mathrm{~m} 1+\mathrm{g}} \mathrm{Ir}$ reaction: all experimental data and TENDL predictions
Fig. $63{ }^{192} \mathrm{Os}(d, 2 \mathrm{n}){ }^{192 \mathrm{~m} 1+\mathrm{g}} \mathrm{Ir}$ reaction: selected experimental works (with uncertainties) and Padé fit with derived uncertainties (dashed line, right hand scale)
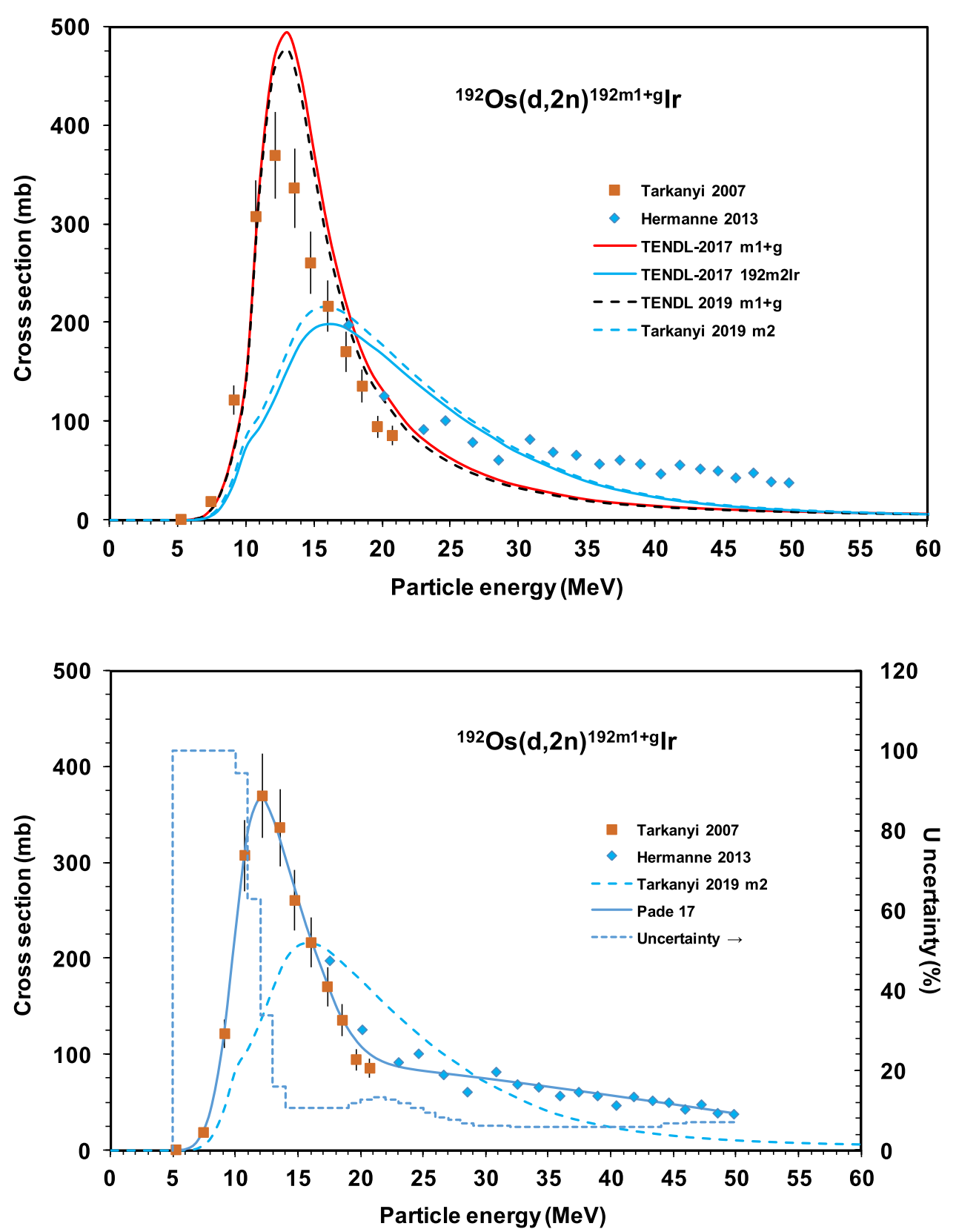

\section{Cross sections for production of ${ }^{209} \mathrm{Bi}(a, 2 n){ }^{211} \mathrm{At}$ and ${ }^{209} \mathrm{Bi}(a, 3 n){ }^{210} \mathrm{At}$ \\ ${ }^{209} \mathrm{Bi}(\boldsymbol{a}, 2 \mathrm{n})^{211}$ At reaction}

A total of seven data sets were found in literature: [121-127] (in Refs. [126] and [127] two data sets were reported: by direct measurement and through decay of ${ }^{211} \mathrm{Po}$ ). Comparison of available data versus TENDL evaluations is shown in Fig. 67. No new data were reported since the last evaluation in [2]. The data by Stickler [124] were deselected, due to significantly lower cross-section values. Fitted data versus the Padé fit are shown in Fig. 68.

\section{${ }^{209} \mathrm{Bi}(a, 3 \mathrm{n}){ }^{210}$ At reaction}

A total of 13 data sets were found in literature: [121-132] (two data sets were reported in [126, 127]: by direct measurement and through decay of ${ }^{210} \mathrm{Po}$ ). Available data are compared with TENDL evaluations in Fig. 69. No new data were published since the last evaluation. The data by Rat$\tan$ [128] were deselected because they show significantly lower cross-section values, similarly data above $38 \mathrm{MeV}$ of incident $\alpha$-energy from Rizvi [130] were also deselected due 


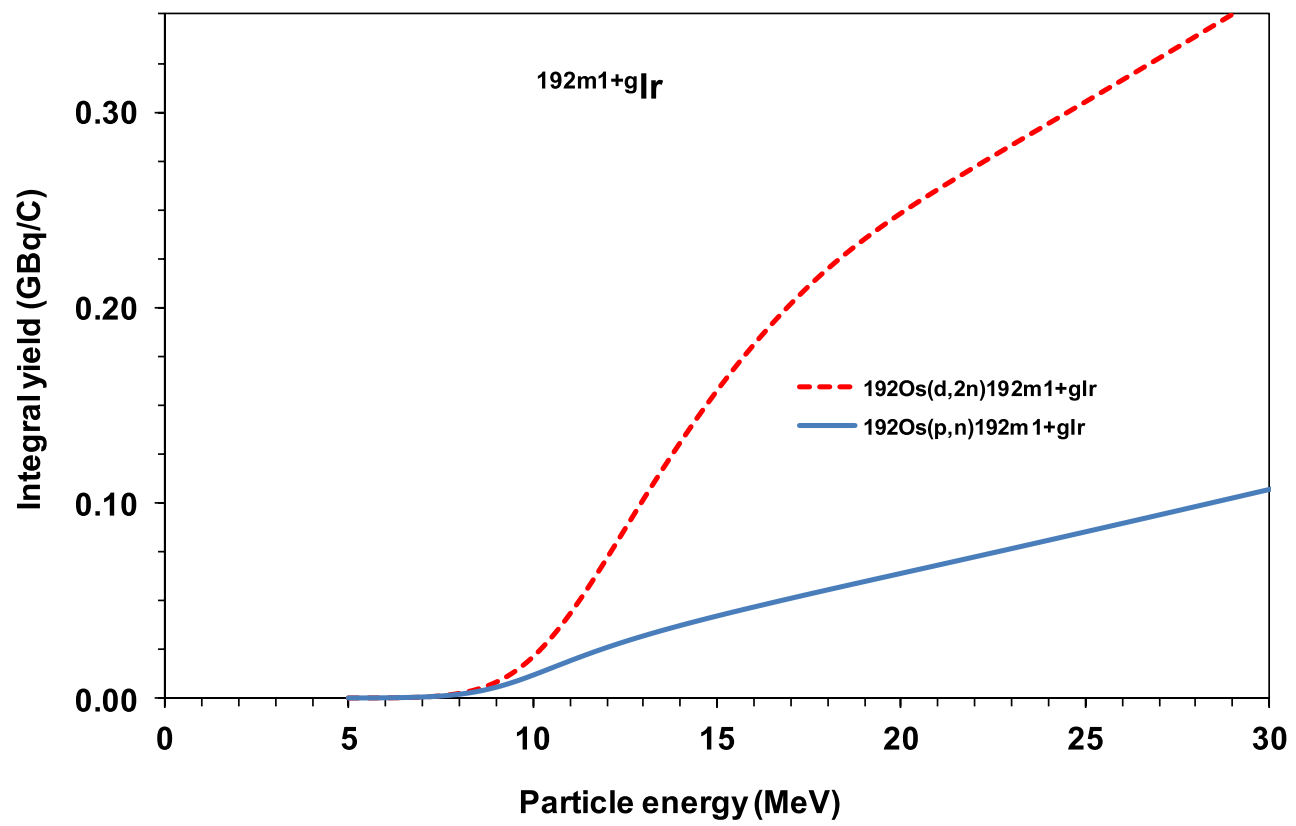

Fig. 64 Yield calculated from the recommended cross sections for ${ }^{192} \mathrm{Os}(p, \mathrm{n}){ }^{192} \operatorname{Ir}$ and ${ }^{192} \mathrm{Os}(d, 2 \mathrm{n}){ }^{192} \mathrm{Ir}$ reactions

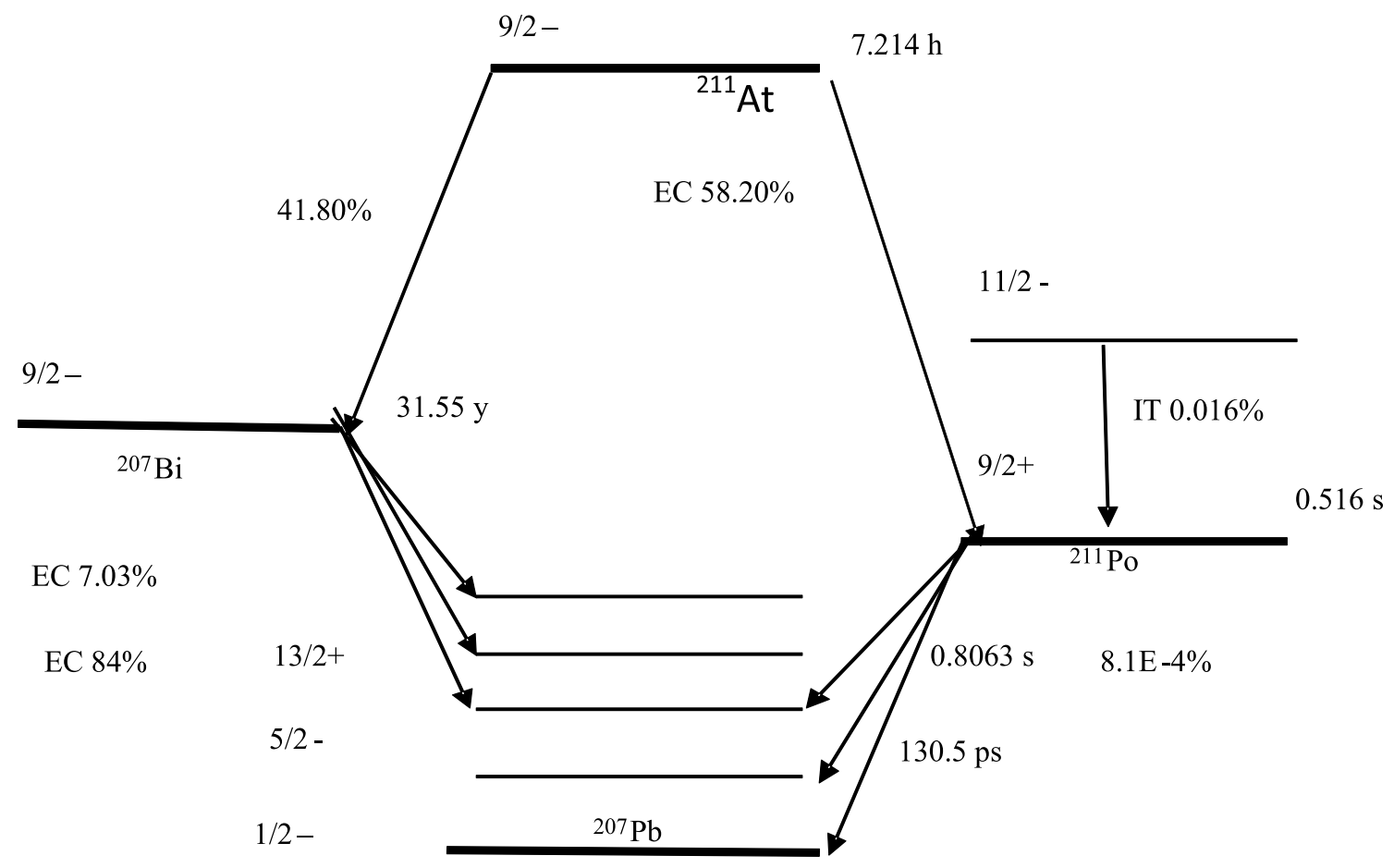

Fig. 65 Decay scheme of ${ }^{211} \mathrm{At},{ }^{211 \mathrm{~m}} \mathrm{Po}$ and ${ }^{211} \mathrm{Po}$ 
Fig. 66 Decay scheme of ${ }^{210} \mathrm{At}$ and ${ }^{210} \mathrm{Po}$
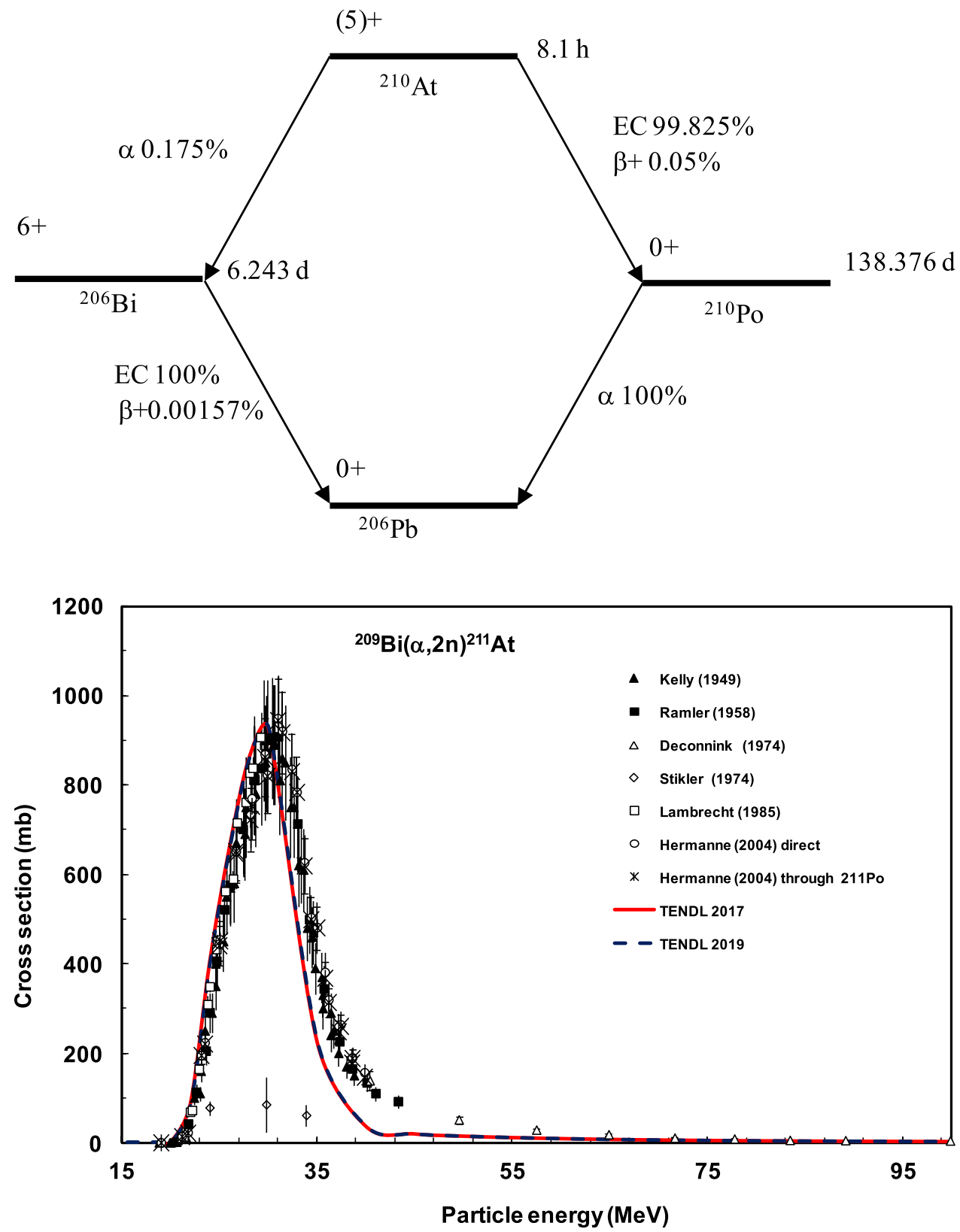

to too low and scattered cross-section values. The selected data were fitted and are compared vs the Padé fit in Fig. 70.

\section{Integral yields for production of ${ }^{211} \mathrm{At}$ and ${ }^{210} \mathbf{A t}$}

Calculated integral yields of the ${ }^{209} \mathrm{Bi}(\alpha, 2 \mathrm{n})^{211} \mathrm{At}$ and ${ }^{209} \mathrm{Bi}(\alpha, 3 \mathrm{n}){ }^{210}$ At reactions are shown in Fig. 71.

\section{Summary}

New evaluations were performed on 25 reactions for production of ${ }^{67} \mathrm{Cu},{ }^{103} \mathrm{Pd},{ }^{102 \mathrm{mg}} \mathrm{Rh},{ }^{114 \mathrm{~m}} \mathrm{In},{ }^{125} \mathrm{I},{ }^{169} \mathrm{Yb},{ }^{177} \mathrm{Lu},{ }^{186} \mathrm{Re}$, ${ }^{192} \mathrm{Ir}$ and ${ }^{210,211}$ At therapeutic radioisotopes by upgrading the compilations with new experimental data and to get uncertainties of the recommended data. The experimental data were compared with theoretical predictions taken from the TENDL-2017 and TENDL-2019 libraries. A Padé fitting method was applied for the selected evaluated datasets to deduce recommended data and their uncertainties. Based on recommended production data integral yields were calculated. Recommended cross-section data and their 


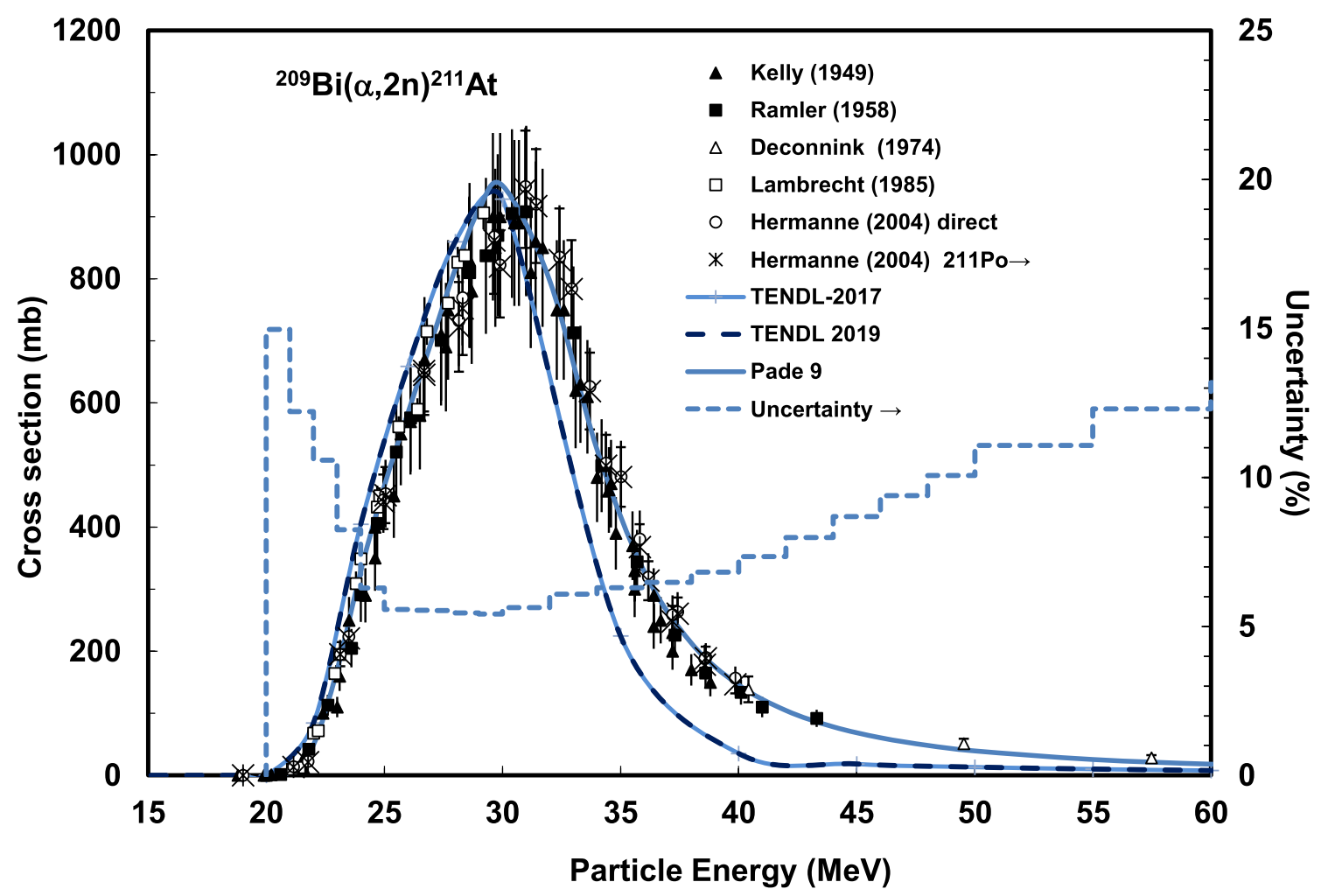

Fig. $68{ }^{209} \mathrm{Bi}(\alpha, 2 \mathrm{n}){ }^{211}$ At reaction: selected experimental works (with uncertainties) and Padé fit with derived uncertainties (dashed line, right hand scale)

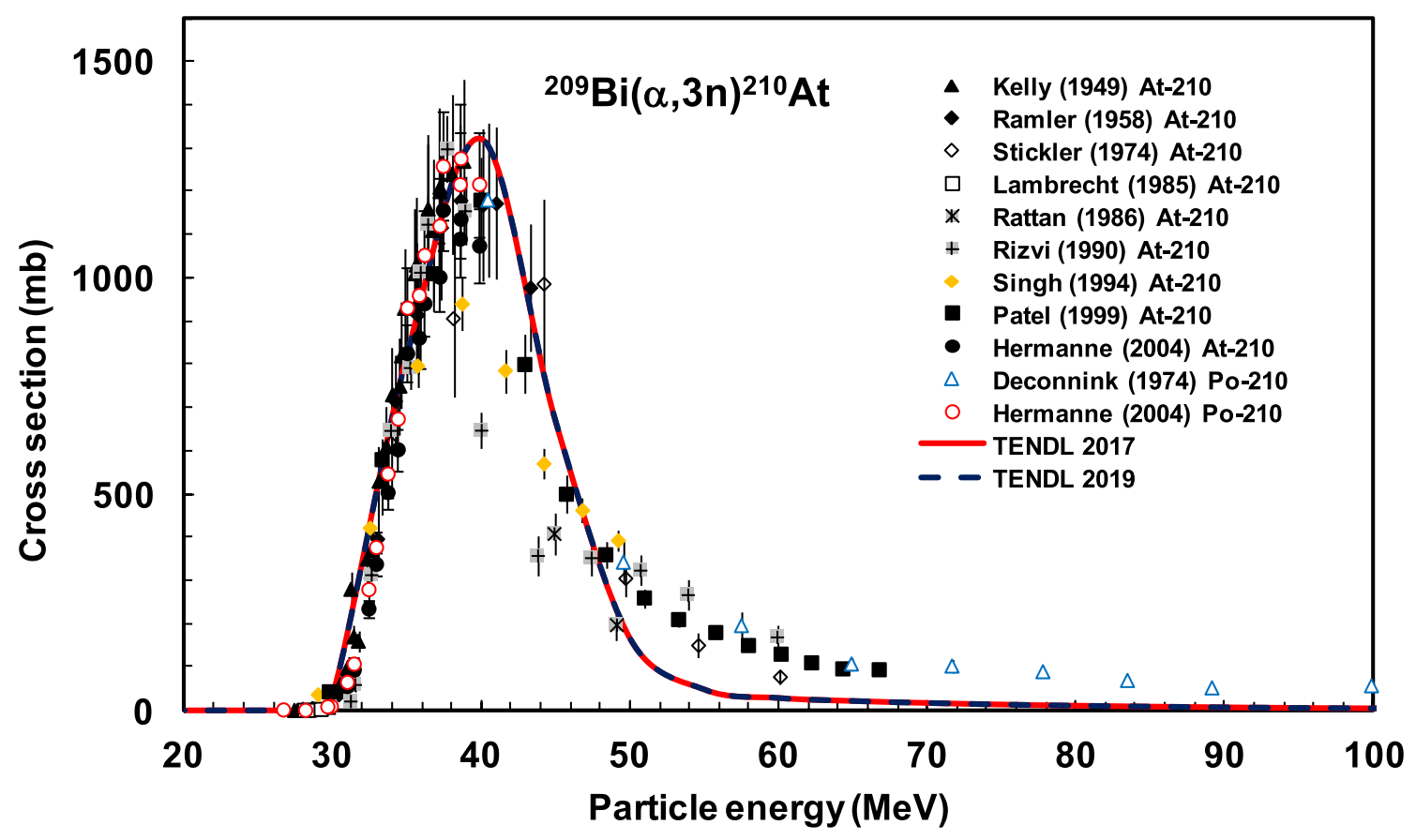

Fig. $69{ }^{209} \mathrm{Bi}(\alpha, 3 \mathrm{n}){ }^{210}$ At reaction: all experimental data and TENDL predictions 


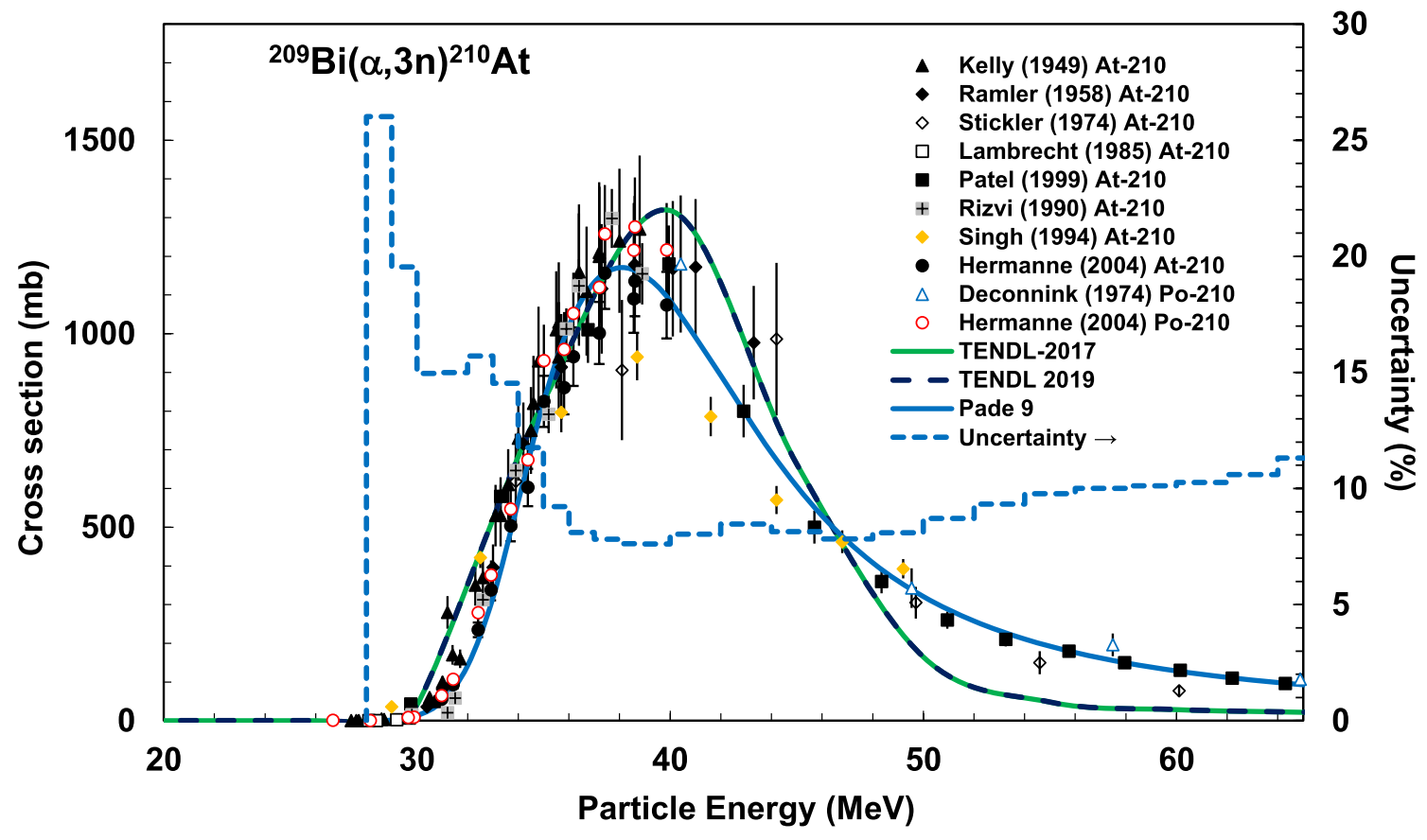

Fig. $70{ }^{209} \operatorname{Bi}(\alpha, 3 n){ }^{210}$ At reaction: selected experimental works (with uncertainties) and Padé fit with derived uncertainties (dashed line, right hand scale)

Fig. 71 Yield calculated from the recommended cross sections for ${ }^{209} \mathrm{Bi}(\alpha, 2 \mathrm{n})^{211} \mathrm{At}$ and ${ }^{209} \mathrm{Bi}(\alpha, 3 \mathrm{n}){ }^{210}$ At reactions

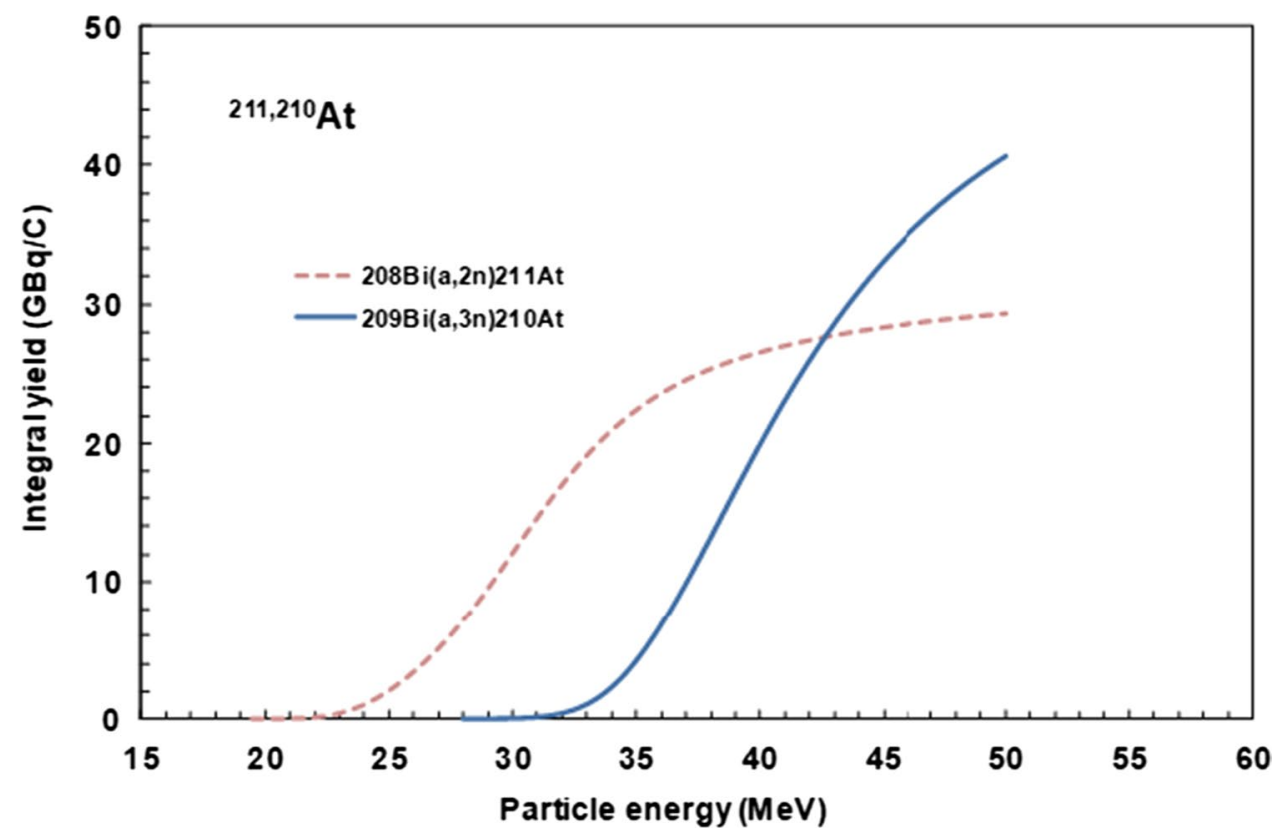

uncertainties for production of therapeutic radionuclides are available on the Web page of the IAEA Nuclear Data Section at https://nds.iaea.org/radionuclides and also at the IAEA medical portal https://nds.iaea.org/medportal. These data have importance for radionuclide production and can be used to validate nuclear reaction models.
Open Access This article is licensed under a Creative Commons Attribution 4.0 International License, which permits use, sharing, adaptation, distribution and reproduction in any medium or format, as long as you give appropriate credit to the original author(s) and the source, provide a link to the Creative Commons licence, and indicate if changes were made. The images or other third party material in this article are included in the article's Creative Commons licence, unless indicated otherwise in a credit line to the material. If material is not included in 
the article's Creative Commons licence and your intended use is not permitted by statutory regulation or exceeds the permitted use, you will need to obtain permission directly from the copyright holder. To view a copy of this licence, visit http://creativecommons.org/licenses/by/4.0/.

\section{References}

1. Gul K, Hermanne A, Mustafa MG, Nortier FM, Oblozinský P, Qaim SM, Scholten B, Shubin Y, Takács S, Tárkányi FT, Zhuang Y (2001) Charged particle cross-section database for medical radioisotope production: diagnostic radioisotopes and monitor reactions IAEA Technical Report IAEA-TECDOC-1211, May 2001, Vienna

2. Bĕták E, Caldeira AD, Capote R, Carlson BV, Choi HD, Guimarães FB, Ignatyuk AV. Kim SK, Kiraly B, Kovalev SF, Menapace E, Nichols AL, Nortier M, Pompeia P, Qaim SM, Scholten B, Shubin Yu N, Sublet J-Ch, Tárkányi F (2011) Nuclear data for production of therapeutic radionuclides (Technical Editors S.M. Qaim, F. Tárkányi, R. Capote) Technical Report Series No. 473, IAEA. Vienna, 2011

3. Hermanne A, Ignatyuk AV, Capote R, Carlson BV, Engle JW, Kellett MA, Kibedi T, Kim G, Kondev FG, Hussain M, Lebeda O, Luca A, Nagai Y, Naik H, Nichols AL, Nortier FM, Suryanarayana SV, Takács S, Tárkányi FT, Verpelli M (2018) Reference cross sections for charged-particle monitor reactions. Nucl Data Sheets 148:338-382

4. Tárkányi FT, Ignatyuk AV, Capote R, Carlson BV, Engle JW, Kellett MA, Kibedi T, Kim G, Kondev FG, Hussain M, Lebeda O, Luca A, Nagai Y, Naik H, Nichols AL, Nortier FM, Suryanarayana SV, Takács S, Verpelli M (2019) Recommended nuclear data for medical radioisotope production: diagnostic gamma emitters. J Radioanal Nucl Chem 319:487-531

5. Tárkányi FT, Ignatyuk AV, Capote R, Carlson BV, Engle JW, Kellett MA, Kibedi T, Kim G, Kondev FG, Hussain M, Lebeda O, Luca A, Nagai Y, Naik H, Nichols AL, Nortier FM, Suryanarayana SV, Takács S, Verpelli M (2019) Recommended nuclear data for medical radioisotope production: diagnostic positron emitters. J Radioanal Nucl Chem 319:533-666

6. Engle JW, Ignatyuk AV, Capote R, Carlson BV, Hermanne A, Kellett MA, Kibedi T, Kim G, Kondev FG, Hussain M, Lebeda O, Luca A, Nagai Y, Naik H, Nichols AL, Nortier FM, Suryanarayana SV, Takács S, Tárkányi FT, Verpelli M (2019) Recommended nuclear data for production of selected therapeutic radionuclides. Nuclear Data Sheets 155:56-74

7. Hermanne A, Tarkanyi FT, Ignatyuk AV, Takacs S, Capote R (2021) Upgrade of IAEA recommended data of selected nuclear reactions for production of PET and SPECT isotopes. Nuclear Data Sheets 173:285-308

8. Padé HE (1892) Sur la représentation d'une fonction par des fractions rationnelles. Ann L'École Norm. 9(3):3-93

9. Vinogradov VN, Gai EV, Rabotnov NS (1987) Analytical approximation of data in nuclear and neutron physics. Energoatomizdat, Moscow

10. Capote R, Badikov S, Carlson AD, Duran I, Gunsing F, Neudecker D, Pronyaev VG, Schillebeeckx P, Schnabel G, Smith DL, Wallner A (2020) Unrecognized sources of uncertainties (USU) in experimental nuclear data. Nuclear Data Sheets 1(163):191-227

11. KoningAJ, Rochman D, Sublet JC (2017) TENDL-2017 TALYSbased evaluated nuclear data library. https://tendl.web.psi.ch/ tendl_2017/tendl2017.html

12. Koning AJ, Rochman D, Sublet JC, Dzysiuk N, Fleming M, Van der Marck S (2019) TENDL: complete nuclear data library for innovative nuclear science and technology. Nuclear Data Sheets. $155: 1-55$

13. Bonardi M (1987) The contribution to nuclear data for biomedical radioisotope production from the Milan cyclotron facility. In: Proceedings of the IAEA consultants' meeting on data requirements for medical radioisotope production, Tokyo, Japan, INDC(NDS)-195/GZ, (ed. K. Okamoto) 1988, pp 98-112. International Atomic Energy Agency (IAEA)

14. Otuka N, Takács S (2015) Definitions of radioisotope thick target yields. Radiochim Acta 103(1):1-6

15. Evaluated Nuclear Structure Data File (ENSDF). Available online at www.nndc.bnl.gov/ensdf/. Developed and maintained by the International Network of Nuclear Structure and Decay Data Evaluators (NSDD) (see nds.iaea.org/nsdd/)

16. LiveChart of Nuclides, IAEA decay data retrieval code. Available online at nds.iaea.org/livechart/

17. NuDat, Brookhaven National Laboratory, USA. Decay data retrieval code. Available online at www.nndc.bnl.gov/nudat3/

18. Cohen BL, Newman E, Handley TH (1955) (p, pn)+(p,2n) and $(p, 2 p)$ cross sections in medium weight elements. Phys Rev 99:723-727 (EXFOR: B0049)

19. Morrison DL, Caretto AA Jr (1964) Recoil study of the ${ }^{68} \mathrm{Zn}(\mathrm{p}, 2 \mathrm{p}){ }^{67} \mathrm{Cu}$ reaction. Phys Rev 133:B1165-B1170 (EXFOR: R0047)

20. Morrison DL, Caretto AA (1962) Excitation functions of (p, xp) reactions. Phys Rev 127:1731-1738 (EXFOR:C0697)

21. McGee T, Rao CL, Saha GB, Yafee L (1970) Nuclear interactions of ${ }^{45} \mathrm{Sc}$ and ${ }^{68} \mathrm{Zn}$ with protons of medium energy. Nucl Phys A 150:11-29 (EXFOR: B0053)

22. Mirzadeh S, Mausner LF, Srivastava SC (1986) Production of nocarrier added ${ }^{67} \mathrm{Cu}$. Appl Radiat Isot 37:29-36 (EXFOR: 12970)

23. Levkovskij VN (1991) Activation cross section nuclides of average masses $(A=40-100)$ by protons and alpha-particles with average energies $(\mathrm{E}=10-50 \mathrm{MeV})$. Moscow, Russia (EXFOR: A0510)

24. Stoll T, Kastleiner S, Shubin YN, Coenen HH, Qaim SM (2002) Excitation functions of proton induced reactions on ${ }^{68} \mathrm{Zn}$ from threshold up to $71 \mathrm{MeV}$ with specific reference to the production of ${ }^{67} \mathrm{Cu}$. Radiochim Acta 90:309-313 (EXFOR: O1002)

25. Bonardi ML, Groppi F, Mainardi HS, Kokhanyu VM, Lapshina EV, Mebel MV, Zhuikov BL (2005) Cross-section studies on ${ }^{64} \mathrm{Cu}$ with zinc target in the proton energy range from 141 down to $31 \mathrm{MeV}$. J Radioanal Nucl Chem 264:101-105 (EXFOR: O1310)

26. Szelecsényi F, Steyn GF, Dolley SG, Kovács Z, Vermeulen C, van der Walt TN, New cross-section data on the ${ }^{68} \mathrm{Zn}(\mathrm{p}, 2 \mathrm{p}){ }^{67} \mathrm{Cu}$ nuclear reaction: production possibility of ${ }^{67} \mathrm{Cu}$ used for internal radiotherapy. In: $15^{\text {th }}$ Pacific Basin Nuclear Conf. (Proc. Conf. Sydney, 2006), CD-ROM (EXFOR: no)

27. Szelecsényi F, Steyn GF, Dolley SG, Kovács Z, Vermeulen C, van der Walt TN (2009) Investigation of the ${ }^{68} \mathrm{Zn}(\mathrm{p}, 2 \mathrm{p}){ }^{67} \mathrm{Cu}$ nuclear reaction: new measurements up to $40 \mathrm{MeV}$ and compilation up to $100 \mathrm{MeV}$ Nucl. Instrum Meth Phys Res B 267:18771881 (EXFOR: D0574)

28. Schwarzbach R, Zimmermann K, Novak-Hofer I, Schubiger PA (2001) A comparison of $\mathrm{Cu}-67$ production by proton (67- to $12-\mathrm{MeV}$ ) induced reaction on $\mathrm{Zn}$-nat and on enriched $\mathrm{Zn}-68 /$ Zn-70. J Labelled Compd Radiopharmaceut 44:S809-S811. https://doi.org/10.1002/jlcr.25804401284 (EXFOR: O1369)

29. Pupillo G, Sounalet T, Michel N, Moua L, Esposito J, Haddad F (2018) New production cross sections for the theranostic radionuclide ${ }^{67} \mathrm{Cu}$. Nucl Instrum Meth Phys Res B 415:41-47 (EXFOR:O2374)

30. Kastleiner S, Coenen HH, Qaim SM (1999) Possibility of production of ${ }^{67} \mathrm{Cu}$ at a small sized cyclotron via the $(\mathrm{p}, \alpha)$ reaction on enriched ${ }^{70} \mathrm{Zn}$. Radiochim Acta 84:107-110 (EXFOR: O0738) 
31. Tárkányi F, Takács S, Ditrói F, Hermanne A, Sonck M, Shubin $\mathrm{Yu}(2004)$ Excitation functions of deuteron induced nuclear reactions on natural zinc up to $50 \mathrm{MeV}$. Nucl Instrum Meth Phys Res B 217:531-550 (EXFOR:D4144)

32. Khandaker MU, Haba H, Murakami M, Otuka N (2015) Production cross-sections of long-lived radionuclides in deuteroninduced reactions on natural zinc up to $23 \mathrm{MeV}$. Nucl Instrum Methods Phys Res B 346:8-16 (EXFOR:E2473)

33. Blaser JP, Boehm F, Marmier P, Scherrer P (1951) Anregungsfunktionen und Wirkungsquerschnitte der ( $\mathrm{p}, \mathrm{n})$-Reaktion (II). Helv Phys Acta 24:441-464 (EXFOR: P0033)

34. Albert RD (1959) (p, n) cross section and proton opticalmodel parameters in the 4 to $5.5 \mathrm{MeV}$ energy region. Phys Rev 115:925-927 (EXFOR: T0130)

35. Johnson CH, Galonsky A, Inskeep CN (1960) Cross sections for $(p, n)$ reactions in intermediate-weight nuclei Oak Ridge. Nat. Lab., Rep. ORNL-2910 25 (unpublished) (EXFOR: T0135)

36. Bramblett RL, Bonner TW (1960) Neutron evaporation spectra from (p, n) reactions. Nucl Phys 20:395-407. https://doi.org/10. 1016/0029-5582(60)90182-6 (EXFOR:F1108)

37. Harper PV, Lathrop K, Need JL (1961) The thick target yield and excitation function for the reaction ${ }^{103} \mathrm{Rh}(\mathrm{p}, \mathrm{n}){ }^{103} \mathrm{Pd}$ Oak Ridge. Natl. Lab., Rep. ORNL-LR-DWG 51564, pp 124-128 (EXFOR: no)

38. Haansen LF, Albert RD (1962) Statistical theory predictions for 5 to $11 \mathrm{MeV}(\mathrm{p}, \mathrm{n})$ and $\left(\mathrm{p}, \mathrm{p}^{\prime}\right)$ nuclear reactions $\mathrm{i}^{\mathrm{n}} 51 \mathrm{~V}, 59 \mathrm{Co}$, 63Cu, 65Cu an ${ }^{\mathrm{d}}$ 03Rh Phys. Rev 128:291-299 (EXFOR: B0066)

39. Mukhammedov S, Vasidov A (1986) Determination of rhodium by proton-activation technique using the $(\mathrm{p}, \mathrm{n})$ reaction at a cyclotron. Izv Akad Nauk Uzb SSR Ser Fiz-Mat 2:329 (EXFOR: no)

40. Hermanne A, Sonck M, Fenyvesi A, Daraban L (2000) Study on production of ${ }^{103} \mathrm{Pd}$ and characterization of possible contaminants in the proton irradiation of ${ }^{103} \mathrm{Rh}$ up to $28 \mathrm{MeV}$ Nucl. Instrum Meth Phys Res B 170:281-292 (EXFOR: D4108, O0843)

41. Sudar S, Cserpak F, Qaim SM (2002) Measurements and nuclear model calculation on proton-induced reactions on ${ }^{103} \mathrm{Rh}$ up to $40 \mathrm{MeV}$ : evaluation of the excitation function of the ${ }^{103} \mathrm{Rh}(\mathrm{p}$, $\mathrm{n}^{10} 3 \mathrm{Pd}$ reaction relevant to the production of the therapeutic radionuclide ${ }^{10} 3 \mathrm{Pd}$ Appl. Radiat Isot 56:821-831 (EXFOR: D4125, O1010)

42. Tárkányi F, Ditrói F, Takács S, Hermanne A, Baba M, Yuki H, Ignatyuk AV (2017) Investigation of activation cross sections of proton induced reactions on rhodium up to $70 \mathrm{MeV}$ for practical applications. Nucl Instrum Meth Phys Res B 412:190-197 (EXFOR: D4377)

43. Hermanne A, Sonck M, Takács S, Tárkányi F, Shubin Y (2002) Study on alternative production of ${ }^{103} \mathrm{Pd}$ and characterization of contaminants in the deuteron irradiation of ${ }^{103} \mathrm{Rh}$ up to $21 \mathrm{MeV}$. Nucl Instrum Meth Phys Res B 187:3-14 (EXFOR: O0843)

44. Hermanne A, Sonck M, Takács S, Tárkányi F, Shubin Y (2002) Deuteron bombardment of ${ }^{103} \mathrm{Rh}$ : a new promising pathway for production of ${ }^{103} \mathrm{Pd}$. J Nucl Sci Technol Suppl 2:1286-1289 (EXFOR: D4097)

45. Tárkányi F, Hermanne A, Kiraly B, Takács S, Ditrói F, Csikai J, Fenyvesi A, Uddin MS, Hagiwara M, Baba M, Ido T, Shubin YuN, Ignatyuk AV (2009) New cross-sections for production of ${ }^{103} \mathrm{Pd}$; review of charged particle production routes. Appl Radiat Isot 67:1574-1581 (EXFOR: D4220)

46. Ditrói F, Tárkányi F, Takács S, Hermanne A, Yamazaki H, Baba M, Mohammadi A, Ignatyuk AV (2011) Study of activation cross-sections of deuteron induced reactions on rhodium up to 40 MeV. Nucl Instrum Meth Phys Res B 269:1963-1972 (EXFOR: D4250)
47. Hermanne A, Tárkányi F, Takács S, Ditrói F (2015) Extension of activation cross section data of deuteron induced nuclear reactions on rhodium up to $50 \mathrm{MeV}$. Nucl Instrum Meth Phys Res B 362:110-115 (EXFOR: D4337)

48. Blaser J-P, Boehm F, Marmier P, Peaslee DC (1951) Fonctions d'excitation de la reaction (p, n) I. Helv Phys Acta 24:3-38 (EXFOR: B0048)

49. Blsser HG, Handley TH (1955) Survey of (p, n) reactions at 12 MeV. Phys Rev 100:1340-1344 (EXFOR: B0052)

50. Wing J, Huizenga JR (1962) (p, n) cross sections of ${ }^{51} \mathrm{~V},{ }^{52} \mathrm{Cr}$, ${ }^{63} \mathrm{Cu},{ }^{65} \mathrm{Cu},{ }^{107} \mathrm{Ag},{ }^{109} \mathrm{Ag},{ }^{111} \mathrm{Cd},{ }^{114} \mathrm{Cd}$, and ${ }^{139} \mathrm{La}$ from 5 to 10.5 MeV. Phys Rev 128:280-290 (EXFOR: T0124)

51. Nickarz WJ, Caretto AA (1969) Production of ${ }^{111}$ In and ${ }^{114 m} \mathrm{In}$ from the separated isotopes of cadmium using 70 to $400 \mathrm{MeV}$ protons. Phys Rev 178:1887-1893 (EXFOR: C0345)

52. Skakun YA, Kljucharev AP, Rakivnenko YuN, Romanij IA (1975) Excitation functions of (p, n)- and (p,2n)-reactions on cadmium isotopes Izv. Rossiiskoi Akademii Nauk. Ser Fiz 39:24-30 (EXFOR: A0001)

53. Abramovich SN, Guzhovkij BY, Zvenigorodskii AG, Trusillo SV (1975) Isobaric analog resonances appearing during elastic scattering of protons and in the $(\mathrm{p}, \mathrm{n})$ reaction of ${ }^{110} \mathrm{Cd},{ }^{112} \mathrm{Cd}$, ${ }^{114} \mathrm{Cd},{ }^{116} \mathrm{Cd}$ nuclei Izv. Rossiiskoi Akademii Nauk Ser Fiz. 39:1688-1694 (EXFOR: A0129)

54. Nortier FM, Mills SJ, Steyn GF (1990) Excitation functions and production rates of relevance to the production of ${ }^{111}$ In by proton

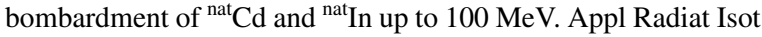
41:1201-1208 (EXFOR: A0500)

55. Zaitseva NG, Knotek O, Kowalew A, Mikecz P, Rurarz E, Khalkin VA, Ageev VA, Klyuchnikov AA, Kuzina LA, Linev AF (1990) Excitation functions and yields for ${ }^{111}$ In production

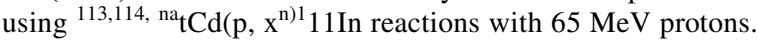
Appl Radiat Isot 41:177-183 (EXFOR: A0569, D4070)

56. Mirzaei M, Afarideh H, Haji-Saeid SM, Ardeneh K (1999) Production of ${ }^{111}$ In by irradiation of natural cadmium with deuterons and protons in NRCAM cyclotron. In: International conference on cyclotrons and their applications (Proc. Int. Conf. Caen, 1998), (Baron E., Lieuvin M., Eds), Institute of Physics Publishing, Bristol, pp 65-67 (EXFOR: no)

57. Zarubin PP, Sergeev VO (2001) Study of (pn) reaction on ${ }^{114} \mathrm{Cd}$ nucleus. Bull Russ Acad Sci Phys 65:1753 (EXFOR: F0687)

58. Tárkányi F, Takács S, Hermanne A, Van Den Winkel P, Van Der Zwart R, Skakun Ye A, Shubin YuN, Kovalev SF (2005) Investigation of the production of the therapeutic radioisotope ${ }^{114 \mathrm{~m}}$ In through proton and deuteron induced nuclear reactions on cadmium. Radiochimica Acta 93:561-570 (EXFOR: D4160)

59. Said SA, Elmaghraby EK, Asfour FI (2006) Experimental investigation and nuclear model calculations on proton-induced reactions on highly enriched ${ }^{114} \mathrm{Cd}$ at low energies. Appl Radiat Isot 64:1655-1660 (EXFOR: O1502)

60. Tárkányi F, Ditrói F, Takács S, Csikai J, Hermanne A, Uddin S, Baba M (2006) Activation cross sections on cadmium: proton induced nuclear reactions up to $80 \mathrm{MeV}$. Nucl Instrum Meth Phys Res B 245:379-394 (EXFOR: D4170)

61. Khandaker MU, Kim K, Lee MW, Kim KS, Kim GN, Cho YS, Lee YO (2008) Production cross-sections for the residual radionuclides from the $\mathrm{Cd}(\mathrm{p}, \mathrm{x})$ nuclear processes. Nucl Instrum Meth Phys Res B 266:4877-4887 (EXFOR: D0516)

62. Hermanne A, Adam-Rebeles R, Van den Winkel P, Tárkányi F, Takács S (2014) Production of ${ }^{111}$ In and ${ }^{114 m}$ In by proton induced reactions: an update on excitation functions, chemical separation. Radiochim Acta 102:1111-1126 (EXFOR: D4320)

63. Nassiff SJ, Usher OH, Wasilevsky C (1979) Cross sections for the formation of ${ }^{114 \mathrm{~m}}$ In and ${ }^{116 \mathrm{~m}}$ In on bombardment of cadmium by deuterons. Radiat Phys Chem 13:129-132 (EXFOR: no) 
64. Tárkányi F, Takács S, Hermanne A, van den Winkel P, van der Zwart R, Ye A, Skakun YuN, Shubin SFK (2005) Investigation of the production of the therapeutic radioisotope ${ }^{114 \mathrm{~m}}$ In through proton and deuteron induced nuclear reactions on cadmium. Radiochimica Acta 93:561-569 (EXFOR: D4160)

65. Tárkányi F, Király B, Ditrói F, Takács S, Csikai J, Hermanne A, Uddin MS, Hagiwara M, Baba M, Ido T, Shubin YuN, Kovalev SF (2007) Activation cross sections on cadmium: Deuteron induced nuclear reactions up to $40 \mathrm{MeV}$. Nucl Instrum Meth Phys Res B 259:817-828 (EXFOR: D4179)

66. Hermanne A, Tárkányi F, Takács S, Van den Winkel P, Rebeles RA, Ignatyuk A, Kovalev SF (2010) Production of the therapeutic radioisotope ${ }^{114 \mathrm{~m}} \mathrm{In}$ through the ${ }^{116} \mathrm{Cd}(\mathrm{p}, 3 \mathrm{n}){ }^{114 \mathrm{~m}} \mathrm{In}$ reaction. Appl Radiat Isot 68:14-17 (EXFOR: D4229)

67. Johnson CH, Galonsky A, Inskeep CN (1958) Cross sections for $(\mathrm{p}, \mathrm{n})$ reactions in cadmium and tellurium isotopes. Rep. ORNL2501, Oak Ridge Natl Lab., TN (EXFOR: T0138)

68. Zweit J, Sharma H, Downey S (1987) Roduction of gallium-66, a short-lived emitting, positron radionuclide. Appl Radiat Isot 38:499-501 (EXFOR: D0120)

69. Hohn A, Nortier FM, Scholten B, van der Walt TN, Coenen HH, Qaim SM (2001) Excitation functions of ${ }^{125} \mathrm{Te}(\mathrm{p}, \mathrm{xn})$-reactions from their respective thresholds up to $100 \mathrm{MeV}$ with special reference to the production of ${ }^{12} 4 \mathrm{I}$. Appl Radiat Isot 55:149-156 (EXFOR: A0215)

70. El-Azony K, Suzuki K, Fukumura T, Szelecsenyi F, Kovacs Z (2008) Proton induced reactions on natural tellurium up to 63 $\mathrm{MeV}$ : Data validation and investigation of possibility of ${ }^{124} \mathrm{I}$ production. Radiochim Acta 96:763-769 (EXFOR: D0502)

71. Ahmed AM, Hassan HE, Hassan KF, Khalaf AM, Saleh ZA (2011) Cross sections for the formation of radioiodines in proton bombardment of natural tellurium with particular reference to the validation of data for the production of ${ }^{123} \mathrm{I}$. Radiochim Acta 99:317-323 (EXFOR: D0647)

72. Bastian TH, Coenen HH, Qaim SM (2001) Excitation functions of ${ }^{124} \mathrm{Te}\left(\mathrm{d}, \mathrm{xn}^{) 124,12} 5 \mathrm{I}\right.$ reactions from threshold up to $14 \mathrm{MeV}$ : comparative evaluation of nuclear routes for the production of ${ }^{12} 4$ I. Appl Radiat Isot 55:303-308 (EXFOR: A0248)

73. Zaidi JH, Qaim SM, Stocklin G (1983) Excitation functions of deuteron induced nuclear reactions on natural tellurium and enriched 122-Te: production of 123 -I via the ${ }^{122} \mathrm{Te}(\mathrm{d}$, $n^{12} 3$ I-process. Appl Rad Isot 34:1425-1430

74. Hermanne A, Tárkányi F, Takács S, Ditroi F, Ignatyuk A (2020) Deuteron induced reactions on tellurium: an alternative for production of ${ }^{123}$ I? Nucl Instrum Meth Phys Res B 466:20-30

75. Birattari C, Gadloli E, Gadioli Erba E, Grassi AM, Strini G, Tagliaferri G (1973) Pre-equilibrium processes in (p, n) reactions. Nucl Phys A 201:579-592 (EXFOR: B0018)

76. Spahn I, Takács S, Shubin YN, Tárkányi F, Coenen HH, Qaim SM (2005) Cross section measurement of the ${ }^{169} \mathrm{Tm}(\mathrm{p}, \mathrm{n})$ reaction for the production of the therapeutic radionuclide ${ }^{16} 9 \mathrm{Yb}$ and comparison with its reactor-based generation. Appl Radiat Isot 63:235-239 (EXFOR: D4148)

77. Sonnabend K, Glorius J, Gorres J, Knorzer M, Muller S, Sauerwein A, Tan WP, Wiescher M (2011) Activation experiments for p-process nucleosynthesis. J Phys Conf Ser 312:042007 (EXFOR: C1887)

78. Tárkányi F, Hermanne A, Takács S, Ditrói F, Spahn I, Ignatyuk AV (2012) Activation cross-sections of proton induced nuclear reactions on thulium in the $20-45 \mathrm{MeV}$, energy range. Appl Radiat Isot 70:309-314 (EXFOR: D4259)

79. Tárkányi F, Hermanne A, Takács S, Ditrói F, Spahn I, Kovalev SF, Ignatyuk AV, Qaim SM (2007) Activation cross sections of the ${ }^{169} \mathrm{Tm}(\mathrm{d}, 2 \mathrm{n})$ reaction for production of the therapeutic radionuclide ${ }^{169} \mathrm{Yb}$. Appl Radiat Isot 65:663-668 (EXFOR: D4180)
80. Hermanne A, Tárkányi F, Takács S, Ditrói F, Baba M, Ohtshuki T, Spahn I, Ignatyuk AV (2007) Excitation functions for production of medically relevant radioisotopes in deuteron irradiations of Pr and Tm targets. J Label Compd Radiopharm 50:102 (EXFOR: no)

81. Hermanne A, Tárkányi F, Takács S, Ditrói F, Baba M, Ohtshuki T, Spahn I, Ignatyuk AV (2009) Excitation functions for production of medically relevant radioisotopes in deuteron irradiations of Pr and Tm targets Nucl. Instrum Meth Phys Res B 267:727736 (EXFOR: D4209)

82. Hermanne A, Tárkányi F, Takács S, Ditrói F (2016) Extension of excitation functions up to $50 \mathrm{MeV}$ for activation products in deuteron irradiations of Pr and Tm targets. Nucl Instrum Meth Phys Res B 383:81-88 (EXFOR: D4355)

83. Saito M, Aikawa M, Komori Y, Haba H, Takács S (2017) Production cross sections of ${ }^{169} \mathrm{Yb}$ and $\mathrm{Tm}$ isotopes in deuteron-induced reactions on ${ }^{169} \mathrm{Tm}$. Appl Rad Isot 125:23-26 (EXFOR: E2533)

84. Hermanne A, Takács S, Goldberg MB, Lavie E, Yu NS, Kovalev S (2006) Deuteron-induced reactions on Yb: Measured cross sections and rationale for production pathways of carrier-free, medically relevant radionuclides. Nucl Instrum Meth Phys Res B 247:223-231 (EXFOR: D4175)

85. Tárkányi F, Ditrói F, Takács S, Hermanne A, Yamazaki H, Baba M, Mohammadi A, Ignatyuk AV (2013) Activation cross-sections of longer-lived products of deuteron induced nuclear reactions on ytterbium up to $40 \mathrm{MeV}$. Nucl Instrum Meth Phys Res B 304:36-48 (EXFOR: D4287)

86. Tárkányi F, Ditrói F, Takács S, Hermanne A, Ignatyuk AV (2014) New data on activation cross section for deuteron induced reactions on ytterbium up to $50 \mathrm{MeV}$. Nucl Instrum Meth Phys Res B 336:37-44 (EXFOR: D4308)

87. Khandaker MU, Haba H, Otuka N, Usman AR (2014) Investigation of $(\mathrm{d}, \mathrm{x})$ nuclear reactions on natural ytterbium up to $24 \mathrm{MeV}$ Nucl. Instrum Meth Phys Res B 335:8-18 (EXFOR: E2457 \#1)

88. Manenti S, Groppi F, Gandini A, Gini L, Abbas K, Holzwarth U, Simonelli F, Bonardi M (2011) Excitation function for deuteron induced nuclear reactions on natural ytterbium for production of high specific activity ${ }^{177 \mathrm{~g}} \mathrm{Lu}$ in no-carrier-added form for metabolic radiotherapy. Appl Rad Isot 69:37-45 (EXFOR: O1877)

89. Tárkányi F, Ditrói F, Takács S, Hermanne A, Ignatyuk AV (2014) New data on activation cross section for deuteron induced reactions on ytterbium up to $50 \mathrm{MeV}$. Nucl Instrum Meth Phys Res B 336:37-44 (EXFOR: D4308)

90. Shigeta N, Matsuok H, Osa A, Koizum M, Izumo M, Kobayashi K, Hashimoto K, Sekine T, Lambrecht RM (1996) Production method of no-carrier-added ${ }^{186}$ Re. J Radioanal Nucl Chem 205:85-92 (EXFOR: E2082)

91. Ishioka S, Sekine NT, Lambrecht RM (1999) Comments on the cross sections of ${ }^{186} \mathrm{Re}$ in the ${ }^{186} \mathrm{~W}(\mathrm{p}, \mathrm{n})$ and ${ }^{186} \mathrm{~W}(\mathrm{~d}, 2 \mathrm{n})$ reactions in connection to the paper given by Zhu et al. and correction of the calculated yields of ${ }^{186} \mathrm{Re}$ in the ${ }^{186} \mathrm{~W}(\mathrm{p}, \mathrm{n})$ reaction. J Radioanal Nucl Chem 241:383 (EXFOR: no)

92. Zhang XD, Li WX, Fang KM, He WY, Sheng R, Ying DZ, Hu WQ (1999) Excitation functions for ${ }^{\text {nat }} W_{(p, x n)}{ }^{181-186}$ Re reactions and production of no carrier-added ${ }^{186} \mathrm{Re}$ via ${ }^{186} \mathrm{~W}_{(\mathrm{p}, \mathrm{n})}{ }^{186} \mathrm{Re}$ reaction. Radiochim Acta 86:11-16 (EXFOR: no)

93. Miah MH, Kuhnenn J, Herpers U, Michel R, Kubik P (2002) Production of residual nuclides by proton-induced reactions on target $\mathrm{W}$ at energy of $72 \mathrm{MeV}$. In: Int. Conf. Nucl. Data for Science and Technology (Proc. Int. Conf. Tsukuba, 2001), (A. K. Shibata et al., Eds), J. Nucl. Sci. Technol. Suppl. 2, pp 369-372 (EXFOR: O1100)

94. Tárkányi F, Takács S, Szélecsényi F, Ditrói F, Hermanne A, Sonck M (2006) Excitation functions of proton induced nuclear reactions on natural tungsten up to $34 \mathrm{MeV}$. Nucl Instrum Meth Phys Res B 252:160-174 (EXFOR: D4163) 
95. Menapace E, Bonardi ML, Groppi F, Persico E, Alfassi ZB (2007) Experimental and calculated nuclear reaction data relative to Innovative production of medical radioisotopes. In: Int. Conf. Nuclear Data for Science and Technology, Nice, 2007, Bersillon, O. (ed.); Bauge, E. (ed.) ID\#655. Vol 2, pp 1403-1406 (EXFOR: D0482)

96. Tárkányi F, Hermanne A, Takács S, Ditrói F, Kovalev F, Ignatyuk AV (2007) New measurement and evaluation of the excitation function of the ${ }^{186} \mathrm{~W}(\mathrm{p}, \mathrm{n})$ nuclear reaction for production of the therapeutic radioisotope ${ }^{18} 6 \mathrm{Re}$. Nucl Instrum Meth Phys Res B 264:389-394 (EXFOR: D4193)

97. Lapi S, Mills WJ, Wilson J, McQuarrie S, Publicover J, Schueller M, Schyler D, Ressler JJ, Ruth TJ (2007) Production cross sections of ${ }^{181-186}$ Re isotopes from proton bombardment of natural tungsten. Appl Radiat Isot 65:345-349 (EXFOR: C1501)

98. Khandaker MU, Uddin MS, Kim K, Lee MW, Kim KS, Lee YS, Kim GN, Cho YS, Lee YO (2008) Excitation functions of proton induced nuclear reactions on ${ }^{\text {nat }} \mathrm{W}$ up to $40 \mathrm{MeV}$. Nucl Instrum Meth Phys Res B 266:1021-1029 (EXFOR: D0282)

99. Titarenko YuE, Batyaev VF, Titarenko AYu, Butko MA, Pavlov KV, Florya SN, Tikhonov RS, Zhivun VM, Ignatyuk AV, Mashnik SG, Leray S, Boudard A, Cugnon J, Mancusi D, Yariv Y, Nishihara K, Matsuda N, Kumawat H, Mank G, Gudowski W (2011) Measurement and simulation of the cross sections for nuclide production in W-nat and Ta-181 targets irradiated with 0.04- to 2.6-GeV protons. Yadernaya Fizika 74:574-595 (EXFOR:A0904)

100. Bonardi M, Groppi F, Persico E, Manenti S, Abbas K, Holzwarth U, Simonelli F, Alfassi ZB (2011) Excitation functions and yields for cyclotron production of radiorhenium via ${ }^{n a t} \mathrm{~W}\left(\mathrm{p}, \mathrm{xn}^{181-186} \mathrm{gRe}\right.$ nuclear reactions and tests on the production of ${ }^{186} \mathrm{gRe}$ using enriched ${ }^{18} 6 \mathrm{~W}$. Radiochim Acta 99:1-11 (EXFOR:O1884)

101. Tárkányi F, Ditrói F, Takács S, Hermanne A (2017) New measurements of excitation functions of ${ }^{186} \mathrm{~W}_{(\mathrm{p}, \mathrm{x})}$ nuclear reactions up to $65 \mathrm{MeV}$. Production of a ${ }^{178} \mathrm{~W} /{ }^{178 \mathrm{~m}} \mathrm{Ta}$ generator. Nucl Instrum. Meth. Phys. Res. B 391:27-37 (EXFOR:D4363)

102. Szelecsenyi F, Takács S, Tárkányi F, Sonck M, Hermanne A (1997) Study of production possibility of no-carrier-added ${ }^{186} \mathrm{Re}$ via proton induced reaction on tungsten for use in radiotherapy. In: 6th Int. Symp. Synthesis and Applications of Isotopically Labeled Compounds (Proc. Int. Symp. Philadelphia, 1997), (J. R. Heys, D. G. Mellilo, Eds), John Wiley and Sons, Chichester (1998) 701-704. Preliminary data of Tárkányi et al. (2006) (EXFOR: D4087)

103. Pement FW, Wolke RL (1966) Compound-statistical features of deuteron-induced reactions:(II) The compound nucleus and stripping-evaporation mechanisms in $(\mathrm{d}, 2 \mathrm{n})$ reactions. Nucl Phys 86:429-442 (EXFOR: P0115)

104. Nassiff SJ, Munzel H (1973) Cross sections for the reactions ${ }^{66} \mathrm{Zn}\left(\mathrm{d}, \mathrm{n}^{6} 7 \mathrm{Ga},{ }^{5} \mathrm{Cr}\left(\mathrm{d}, 2 \mathrm{n}^{52} \mathrm{gMn}\right.\right.$ and ${ }^{18} 6 \mathrm{~W}\left(\mathrm{~d}, 2 \mathrm{n}^{18} 6 \mathrm{Re}\right.$. Radiochim Acta 19:97-99 (EXFOR: A0202)

105. Zhenlan T, Fuying Z, Huiyuan Q, Gongqing W (1981) Excitation functions for ${ }^{182-186} \mathrm{~W}(\mathrm{~d}, 2 \mathrm{n}){ }^{182-186} \mathrm{Re}$ and ${ }^{186} \mathrm{~W}(\mathrm{~d}, \mathrm{p}){ }^{18} 7 \mathrm{~W}$ reactions. Chin J Nucl Phys 3:242 (EXFOR: S0014)

106. Mukhammedov S, Vasidov A, Pardaev E (1984) Application of proton and neutron activation method of analysis for the determination of elements with $\mathrm{Z}$ greater than 42 . Atomnaya Energiya 56:56-58 (EXFOR: A0212)

107. Ishioka NS, Watanabe S, Osa A, Koizumi M, Matsuoka H, Sekine T (2001) Excitation functions of rhenium isotopes on the ${ }^{\text {nat }} \mathrm{W}(\mathrm{d}, \mathrm{xn})$ reactions and production of no-carrier added ${ }^{186}$ Re Int. Conf. Nucl. Data for Science and Technology (Proc. Int. Conf. Tsukuba, 2001), (K. Shibata, et al., Eds), J. Nucl. Sci. Technol. Suppl. 2, pp 1334-1337 (EXFOR: E2083)
108. Tárkányi F, Takács S, Szelecsenyi F, Ditrói F, Hermanne A, Sonck M (2003) Excitation functions of deuteron induced nuclear reactions on natural tungsten up to $50 \mathrm{MeV}$. Nucl Instrum Meth Phys Res B 211:319-330 (EXFOR: D4141)

109. Szelecsenyi F, Takács S, Tárkányi F, Sonck M, Hermanne A (1999) Study of production possibility of ${ }^{186} \mathrm{Re}$ via the ${ }^{186} \mathrm{~W}(\mathrm{~d}, 2 \mathrm{n}){ }^{186} \mathrm{Re}$ nuclear reaction for use of radiotherapy. $\mathrm{J}$ Labelled Compd Radiopharm Suppl 42:912 (EXFOR: no)

110. Alekseev IE, Lazarev VV (2006) Cyclotron production and radiochemical isolation of the therapeutical radionuclide ${ }^{186} \mathrm{Re}$. Soviet Radiochem 48:446-449 (EXFOR: no)

111. Ochiai K, Nakao M, Kubota N, Sato S, Yamauchi M, Ishioka NH, Nishitani T, Konno C (2007) Deuteron induced activation cross section measurement. In: Proceedings of the 2007 International Conference on Nuclear Data for Science and Technology ND 2007; Nice (France); 22-27 Apr 2007, p. 1011-1014 (C, 2007 NICE, 2, 1011, 2007) Conf. on Nucl. Data for Sci. and Technology, Nice 2007, vol 2, p 1011 (2007), France (EXFOR: E2121)

112. Manenti S, Persico E, Abbas K, Bonardi ML, Gini L, Groppi F, Holzwarth U, Simonelli F (2014) Excitation functions and yields for cyclotron production of radiorhenium via deuteron irradiation: ${ }^{\text {nat }} \mathrm{W}(\mathrm{d}, \mathrm{xn}){ }^{181,182(\mathrm{~A}+\mathrm{B}), 183,184(\mathrm{~m}+\mathrm{g}), 186 \mathrm{~g}}$ Re nuclear reactions and tests on the production of ${ }^{186 \mathrm{~g}} \mathrm{Re}$ using enriched $186 \mathrm{~W}$. Radiochimica Acta 102:669-680 (EXFOR: O2224)

113. Duchemin C, Guertin A, Haddad F, Michel N, Metivier V (2015) Cross section measurements of deuteron induced nuclear reactions on natural tungsten up to $34 \mathrm{MeV}$. Appl Rad Isot 97:52-58 (EXFOR: O2258)

114. Khandaker MU, Nagatsu K, Minegishi K, Wakui T, Zhang M-R, Otuka N (2017) Study of deuteron-induced nuclear reactions on natural tungsten for the production of theranostic ${ }^{186} \mathrm{Re}$ via AVF cyclotron up to $38 \mathrm{MeV}$. Nucl Instrum Meth Phys Res B 403:5168 (EXFOR: E2537 \#1)

115. Hilgers K, Sudar S, Qaim SM (2005) Experimental study and nuclear model calculations on the ${ }^{192} \mathrm{Os}\left(\mathrm{p}, \mathrm{n}^{19} 2 \mathrm{Ir}\right.$ reaction: comparison of reactor and cyclotron production of the therapeutic radionuclide ${ }^{19}$ 2Ir. Appl Radiat Isot 63:93-98 (EXFOR: O1274)

116. Hilgers K, Qaim SM, Coenen HH (2004) New cross section data for production of the therapeutic radionuclides ${ }^{64} \mathrm{Cu},{ }^{140} \mathrm{Nd}$ and ${ }^{192}$ Ir. Conf Nucl Data Sci Technnol Santa Fe 2:1631-1633. https://doi.org/10.1063/1.1945319 (EXFOR: O1362)

117. Szelecsenyi F, Vermeulen C, Steyn GF, Kovacs Z, Aardaneh K, van der Walt TN (2010) Excitation functions of $186,187,188,189,190,192$ Ir formed in proton-induced reactions on highly enriched ${ }^{192} \mathrm{Os}$ up to $66 \mathrm{MeV}$. Nucl Instrum Meth Phys Res B 268:3306-3314. https://doi.org/10.1016/j.nimb.2010.07. 010 (EXFOR: D0633)

118. Hermanne A, Rebeles RA, Tárkányi F, Takács S (2015) Excitation functions of proton induced reactions on ${ }^{\text {nat }} \mathrm{Os}$ up to $65 \mathrm{MeV}$ : experiments and comparison with results from theoretical codes. Nucl Instrum Meth Phys Res B 345: 58-68. https://doi.org/10. 1016/j.nimb.2014.12.051 (EXFOR:D4324)

119. Tárkányi F, Hermanne A, Takács S, Hilgers K, Kovalev SF, Ignatyuk AV, Qaim SM (2007) Study of the ${ }^{192} \mathrm{Os}(\mathrm{d}, 2 \mathrm{n})$ reaction for production of the therapeutic radionuclide ${ }^{192} \mathrm{Ir}$ in no-carrier added form. Appl. Radiat. Isot. 65:1215-1220 (EXFOR: D4192)

120. Hermanne A, Adam Rebeles R, Tárkányi F, Takács S, Takács MP, Ignatyuk A, Uddin MS (2013) Excitation functions of deuteron induced reactions on ${ }^{\text {nat }} \mathrm{Os}$ up to $50 \mathrm{MeV}$ : Experiments and comparison with results from theoretical codes. Nucl Instrum Meth Phys Res B 297:75-85 (EXFOR: D4324)

121. Kelly EL, Segrè E (1949) Some excitation functions of bismuth. Phys Rev 75:999-1005 (EXFOR: no D0490)

122. Ramler WJ, Wing J, Henderson DJ, Huizenga JR (1959) Excitation functions of Bismuth and lead. Phys Rev 114:154-162 (EXFOR: A0246) 
123. Deconninck G, Longrée M (1974) Fonctions d'excitation des réactions induites par particules alpha sur ${ }^{209} \mathrm{Bi}$ entre 40 et 100 $\mathrm{MeV}$. Annales de la Societé Scientifique de Bruxelles T88:341 (EXFOR: D0204)

124. Stickler JD, Hofstetter KJ (1974) Comparison of ${ }^{3} \mathrm{He}-,{ }^{4} \mathrm{He}-$, and ${ }^{12} \mathrm{C}$-induced nuclear reactions in heavy-mass targets at medium excitation energies (I.), Experimental cross sections. Phys Rev C 9:1064-1071 (EXFOR: D0493)

125. Lambrecht RM, Mirzadeh S (1985) Cyclotron isotopes and radiopharmaceuticals-XXXV astatine-211. Int J Appl Rad Isot 36:443-450 (EXFOR: A0249)

126. Hermanne A, Tárkányi F, Takács S, Szücs Z, Shubin YuN, Dityuk AI (2005) Experimental study of the cross-sections of $\alpha$-particle induced reactions on ${ }^{209} \mathrm{Bi}$. Appl Rad Isot 63:1-9 (EXFOR: O1272)

127. Hermanne A, Tárkányi F, Takács S, Szücs Z (2005) Experimental study of the cross sections of alpha-particle induced reactions on ${ }^{209} \mathrm{Bi}$. In: Int. Conf. Nucl. Data for Science and Technology, Santa Fe, USA, 26 Sep - 1 Oct 2004, Proceedings, Editors: R.C. Haight, P. Talou, T. Kawano, AIP (AIP Conference Proceedings 769), pp 957-960 (EXFOR: O1272)
128. Rattan SS, Singh RJ, Sahakundu SM, Prakash S, Ramaniah MV (1986) Alpha particle induced reactions of ${ }^{209} \mathrm{Bi}$ and ${ }^{63} \mathrm{Cu}$ and ${ }^{65} \mathrm{Cu}$. Radiochim Acta 39:61-63 (EXFOR: A0353)

129. Rattan SS, Chakravarty N, Ramaswami A, Singh RJ (1992) Alpha particle induced reactions of ${ }^{209} \mathrm{Bi}$ at 55.7 and $58.6 \mathrm{MeV}$. Radiochimica Acta 57:7-10 (EXFOR: O1300)

130. Rizvi IA, Bhardwaj MK, Afzal Ansari M, Chaubey AK (1990) Non-equilibrium reaction mechanism in alpha-particle induced excitation function for ${ }^{209} \mathrm{Bi}$ up to $60 \mathrm{MeV}$. Appl Rad Isot 41:215-219 (EXFOR: D0492)

131. Singh NL, Mukherjee S, Somayajulu DRS (1994) Non-equilibrium analysis of $(\mathrm{a}, \mathrm{xn})$ reactions on heavy nuclei. Nuovo Cimento A 107:1635-1645 (EXFOR: O1119)

132. Patel HB, Shah DJ, Singh NL (1999) Study of (a, xn) reactions on $169 \mathrm{Tm}, 181 \mathrm{Ta}$ and $209 \mathrm{Bi}$ up to $70 \mathrm{MeV}$. Nuovo Cimento 112:1439-1452 (EXFOR: D0491)

Publisher's Note Springer Nature remains neutral with regard to jurisdictional claims in published maps and institutional affiliations. 